JORGE CARLOS AMIN

\title{
EFICÁCIA DA RESTRIÇÃO DE VELOCIDADE E OUTRAS AÇÕES NA PREVENÇÃO DE ACIDENTES EM TRAVESSIAS URBANAS DE RODOVIAS
}

Dissertação apresentada à Escola de Engenharia de São Carlos, da Universidade de São Paulo, como parte dos requisitos para a obtenção do título de mestre em ciências, no Programa de PósGraduação em Engenharia de Transportes. Área de concentração: Planejamento e Operações de Sistema de Transportes.

ORIENTADORA

Prof. ${ }^{\text {a }}$ Dr. ${ }^{\text {a }}$ Barbara Stolte Bezerra 
Ficha catalográfica preparada pela Seção de Tratamento da Informação do Serviço de Biblioteca - EESC/USP

Eficácia da restrição de velocidade e outras ações na prevenção de acidentes em travessia urbanas de rodovias. / Jorge Carlos Amin ; orientador Barbara stolte Bezerra. São Carlos, 2012 .

Dissertação (Mestrado - Programa de Pós-Graduação em Engenharia de Transportes e Área de Concentração em Planejamento e Operações de Sistemas de Transportes)-Escola de Engenharia de São Carlos da Universidade de São Paulo, 2012 .

1. Transportes. 2. Travessias urbanas. 3. Rodovias. 4. Acidentes. 5. Eficácia. 6. Segurança viária. I. Título. 


\section{FOLHA DE IULGAMENTO}

Candidato: Engenheiro JORGE CARLOS AMIN.

Título da dissertação: "Eficácia da restrição de velocidade e outras ações na prevenção de acidentes em travessias urbanas de rodovias".

Data da defesa: 12/03/2012

\section{Comissão Julgadora:}

Resultado:

Prof ${ }^{\mathrm{a}}$. Dra ${ }^{\mathrm{a}}$. Bárbara Stolte Bezerra (Orientadora)

AProvitDO

(Universidade Estadual Paulista Júlio de Mesquita Filho/UNESP-

Campus de Bauru)

Prof. Titular Antonio Clóvis Pinto Ferraz

APRoumos

(Escola de Engenharia de São Carlos/EESC)

Prof ${ }^{\mathrm{a}}$. Associada Adriane Monteiro Fontana

APROVADO

(Faculdade de Tecnologia de São Caetano do Sul/FATEC-SCS)

Coordenador do Programa de Pós-Graduação em Engenharia de Transportes e

Presidente da Comissão de Pós-Graduação

Prof. Associado Paulo Cesar Lima Segantine 

Dedico este trabalho a minha família 



\section{AGRADECIMENTOS}

Em primeiro lugar, agradeço a Deus pelos dons recebidos e pelos seres queridos colocados em meu caminho.

Agradeço especialmente a minha família, principal fonte de apoio durante este trabalho. A minha amada esposa Nancy, pelo sacrifício realizado ao meu lado postergando tantas coisas para possibilitar a minha dedicação a este trabalho. A meus filhos Jorge, Santiago, Maria Laura e Francisco, fontes de constante alegria na minha vida, que sempre me alentaram a perseverar no estudo para completar o trabalho, e especialmente a Jorge, que contribuiu concretamente mediante revisões do texto.

Agradeço a minha orientadora Barbara, que soube me alentar nos momentos de desânimo, cobrar com firmeza pelo cumprimento do planejamento realizado e o cronograma estabelecido e por sentar ao meu lado para, juntos, revisar cálculos, esclarecer conceitos e me ajudar a corrigir o texto final. Sem sua inestimável ajuda ao longo deste trabalho não teria conseguido chegar até o fim.

Agradeço os conselhos do Professor Doutor Antonio Clóvis Pinto Ferraz, quem aceitou e me orientou inicialmente nesta dissertação de mestrado. Em seu nome, agradeço a todo o corpo docente e administrativo da Escola de Engenharia de São Carlos pela dedicada atenção que recebi durante minha passagem por esta prestigiosa instituição de altos estudos. Ter sido aluno desta escola me enche de orgulho. Encontrei nela, além de um corpo de professores de excelência, gente que aprecio como verdadeiros amigos.

Sou infinitamente grato à Universidade de São Paulo por ter me brindado a oportunidade de aperfeiçoar o meu conhecimento profissional e de ter formado parte de sua história. Trata-se da terceira instituição acadêmica onde teve a oportunidade de estudar, sendo a primeira fora de meu país de origem, Argentina, depois de um prolongado período afastado do âmbito acadêmico que, no início de carreira, foi a minha primeira atividade profissional, que abracei com muito entusiasmo.

Em fim, preciso agradecer a um grupo grande de pessoas aqui não citadas que de uma ou outra forma também contribuíram para este logro. A vida esta cheia de anônimos que a tornam realidade e que nos ajudam a ser felizes. Também a eles o meu agradecimento. 

Usa a capacidade que tens. A floresta ficaria silenciosa se só o melhor pássaro cantasse.

(Oscar Wilde) 



\section{RESUMO}

AMIN, J. C. (2012). EFICÁCIA DA RESTRIÇÃO DE VELOCIDADE E OUTRAS AÇÕES NA PREVENÇÃO DE ACIDENTES EM TRAVESSIAS URBANAS DE RODOVIAS. SÃO CARLOS, 132 P. DISSERTAÇÃO (MESTRADO) - ESCOLA DE ENGENHARIA DE SÃO CARLOS - UNIVERSIDADE DE SÃO PAULO.

As travessias urbanas de rodovias constituem-se um local crítico para a ocorrência de acidentes de trânsito. Dessa forma, diversas ações de engenharia são empregadas para a redução do número e da gravidade dos acidentes. Contudo, existem poucos estudos sobre a eficácia dessas ações. No presente trabalho foram utilizadas duas metodologias para a avaliação da eficácia, através de estudos observacionais, são elas: "antes - depois" ingênuo e o método do grupo de comparação, aplicadas em vários segmentos rodoviários caracterizados como travessias urbanas que receberam ações de engenharia para a redução de acidentes. $\mathrm{O}$ primeiro método foi aplicado a todas as ações e o segundo apenas para duas ações. As informações utilizadas neste trabalho foram solicitadas às concessionárias das rodovias do Estado de São Paulo. Foram analisadas sete ações de engenharia: 1) redução de velocidade em conjunto com outras medidas; 2) implantação de defesa de New Jersey elevada; 3) implantação de dispositivo em desnível; 4) cruzamento de pedestres em nível em área demarcada; 5) implantação de passarela; 6) implantação de ciclovia; 7) passagem superior e tela para impedir a passagem de pedestres em nível. Os resultados encontrados demonstram que ação 1 reduz em média em $27 \%$ o número total de acidentes tanto para o método ingênuo como para o método de grupo de comparação. A ação 2 foi a única ação com resultado negativo, com aumento de $19 \%$ no número de acidentes totais e de $42 \%$ no número de acidentes com feridos e mortos. A ação 3 teve uma redução no número total de acidentes em torno de $27 \%$. A ação 4 teve uma redução de $35 \%$ no número total de acidentes. A ação 5 teve uma redução no número total de acidentes em torno de $40 \%$, através do método ingênuo, contra 30\% pelo método de grupo de comparação. A ação 6 teve uma redução no número de acidentes totais de $30 \%$. A ação 7 não teve uma redução expressiva no número total de acidentes, contudo teve uma redução de $32 \%$ no número de feridos e mortos.

PALAVRAS-CHAVE: TRAVESSIAS URBANAS, RODOVIAS, ACIDENTES, EFICÁCIA, SEGURANÇA VIÁRIA. 



\begin{abstract}
AMIN, J. C. (2012). EFFECTIVENESS OF SPEED RESTRICTION AND OTHER MEASURES IN THE PREVENTION OF ACCIDENTS AT URBAN HIGHWAY CROSSINGS. SÃO CARLOS, 132 P. MASTER THESIS - ESCOLA DE ENGENHARIA DE SÃO CARLOS - UNIVERSIDADE DE SÃO PAULO.
\end{abstract}

The urban highway crossings are a critical place for occurrence of traffic accidents. Thus, several engineering measures are employed to reduce the number and severity of accidents. However, there are few studies about the effectiveness of these actions. In this study two methods were used to evaluate the effectiveness, through observational studies, they are: "before - after" naive method and the comparison group, applied in various segments characterized as urban highway crossings in which they had been implemented measures to reduce accidents. The first method was applied to all measures and the second only for two measures. The data used in this study were obtained from the concessionaire of highways of the State of Sao Paulo. It was analyzed seven engineering measures: 1) reduction of speed in conjunction with other measures; 2) implementation of New Jersey defense with higher height; 3) implementation of grade separation structure; 4) level pedestrian crossings in areas demarcated, 5) implementation runway; 6) implementation of bike path; 7) footbridge and barriers to prevent the passage of pedestrians. The results show that the first measure reduces on average by $27 \%$ the total number of accidents for both the naive method and to the method of comparison group. The second measure was the only action with negative results, with $19 \%$ increase in the number of total accidents and $42 \%$ in the number of accidents with injuries and deaths. The third measure had a reduction in the total number of accidents around $27 \%$. The fourth measure had a $35 \%$ reduction in the total number of accidents. The fifth measure had a reduction in the total number of accidents by $40 \%$, through the naive method, compared to $30 \%$ by the method of comparison group. The sixth action had a reduction in total accidents by $30 \%$. The seventh action had not a significant reduction in the total number of accidents, yet had a $32 \%$ reduction in the number of injuries and deaths.

KEYWORDS: URBAN CROSSINGS, HIGHWAYS, ACCIDENTS, EFFECTIVENESS, ROAD SAFETY. 



\section{SUMÁRIO}

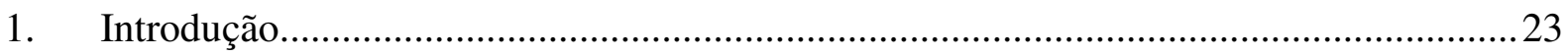

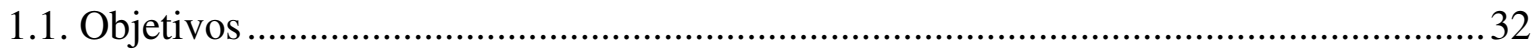

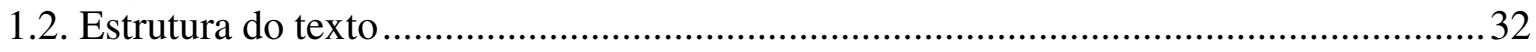

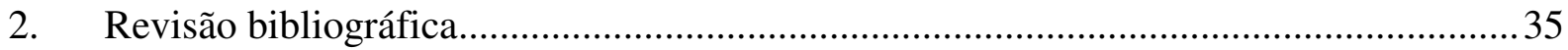

2.1. Travessias Urbanas de rodovias - Caracterização do problema.......................................35

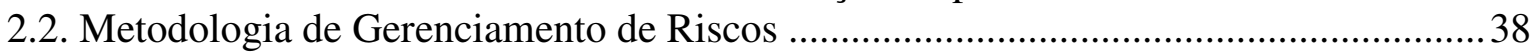

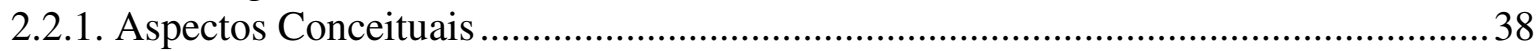

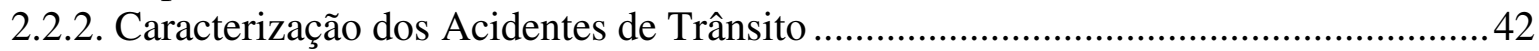

2.2.3. Análise dos Acidentes de Trânsito e Diagnóstico das Causas .......................................45

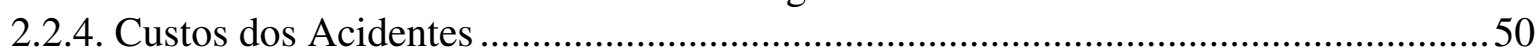

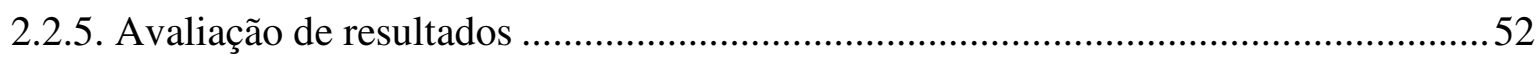

2.2.6. Travessias Urbanas de rodovias - Problemas de Tráfego a Considerar.....................54

2.2.7. O problema da determinação da velocidade ideal na Travessia Urbana ....................57

2.2.8. O problema da medição da eficácia de ações aplicadas para a prevenção de acidentes

3. Aspectos conceituais da metodologia do tipo "antes-depois" ......................................63

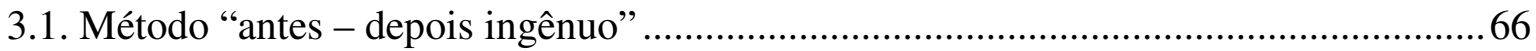

3.1.1. Retratações a serem feitas na utilização dos estudos observacionais ingênuos ..........70

3.2. Método antes - depois utilizando grupos de comparação ............................................ 70

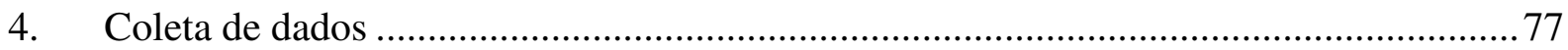

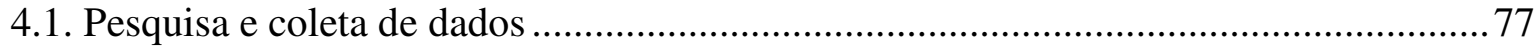

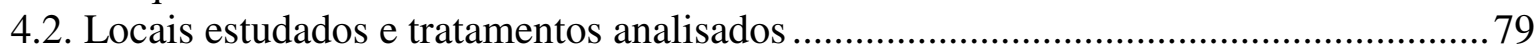

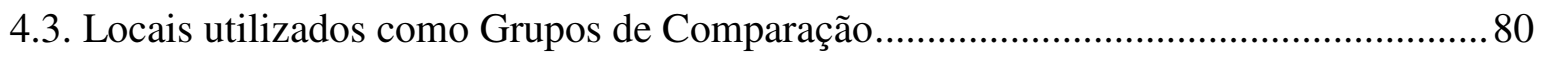

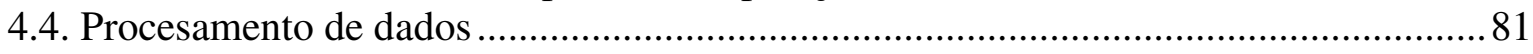

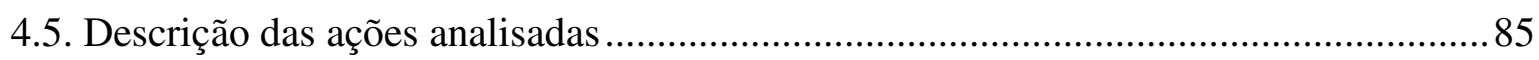

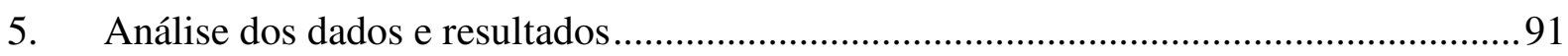

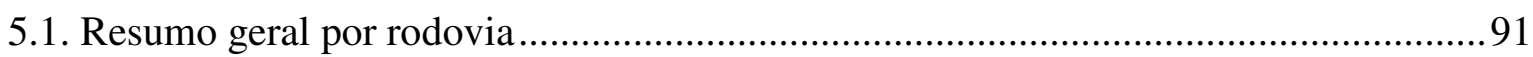

5.2. Resultados do método "antes - depois" ingênuo ............................................................99

5.2.1. Resultados para a solução do tipo 1 - Redução de velocidade e outras medidas..... 100

5.2.2. Resultados para a solução do tipo 2 - Implantação de defesa New Jersey elevada. 101

5.2.3. Resultados para a solução do tipo 3 - Construção de novo dispositivo de acesso .. 103

5.2.4. Resultados para a solução do tipo 4 - Cruzamento de pedestre em nível em área

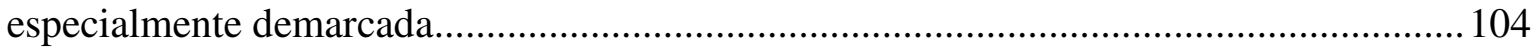

5.2.5. Resultados para a solução do tipo 5 - Implantação de passarela .............................. 106

5.2.6. Resultados para a solução do tipo 6 - Implantação de ciclovia ................................ 109

5.2.7. Resultados para a solução do tipo 7 - Implantação de passagem superior e tela protetora para impedir o cruzamento de pedestres em nível...............................................109

5.3. Resultados do método grupos de comparação .............................................................. 110

5.3.1. Resultados para a solução do tipo 1 - Redução de velocidade (G-C) ....................... 114

5.3.2. Resultados para a solução do tipo 5 - Implantação de passarela (G-C) ...................115

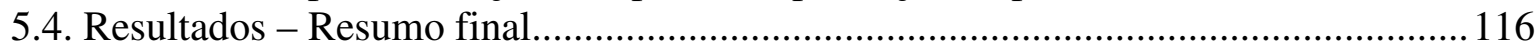


6. Considerações finais

7. Referências bibliográficas

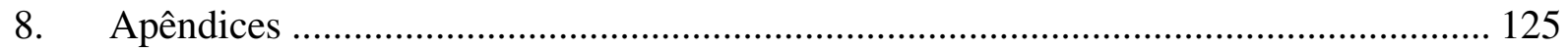

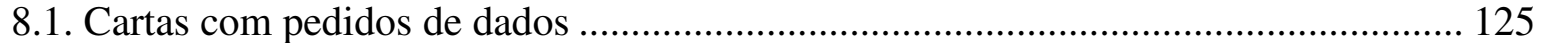

8.1.1. Carta com pedido de dados a ARTESP ................................................................. 125

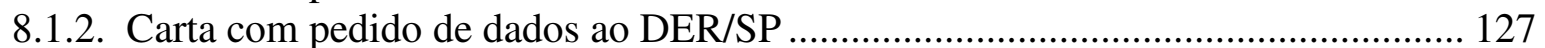

8.2. Planilhas com resultados de acidentes com Danos Materiais .................................. 129

8.3. Planilhas com resultados de acidentes com Feridos e Mortos .................................. 139

8.4. CD com arquivos das planilhas de cálculo e bases de dados utilizados.................... 149 


\section{LISTA DE ILUSTRAÇÕES}

Figura 1. 1 - Relatório da Situação Mundial sobre Segurança Rodoviária.

Figura 1. 2 - Vítimas de acidentes de trânsito e \% de óbitos no local e posterior, ocorridas no

Brasil em 2005.

Figura 1. 3 - Comparação do índice de mortes por bilhão de quilômetros percorridos no Brasil (2008) e em outros países (2009).

Figura 1. 4 - Travessia irregular de pedestres em pista dupla - SP310 - Rio Claro........

Figura 1. 5 - Acesso irregular de veículos e vizinhos a um bairro - SP310 - Rio Claro.

Figura 1. 6 - Recorte do jornal onde se critica o baixo limite de velocidade regulamentado no

local.

Figura 1.7 - Fotos do local indicado na Figura 1.6 onde se observa o acumulo de veículos circulando a baixa velocidade.

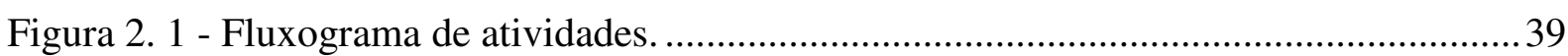

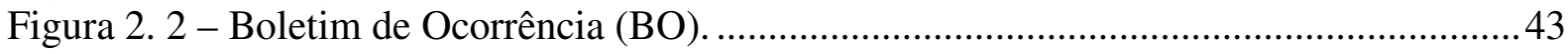

Figura 2. 3 - Causas Multi-Fatores de Acidentes de Trânsito. ................................................. 46

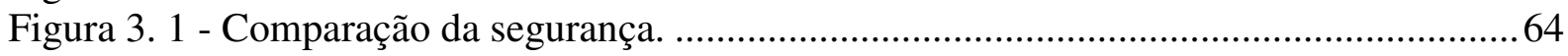

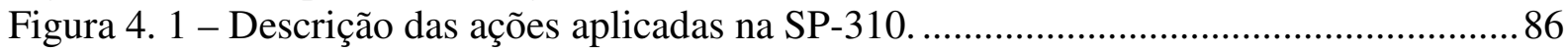

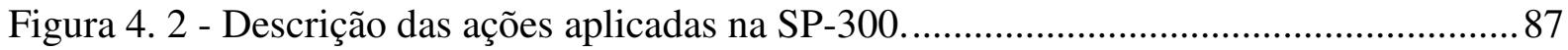

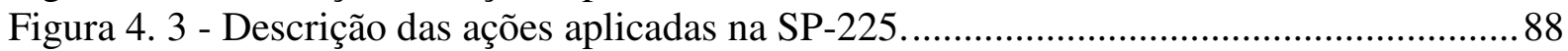

Figura 4. 4 - Descrição das ações aplicadas na SP-127 ........................................................... 88

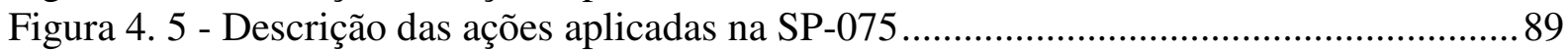

Figura 5. 1 - Defesa New Jersey implantada em Rio Claro.................................................. 102

Figura 5. 2- Local de tratamento para cruzamento de pedestres em nível............................ 105

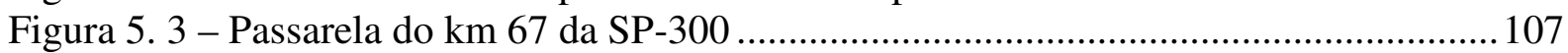

Figura 5. 4 - Analise gráfica dos Grupos de Compração....................................................... 112 



\section{LISTA DE TABELAS}

Tabela 1. 1 - Indicadores da situação dos acidentes de tráfego no Brasil - Números globais relativos à frota de veículos, registro de acidentes com vítimas, óbitos e morbidade hospitalar,

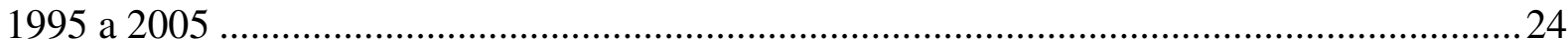

Tabela 1. 2 - Mortos em acidentes de trânsito por região da OMS ........................................26

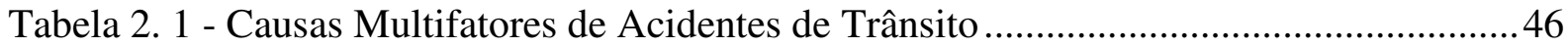

Tabela 2. 2 - Custos de Acidentes em São Paulo ..........................................................................51

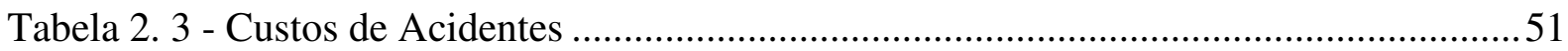

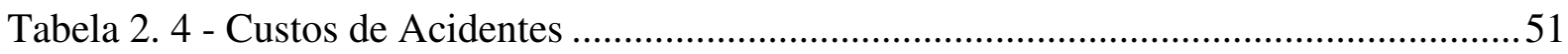

Tabela 2. 5 - Custo de acidentes - Valores Médios Sugeridos ................................................52

Tabela 3.1 - Estimativa quando nem todos os rd(j) são os mesmos ........................................68

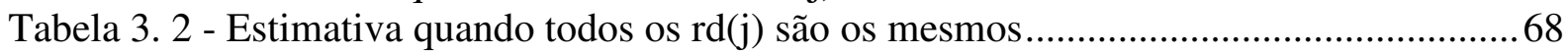

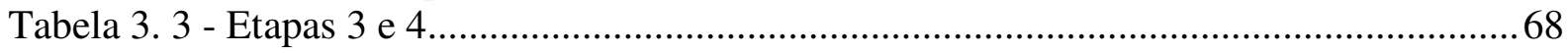

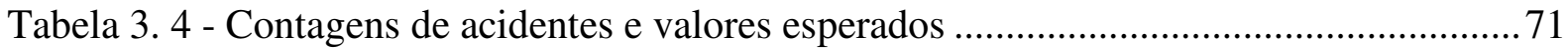

Tabela 3. 5 - Estimativas das ETAPAS 1 e 2 em um "Estudo G-C" ....................................... 75

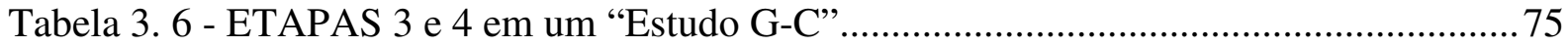

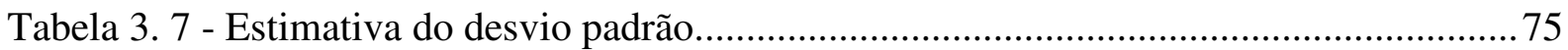

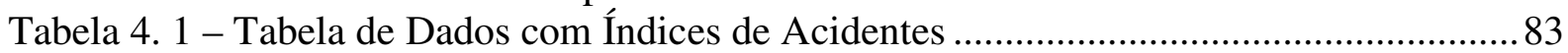

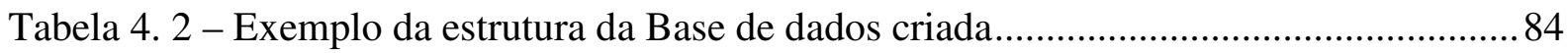

Tabela 4. 3 - Dados de um trecho usado como grupo de comparação...................................... 85

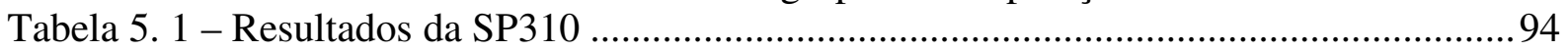

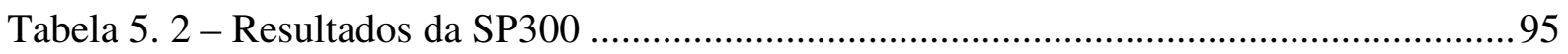

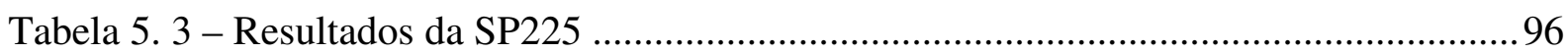

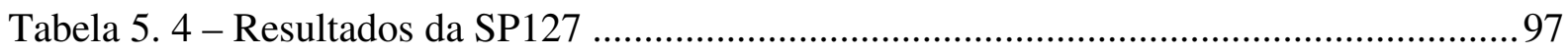

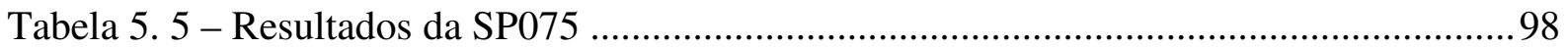

Tabela 5. 6 - Resultados para redução de velocidade ........................................................... 100

Tabela 5. 7- Efeito de dispositivos redutores de velocidade na redução do número de

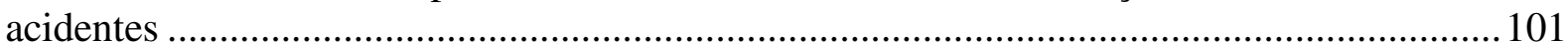

Tabela 5. 8- Resultados para a solução implantação de defesa New Jersey elevada.............. 103

tabela 5. 9- Resultados para a solução construção de novo dispositivo de acesso ................. 104

Tabela 5. 10- Resultados para a solução cruzamento de pedestre em nível em área

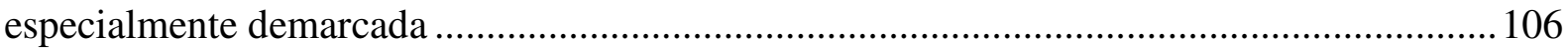

Tabela 5. 11 - Resultados para a solução implantação de passarela ........................................ 108

Tabela 5. 12 - Resultados para a solução implantação de passarela sem caso 6 ................... 108

Tabela 5. 13 - Resultados para a solução implantação de ciclovia...................................... 109

Tabela 5. 14 - Resultados para a solução implantação de passagem superior e tela protetora

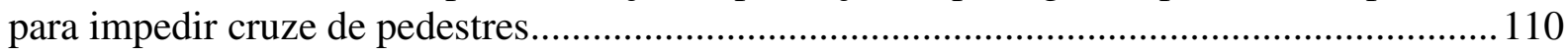

Tabela 5. 15 - Planilha de cálculo do método de grupos de comparação ............................... 113

Tabela 5. 16 - Resultados para redução de velocidade - G-C ............................................ 114

Tabela 5. 17 - Resultados para implantação de passarela - G-C .......................................... 115

Tabela 5. 18 - Resumo de resultados por tratamento para acidentes totais ............................116

Tabela 8. 1 - Resultados para redução de velocidade (DM) ............................................. 130

Tabela 8. 2 - Resultados para implantação de defesa New Jersey elevada (DM) .................. 131

Tabela 8. 3 - Resultados para construção de novo dispositivo de acesso (DM)..................... 132

Tabela 8. 4 - Resultados para a solução cruzamento de pedestre em nível em área

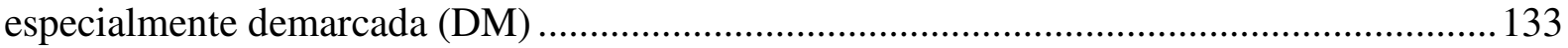


Tabela 8. 5 - Resultados para implantação de passarela, sem caso 6 (DM)

Tabela 8. 6 - Resultados para implantação de ciclovia (DM)

Tabela 8. 7 - Resultados para a solução implantação de passagem superior e tela protetora para impedir cruze de pedestres (DM).

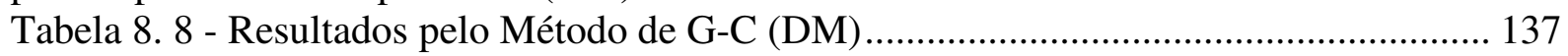

Tabela 8. 9 - Resultados para redução de velocidade (FE+MO) .......................................... 140

Tabela 8. 10 - Resultados para implantação de defesa New Jersey elevada (FE+MO)......... 141

Tabela 8. 11 - Resultados para construção de novo dispositivo de acesso (FE+MO) ........... 142

Tabela 8. 12 - Resultados para a solução cruzamento de pedestre em nível em área especialmente demarcada (FE+MO)

Tabela 8. 13 - Resultados para implantação de passarela, sem caso 6 (FE+MO) .................. 144

Tabela 8. 14 - Resultados para implantação de ciclovia (FE+MO) ..................................... 145

Tabela 8. 15 - Resultados para a solução implantação de passagem superior e tela protetora

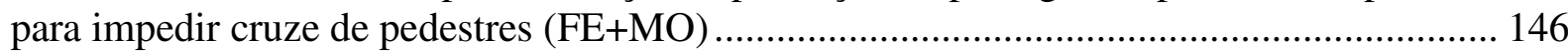

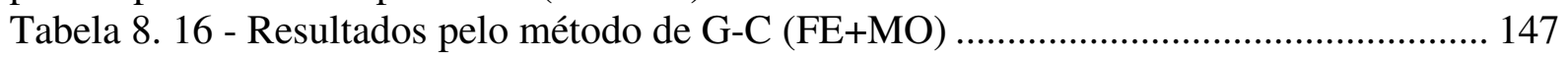




\section{LISTA DE ABREVIATURAS E SIGLAS}

ARTESP: Agência Reguladora De Serviços Públicos Delegados De Transporte Do Estado De São Paulo

ATT: $\quad$ Acidentes de Transporte Terrestre

DENATRAN: Departamento Nacional de Trânsito

DER/SP: Departamento de Estadas de Rodagens do Estado de São Paulo

DM: $\quad$ Acidentes com Danos Materiais

FE: $\quad$ Acidentes com Feridos

FE+MO: Acidentes com Feridos e Mortos

INST: Instituto Nacional de Segurança no Trânsito

G-C: $\quad$ Grupo de Comparação

MO: $\quad$ Acidentes com Mortos

OMS: $\quad$ Organização Mundial da Saúde

SIG: $\quad$ Sistema de Informações Georeferenciadas

SIM/MS: $\quad$ Sistema de Informações sobre Mortalidade do Ministério da Saúde

SUS: $\quad$ Sistema Único de Saúde

TO: $\quad$ Acidentes Totais

VDM: Veículos Médio Diário Anual 



\section{INTRODUÇão}

Dentre os objetivos da Engenharia de Tráfego, a segurança impõe-se como prioridade considerando as proporções atingidas pelos acidentes de trânsito no mundo todo. A Organização Mundial da Saúde já enquadra a insegurança no trânsito como um problema de saúde pública. No Brasil, as estatísticas oficiais mostram um expressivo número de mortes em acidentes de trânsito. Este problema tem especial relevância não somente pelos custos econômicos provocados, mas, sobretudo, pela dor, sofrimento e perda de qualidade de vida imputada às vítimas, seus familiares e à sociedade como um todo. No caso específico dos acidentes rodoviários, este aspecto é potenciado pela gravidade dos mesmos, geralmente devido à utilização de elevadas velocidades de circulação. Neste contexto, acha-se oportuno concentrar esforços, agir criativamente, e desenvolver novas tecnologias, na busca de alternativas que colaborem na solução ou mitigação do problema.

Visando dar uma ideia da dimensão do problema brasileiro, se apresenta nesta introdução um dos indicadores usados tecnicamente para avaliar e acompanhar a situação da segurança no trânsito, a Taxa de Mortalidade, definida como:

$$
\text { Taxa de mortalidade }=\frac{\text { Óbitos no ano e local considerados } \mathrm{x} 100.000}{\text { População do ano e local considerados }}
$$

Para referência deste indicador e outros, apresenta-se na Tabela 1.1 os dados extraídos do trabalho da ABRAMET (2007), que oferece valores de indicadores de frota, acidentes, mortalidade e morbidade, em números e taxas, referentes aos Acidentes de Transporte Terrestre - ATT, conforme definidos pela Organização Mundial da Saúde - OMS na sua Classificação Estatística Internacional de Doenças e Problemas Relacionados à Saúde. Este indicador permite identificar a gravidade da situação dos acidentes de tráfego no Brasil, em constante crescimento. 
Tabela 1. 1 - Indicadores da situação dos acidentes de tráfego no Brasil - Números globais relativos à frota de veículos, registro de acidentes com vítimas, óbitos e morbidade hospitalar, 1995 a 2005

\begin{tabular}{|c|c|c|c|c|c|c|c|c|c|c|}
\hline \multirow[b]{2}{*}{ Ano } & \multicolumn{2}{|c|}{ Frota } & \multicolumn{3}{|c|}{ Acidentes } & \multicolumn{3}{|c|}{ Mortalidade } & \multicolumn{2}{|c|}{ Morbidade } \\
\hline & $\mathbf{N}^{\circ}$ & Taxas & $\mathbf{N}^{\circ}$ & $\begin{array}{c}\text { Taxas } \\
\text { (1) }\end{array}$ & $\begin{array}{c}\text { Taxas } \\
\text { (2) }\end{array}$ & $\mathbf{N}^{\circ}$ & $\begin{array}{c}\text { Taxas } \\
\text { (3) }\end{array}$ & $\begin{array}{c}\text { Taxas } \\
\text { (4) }\end{array}$ & $\mathbf{N}^{\circ}$ & $\begin{array}{c}\text { Taxas } \\
\text { (5) }\end{array}$ \\
\hline 1995 & 26.609 .232 & 170,8 & - & - & - & - & - & - & - & - \\
\hline 1996 & 27.747 .815 & 176,7 & - & - & - & 35.281 & 22,5 & 127,1 & - & - \\
\hline 1997 & 28.886 .466 & 181,0 & - & - & - & 35.560 & 22,3 & 106,9 & - & - \\
\hline 1998 & 30.939 .466 & 191,2 & 262.374 & 162,2 & 8,5 & 30.890 & 19,1 & 99,8 & - & - \\
\hline 1999 & 32.318 .646 & 197,1 & 376.589 & 229,7 & 11,7 & 25.569 & 18,0 & 91,5 & - & - \\
\hline 2000 & 29.503 .503 & 173,8 & 286.994 & 169,7 & 9,7 & 26.995 & 17,1 & 98,3 & 107.969 & 63,6 \\
\hline 2001 & 31.913 .003 & 185,1 & 307.287 & 178,3 & 9,6 & 30.524 & 17,7 & 95,6 & 102.220 & 59,3 \\
\hline 2002 & 34.284 .967 & 196,3 & 251.876 & 144,2 & 7,3 & 32.753 & 18,8 & 89,3 & 108.359 & 62,0 \\
\hline 2003 & 36.658 .501 & 207,3 & 333.689 & 188,7 & 9,1 & 33.139 & 18,7 & 84,5 & 108.751 & 61,5 \\
\hline 2004 & 39.240 .875 & 216,1 & 348.583 & 192,0 & 8,9 & 35.105 & 19,3 & 89,5 & 112.498 & 62,0 \\
\hline 2005 & 42.071 .961 & 228,4 & 383.371 & 208,1 & 9,1 & 35.763 & 19,4 & 84,8 & 118.122 & 64,1 \\
\hline
\end{tabular}

Fonte: ABRAMET (2007).

(1) Taxa de acidentes em relação à população

(2) Taxa de acidentes em relação aos veículos licenciados

(3) Taxa de mortalidade em relação à população

(4) Taxa de mortalidade em relação aos veículos licenciados

(5) Taxa de internação em relação à população

A comparação de 1998 e de 2005 revela um aumento proporcional de 46,1\% nos números absolutos de acidentes com vítimas e de 28,3\% na taxa destes acidentes em relação à população. Se analisado o índice de mortalidade, vê-se que as taxas mantiveram-se em torno de $19 \%$ nos últimos anos.

Se comparada esta taxa de mortalidade com as correspondentes a países desenvolvidos, exceto Japão e Suíça, verifica-se que o Brasil apresenta valores similares aos que estes países tinham duas décadas atrás, conforme mostra a Figura 1.1, e que atualmente apresenta uma taxa que é o dobro à daqueles países. 


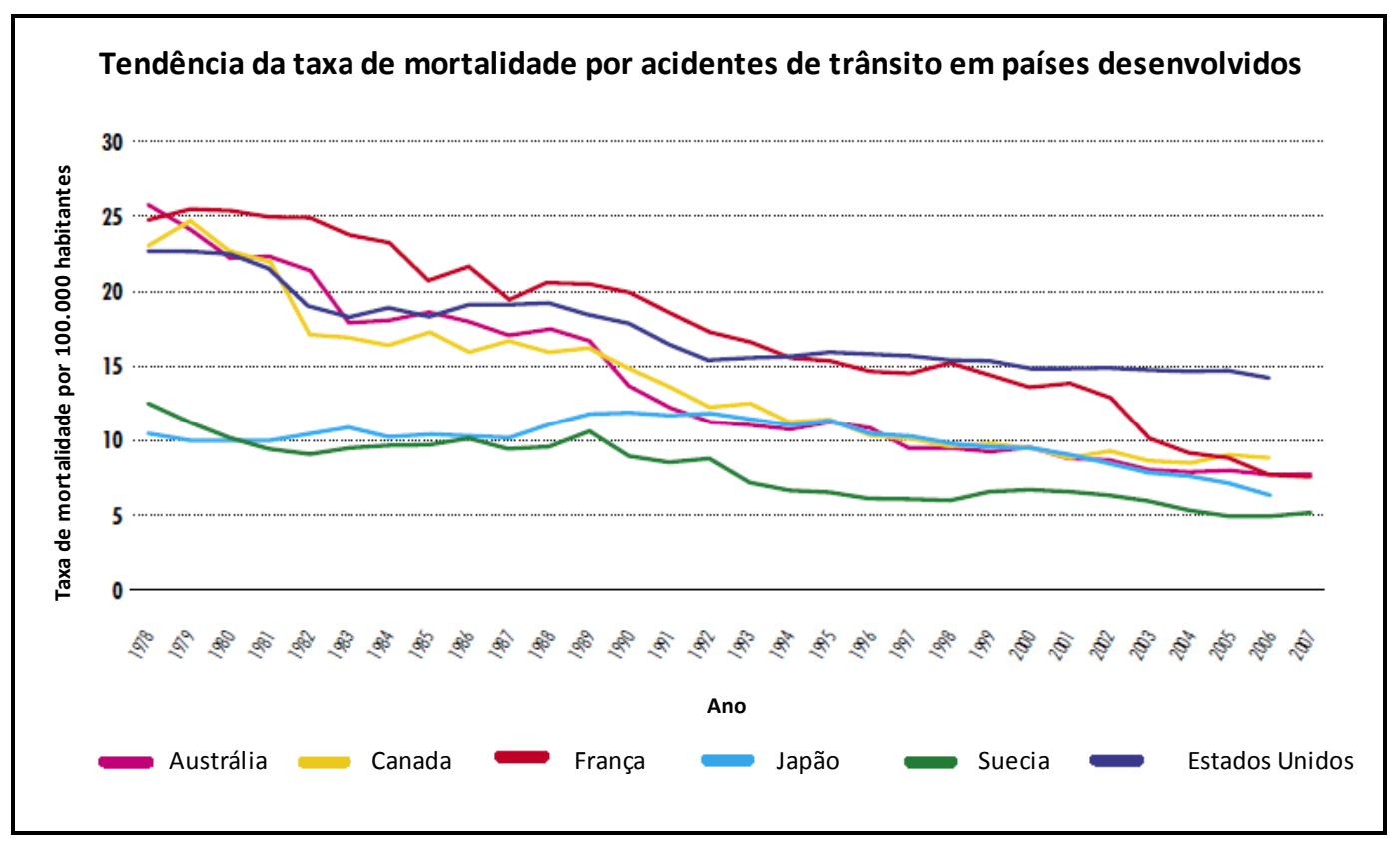

Figura 1. 1 - Relatório da Situação Mundial sobre Segurança Rodoviária.

Fonte: OMS -(2009).

Por outro lado, a Figura 1.2 descreve a contagens de vítimas de acidentes de trânsito e óbitos no local e posterior, ocorridas no Brasil em 2005. Analisando os dados provenientes do Sistema de Informações sobre Mortalidade do Ministério da Saúde - SIM/MS em comparação aos do DENATRAN, verifica-se que cerca de $70 \%$ das mortes ocorrem no próprio local do acidente, sendo que os restantes $30 \%$ vão acontecer a qualquer tempo após a retirada dos feridos do local.

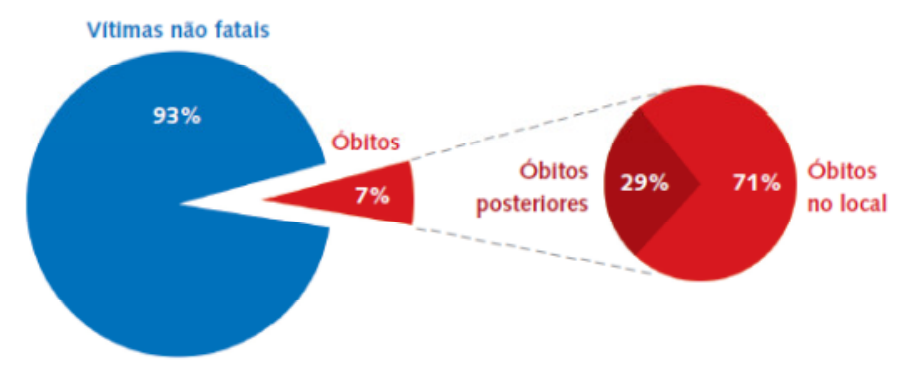

Figura 1. 2 - Vítimas de acidentes de trânsito e \% de óbitos no local e posterior, ocorridas no Brasil em 2005.

Fonte: ABRAMET (2007). 
Este fenômeno fica evidenciado pelos dados da OMS (2009) que se encontram na Tabela 1.2, que captura o ajuste na taxa por considerar os óbitos dos acidentes de trânsito baseado no prazo de 30 dias após a ocorrência dos mesmos. Pode se observar que as taxas recebem maiores ajuste naquelas regiões de menor desenvolvimento econômico.

Tabela 1. 2 - Mortos em acidentes de trânsito por região da OMS

\begin{tabular}{|c|c|c|c|c|}
\hline \multirow[t]{2}{*}{ Região da OMS } & \multicolumn{2}{|c|}{ Dados notificados } & \multicolumn{2}{|c|}{ Dados Ajustados* } \\
\hline & $\mathbf{N}^{\circ}$ & $\begin{array}{c}\text { Taxa por } 100.000 \\
\text { habitantes }\end{array}$ & $\mathbf{N}^{\mathbf{o}}$ & $\begin{array}{c}\text { Taxa por } 100.000 \\
\text { habitantes }\end{array}$ \\
\hline Região da África & 52.302 & 7,2 & 234.768 & 32,2 \\
\hline Região das Américas & 139.466 & 15,2 & 142.252 & 15,8 \\
\hline Região da Ásia Sul Oriental & 143.977 & 8,4 & 285.020 & 16,6 \\
\hline Região da Europa & 113.346 & 12,8 & 117.997 & 13,4 \\
\hline Região do Mediterrâneo Oriental & 76.912 & 14,1 & 175.668 & 32,2 \\
\hline Região do Pacífico Ocidental & 135.316 & 7,6 & 278.321 & 15,6 \\
\hline Taxas Mundiais & 661.319 & 10,1 & 1.234 .026 & 18,8 \\
\hline
\end{tabular}

*Dados ajustados à definição de óbito por acidentes de trânsito num prazo de 30 dias após o evento.

FONTE: OMS (2009)

O seja, os indicadores de mortalidade da Tabela 1.1, já considerados elevados, seriam ainda maiores se considerarmos o numero de mortos que acontece como consequência dos acidentes mais que não são registrados como tal pelas estatísticas brasileiras.

Conforme cita Ferraz et al (2008) este índice de mortes por habitante constitui informação útil para avaliar o desempenho de diferentes políticas de segurança no transito e identificar fatores de êxito ou de insucesso, motivo pelo qual sugere usar o índice de mortes por veiculo por ser mais indicado para comparar a segurança no transito entre diferentes espaços geográficos (por não estar impactado pela taxa de motorização). Recentemente Bastos (2011) apresenta um novo indicador como evolução do anterior incorporando a quilometragem total percorrida pela frota de veículos como medida efetiva para expressar a exposição no transito. Se considerarmos este novo indicador, veremos que também para ele se verifica que Brasil apresenta uma situação crítica se comparado com os países desenvolvidos. Em efeito, observa-se que o índice brasileiro apresenta valores entre 7,16 a 12,70 vezes maiores se comparado com França e Suécia respectivamente, valores que surgem da Figura 1.3 . 


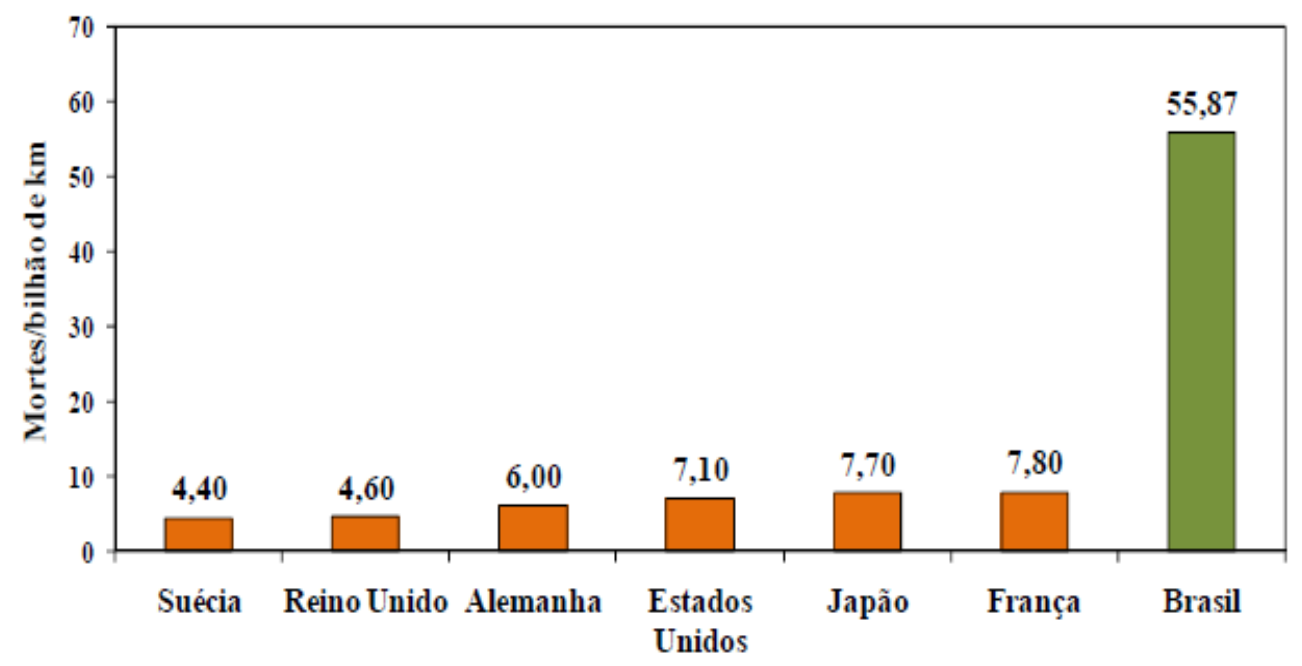

Figura 1. 3 - Comparação do índice de mortes por bilhão de quilômetros percorridos no Brasil (2008) e em outros países (2009).

Fonte: BASTOS (2011).

Após esta rápida apresentação do quadro de situação dos acidentes de trânsito no Brasil, é importante entender quais são os fatores de risco que contribuem para a ocorrência dos mesmos. Trata-se de fatores associados ao homem, à via e ao veículo. A maior incidência desses fatores é atribuída aos condutores e pedestres (fator humano); no entanto, estratégias diversas para a mudança comportamental exigem períodos de tempo relativamente longos para que surtam os efeitos esperados.

Especificamente no Brasil, a entrada em vigor do novo Código de Trânsito Brasileiro no ano 1998, e medidas como obrigatoriedade do uso do cinto de segurança, fiscalização eletrônica da velocidade nas vias urbanas e rurais, fiscalização do consumo de álcool dos motoristas e o uso de cadeirinhas no banco traseiro para menores, recentemente implantado, são exemplos de que o país vem atacando o problema com medidas concretas.

Estas ações de efeito no longo prazo vêm sendo complementadas por outras como a recente etapa de investimentos públicos e privados, estes sob-regimes de concessão, realizados na última década, com grande quantidade de intervenções executadas nas rodovias brasileiras, com resultados pontuais positivos nos locais das intervenções. Estas ações e resultados, embora incipientes e insuficientes para mudar o quadro de gravidade do atual estado de situação no que diz respeito aos acidentes de trânsito, mostram que o governo esta 
decidido a enfrentar o problema com atitude firme e consistente, aplicando soluções técnicas de segurança viária onde necessárias, assim como políticas de longo prazo.

A maioria das obras implantadas e certas ações de engenharia de tráfego aplicadas para resolver problemas específicos, oferecem uma interessante oportunidade para realizar estudos técnicos visando analisar a eficácia das soluções praticadas. Complementariamente surge a possibilidade de comparar os resultados destes estudos com os apresentados em bibliografia especializada como, por exemplo, o "The Handbook of Road Safety Measures" (Elvik \& Vaa, 2004).

Dentre várias alternativas possíveis, o presente trabalho estuda soluções aplicadas em travessias urbanas de rodovias. Para tanto, na apresentação do trabalho, discorre sobre conceitos da técnica de gerenciamento de riscos e analisa a eficácia das soluções adotadas mediante a aplicação da técnica de estudo observacional do tipo "antes e depois" proposto por Hauer (1997).

O problema da segurança em segmentos rodoviários que atravessam áreas urbanas, que denominamos aqui de travessias urbanas, é um assunto amplamente discutido pela Engenharia de Tráfego. Neste trecho de rodovia coincidem dois tipos de usuários. Um deles, circulando a alta velocidade, desenvolvendo percursos de longa distância. O outro, circulando a menor velocidade, procurando tornar mais rápida sua viagem entre dois pontos de sua cidade. Como consequência disto, surge um problema de conflito de interesses entre esses dois grupos, os usuários do tráfego direto e os usuários do tráfego local. Para agravar a situação, estes fluxos heterogêneos, interagem com outro grande número de veículos e pessoas que circulam pelo local: veículos motorizados (motocicletas) e não motorizados (bicicletas e de tração de animal) que, junto com pedestres, circulam pela faixa de domínio e atravessam a estrada com distintos níveis de atenção e cuidado. Ainda, os usuários sofrem a contaminação visual de propagandas e comércios que desviam sua atenção. Por vezes, se encontram com um traçado inadequado resultante de adaptações a situações pré-existentes, ou que aos poucos, cedeu espaço ao crescimento descontrolado da cidade, diminuindo a capacidade e qualidade operacional da via. Todos estes fatores tornam este segmento rodoviário um local crítico onde acontece todo tipo de acidentes.

Tal é o caso da travessia urbana de Rio Claro, localizada entre os Km 172 e 176 da SP-310 - Rodovia Washington Luiz, no Estado de São Paulo, pista dupla que, entre outros tipos de acidentes, apresentava um elevado índice de atropelamentos. O local apresentava passarela para pedestres, da qual foram tiradas as fotos das Figuras 1.3 e 1.4, que mostram o 
intenso fluxo de pedestres que não usam a passarela e se arriscam na travessia entre veículos que circulam a elevada velocidade pela rodovia.

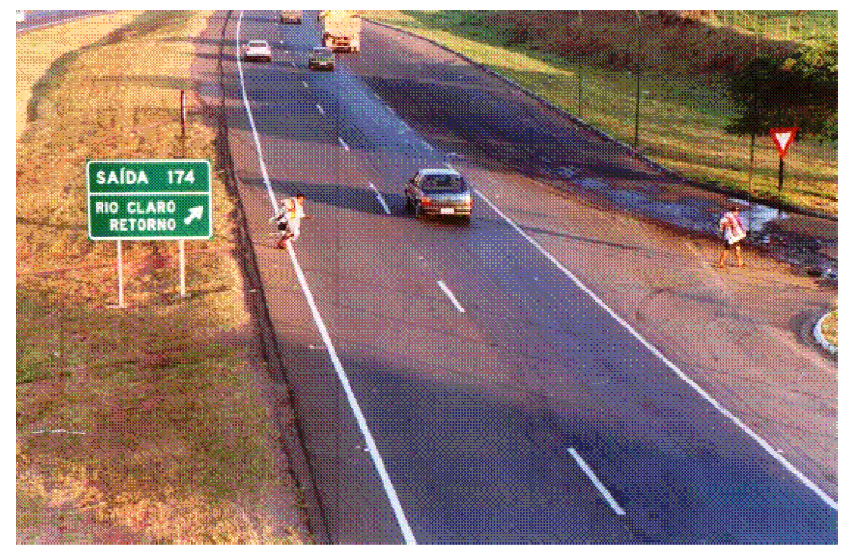

Figura 1. 4 - Travessia irregular de pedestres em pista dupla - SP310 - Rio Claro. Fonte: INST (1999).

Na Figura 1.3 pode se observar que os usuários não usam uma passarela existente no local ao lado e realizam a travessia em nível. A situação é agravada pelo falto que muito deles esperam atrás da placa de orientação, que os encobre, até o momento do cruzamento.

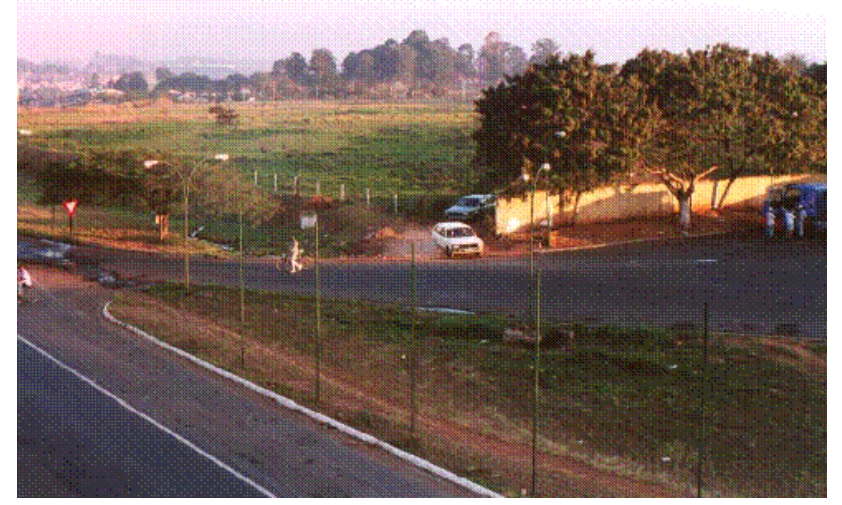

Figura 1. 5 - Acesso irregular de veículos e vizinhos a um bairro - SP310 - Rio Claro. Fonte: INST (1999).

No mesmo local, observa-se uma porcentagem considerável de pedestres e ciclistas que não usam a passarela e veículos que circulam no fluxo oposto da saída de um posto de gasolina. Estes movimentos são resultado de um acesso irregular a um bairro da cidade que encontra nesta alternativa um percurso mais curto é rápido para acessar a rodovia. 
Este segmento rodoviário foi amplamente estudado há uma década e recebeu diversas ações de engenharia de tráfego visando diminuir os acidentes e sua gravidade, os quais ainda se mantêm. Dentre as ações aplicadas, se procedeu a restringir a velocidade de circulação, diminuindo a velocidade máxima a $90 \mathrm{~km} / \mathrm{h}$, com a implantação de radar para controle da mesma. Questiona-se se foi uma medida acertada, suficiente e eficaz. Assim como este, outros segmentos rodoviários da região foram objetos de diversas campanhas e programas de redução de acidentes. Qual a eficácia das medidas aplicadas?

Existem várias outras experiências de trechos urbanos onde se desenvolveram diversas soluções visando à redução de acidentes e sua gravidade. Às vezes, a solução aplicada é qualificada como o fato gerador dos acidentes. Tal é o caso de uso de radares para garantir o atendimento da velocidade regulamentada no local, que resultam em manobras bruscas ou imprevistas de certos veículos quando se deparam, tardiamente, com a presença do aparelho medidor de velocidade, tema estudado por Yamada (2005).

Vale destacar que certas ações de segurança implantadas, dentre as quais a restrição de velocidade, gera certa inconformidade nos usuários, que argumentam que são exageradas e inconvenientes. Tal é o caso relatado no recorte do jornal da Figura 1.5, ilustrado na Figura 1.6, onde se critica o baixo limite de velocidade no local, dado que existem outras medidas de segurança já implantadas (passarela e muro no canteiro central) que o tornariam, ao dizer do jornalista, desnecessário.

Por outro lado, o Estado de São Paulo apresenta um cenário de forte investimento na sua malha rodoviária, favorecido pela implantação de um modelo de gestão de concessionárias privadas. A decisão das entidades privadas, alentadas pela agência fiscalizadora ARTESP, de tornar a segurança um valor diferenciado na prestação dos seus serviços, resultou em um número expressivo de intervenções na malha rodoviária, algumas de caráter meramente operacional (restrições de velocidade, controle de cargas perigosas, etc.), e outras obras de diversas magnitudes visando o melhoramento da capacidade, do desenho geométrico, ou da segurança (dispositivos de entroncamento, faixas adicionais, alargamento de pontes, etc.). Em correspondência, a ARTESP desenvolveu uma metodologia de acompanhamento destas ações gerando uma importante base de dados de acidentes de trânsito. 
Clipagem: Rodovias do Tietê Veículo: Correio Popular Editoria: Correio do Leitor Data: $06 / 10 / 10$

\section{Lentidão}

Joaquim Gonçalves dos Santos

Aposentado. Campinas

A cada dia útil, no chamado horário de pico, pela manhâ e à tarde, nos dois sentidos

de direção, se nota

inconcebivel lentidão e

congestionamento

quilométrico de veículos

que trafegam pela Rodovia

Campinas-Monte Mor

(SP-101). Tudo porque, no

trecho paralelo à Bosch,

existe um radar

determinando velocidade

máxima de $50 \mathrm{Km} / \mathrm{h}$. Daí, a

reduçäo de velocidade que

gera toda a mixordia. Até

pouco, se justificava tal

evento, devido ao grande

número de transeuntes

circulantes à fábrica. Mas,

agora, existe uma bela e

segura passarela para os

pedestres cruzarem a

rodovia, que tem ainda uma

mureta de média altura no

canteiro central.

Poder-se-ia aumentar pelo

menos para $60 \mathrm{Km} / \mathrm{h}$, já

que, fora do trecho citado, a

velocidade salta para

BoKm/h.

Figura 1. 6 - Recorte do jornal onde se critica o baixo limite de velocidade regulamentado no local.

Fonte: Rodovias do Tietê (2010).
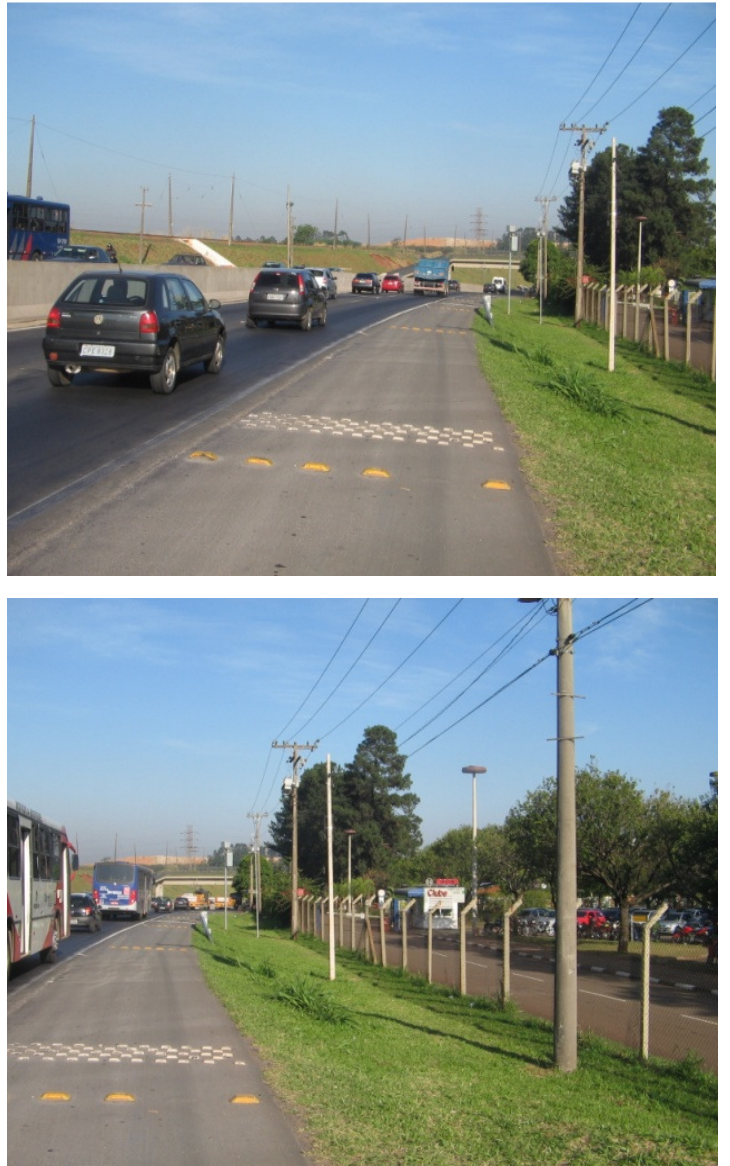

Figura 1. 7 - Fotos do local indicado na Figura 1.6 onde se observa o acumulo de veículos circulando a baixa velocidade.

Fonte: Fotos do pesquisador (2010)

O autor desta pesquisa trabalhou na área operacional de uma das concessionárias de rodovias durante o inicio do programa lançado pelo Governo do Estado de São Paulo, motivo pelo qual participou da implantação de várias atividades relacionadas com a segurança viária, conhece alguns dos planos de ação propostos e os sistemas de acompanhamento definidos, e mantém um estreito relacionamento com os profissionais que atuam neste sector, o que facilitou a obtenção de dados e informações necessárias para a realização da pesquisa.

Neste contexto propício, surgiu a ideia de utilizar os dados disponíveis para estudar a eficácia das soluções técnicas aplicadas a diversos problemas de segurança rodoviária. Mediante a aplicação de metodologia de estudos observacionais do tipo "antes - depois" para análise de diversos casos, o presente estudo abordou algumas das soluções implantadas, focando aquelas desenvolvidas para resolver problemas de segurança nas travessias urbanas de rodovias. 


\subsection{OBJETIVOS}

O presente trabalho discorre sobre soluções aplicadas a problemas de segurança em segmentos rodoviários que atravessam áreas urbanas, denominadas de travessias urbanas de rodovias. Esta escolha deve-se ao fato do pesquisador ter participado pessoalmente na aplicação de soluções de segurança rodoviária em uma travessia rodoviária urbana com altos índices de acidentes. Transcorrido o tempo, se retornou a este segmento rodoviário para verificar a eficácia da solução aplicada. Ainda, aproveitando o relacionamento do autor desta pesquisa com os profissionais que atuam neste setor (o que possibilita a obtenção de dados e informações necessárias para a realização da pesquisa), se estendeu a análise a vários trechos que receberam intervenções na malha rodoviária do estado de São Paulo.

O trabalho apresenta os conceitos principais, e casos de aplicação, das técnicas de gerenciamento de riscos e dos estudos observacionais do tipo "antes - depois", frequentemente citada na prática, más poucas vezes usadas com rigorosidade metodológica.

Foi realizada uma pesquisa, identificando e analisando, de forma crítica e conclusiva, os seguintes assuntos:

- Quais as soluções aplicadas (sejam inovadoras ou técnicas convencionais)?

- Quais as restrições implantadas: velocidade, movimentos de fluxo, tipo de veículos, etc.? Foram adequadas?

- Qual o monitoramento aplicado? Permite verificar a eficácia da solução implantada ao longo do tempo? Pode-se inferir benefícios concretos alcançados?

- Quais as conclusões da eficácia dos mesmos?

Desta forma, pretende-se contribuir com a técnica, divulgando no ambiente acadêmico, a partir da análise metodológica e crítica, casos concretos de intervenções de engenharia de tráfego realizadas nas rodovias do Estado de São Paulo que visam resolver problemas de segurança das travessias urbanas de rodovias.

\subsection{ESTRUTURA DO TEXTO}

Este trabalho está estruturado em seis capítulos. O primeiro capítulo é a introdução onde se realiza a caracterização do problema dos acidentes nas travessias urbanas das rodovias. 
O Capítulo 2 discorre sobre a revisão bibliográfica realizada sobre os assuntos relacionados ao tema, visando identificar como a Engenharia de Tráfego tem encarado o mesmo e qual a atual linha de ação da técnica para resolver as questões de segurança relativas às travessias urbanas de rodovias. Analisam-se as metodologias usadas para identificar os locais críticos das rodovias, apresentado os conceitos de "gerenciamento de riscos" e "auditoria de segurança".

Na sequencia, no Capítulo 3, são apresentados os aspectos conceituais da metodologia de estudos observacionais do tipo "antes - depois" para análise da eficácia das soluções de engenharia realizadas.

O Capítulo 4 explica como se procedeu para a obtenção do material necessário para a realização do trabalho, através das diversas entidades responsáveis pelo gerenciamento das rodovias: Concessionárias Rodoviárias, DER/SP e ARTESP. Dentre os exemplos obtidos foram selecionados alguns casos de soluções técnicas aplicadas em travessias urbanas de rodovias com altos índices de acidentes. Intentou-se colocar especial ênfase no estudo do efeito da restrição de velocidade aplicada, o que foi realizado de forma parcial, pois os dados obtidos não permitiam identificar os efeitos segregados por cada ação aplicada (em geral as soluções aplicadas foram combinações de várias medidas de segurança). Analisaram-se todas as ações de prevenção de acidentes possíveis com os dados recebidos.

No capítulo 5 são apresentados os resultados obtidos das análises de eficácia das medidas de engenharia realizadas para a redução de acidentes em travessias urbanas em rodovias.

O capítulo 6 contém as considerações finais do trabalho e sugestões para trabalhos futuros sobre o tema. 


\section{REVISÃO BIBLIOGRÁFICA}

Este capítulo apresenta a revisão bibliográfica realizada sobre os temas pertinentes a este trabalho.

\subsection{TRAVESSIAS URBANAS DE RODOVIAS - CARACTERIZAÇÃO DO PROBLEMA}

As travessias urbanas de rodovias são segmentos de rodovias que atravessam áreas urbanas. Caracterizam-se por apresentar concentração populacional nas suas áreas adjacentes e a necessidade de atender e conciliar, a demanda de tráfego de dois tipos diferentes de usuários: o de longa distancia e o local. Como consequência disto, surge um problema de conflito de interesses entre esses dois grupos, os usuários do tráfego direto, que desejam atravessar o trecho rapidamente para chegar ao seu destino, e os usuários do trafego local, que utilizam os segmentos rodoviários como meio mais veloz de se locomover dentro da própria cidade.

Corresponde esclarecer inicialmente que, embora o termo travessia urbana também possa ser utilizado para se referir a vias de transporte urbano que visam ligar áreas dentro da própria cidade, com o objetivo de facilitar a locomoção do trânsito urbano por vias mais rápidas, estas não formam parte deste analise.

Ainda existem outros tipos de travessias urbanas, que não são tema do presente trabalho, mas cabe ser citadas. São elas: a travessia constituída por um segmento da antiga rodovia que atravessava a cidade e que, com o crescimento urbano foi incorporada a égide urbana e se transformaram em avenidas principais da cidade; e a travessia urbana com acesso bloqueado, na qual não é permitida a entrada e saída de veículos do segmento rodoviário, mantendo totalmente separados os usuários de passagem dos usuários locais. 
É de grande importância entender o que leva à formação das travessias urbanas de rodovias, os problemas que derivam delas e o que representam essas travessias, tanto em termos de mobilidade como de acessibilidade, dando especial destaque ao conflito de interesses entre os dois tipos de usuários dessas vias, os de passagem e os locais.

Podemos descrever o mecanismo de formação das travessias urbanas de rodovias da seguinte forma: inicialmente a região urbana encontra-se próxima à rodovia a qual foi construída no seu entorno visando possibilitar a integração e desenvolvimento econômico da mesma com o da região. Com o transcorrer do tempo ocorre naturalmente o envolvimento dessa via pelo perímetro urbano, devido ao contínuo crescimento urbano. Dessa forma, o segmento rodoviário próximo à área urbana adquire características próprias de uma travessia urbana uma vez que, mantém sua função original de tráfego direto conectando cidades e regiões, e simultaneamente passa a ser uma via frequentada pelo tráfego local, ou seja, tornase uma opção para locomoção dentro da região urbana.

O ciclo natural é a construção de um contorno rodoviário, visando superar os problemas presentes na travessia urbana de rodovia, já que o novo contorno não terá esses problemas, e apresentara as características inicias da rodovia, servindo para trânsito de passagem. Entretanto, esse contorno rodoviário sofrerá novamente o envolvimento da cidade por seu natural crescimento, que por sua vez levará a construção de um novo contorno, e assim por diante.

Segundo Freire (2003), outro fator que contribui para o contínuo envolvimento das vias e dos contornos rodoviários é o interesse comercial da população local de transferir os negócios que servem aos viajantes para próximo dos contornos, caracterizando o ciclo.

A questão das travessias urbanas de rodovias ganha grande destaque na literatura devido principalmente aos problemas que derivam delas. Os principais pontos críticos de acidentes de trânsito das rodovias brasileiras se localizam em regiões de travessias urbanas.

Apresentam elevados volumes de tráfego, ocupação das faixas lindeiras intensa e muitas vezes desordenada, com modificações traumáticas no uso do solo, com atividades comerciais de pequeno porte para atender aos usuários da via, provocando uma maior expansão urbana, atraindo a população de baixa renda num processo de linearização das cidades, ficando a rodovia como divisor das regiões residenciais e comerciais. A consequência desta situação é o agravamento das condições de segurança do tráfego local.

O tratamento dessas regiões exige uma solução integrada com as esferas de governo envolvidas para a adoção de medidas de modo a minimizar a ocorrência de acidentes. Essa 
solução contempla não somente medidas de engenharia de tráfego e educação de trânsito, mas também medidas referentes a planejamento urbano, envolvendo todas as instâncias de administração e, principalmente, em todas as fases, a comunidade usuária.

A análise de alguns locais de interface rodovia-cidade permite tipificar situações, de modo a possibilitar intervenções de medidas de caráter tanto físico-operacional quanto institucional e comportamental, objetivando a melhoria de qualidade de vida no entorno as rodovias.

Dificilmente poderá ser solucionado o problema das travessias urbanas de rodovias enquanto o conflito de interesses persistirem. A solução mais viável é a separação desses usuários, através da construção de contornos rodoviários cada vez mais distantes das aglomerações urbanas, visando afastar da cidade o tráfego de passagem. Entretanto, como vimos, interesses levam ao crescimento da cidade em direção a esses contornos, levando novamente ao conflito.

Outro tipo de solução, utilizada em diversos países, é a construção de vias expressas que são para uso exclusivo de usuários de passagem que não permitem o fluxo local de veículos devido à restrição de acessos. Dessa forma o conflito não existe e o problema pode ser parcial ou totalmente solucionado. Porém, medidas como essas são extremamente custosas, pois obrigam à construção de uma via a mais além da via convencional.

Seja pelo elevado custo ou por falta de planejamento, esse tipo de medida não se encontra nos planos dos governos locais, tornando-se necessário implementar outras medidas que visem amenizar o conflito entre os dois grupos, sem a possibilidade de eliminá-lo. As principais medidas adotadas são: restrições de velocidade, sinalização e fiscalização ostensiva e maior controle do crescimento das cidades em direção às vias rodoviárias.

Segundo o DNER (1998) os principais acidentes que ocorrem em travessias urbanas são: atropelamento, colisão traseira, abalroamento lateral mesmo sentido, abalroamento transversal. Sendo as principais medidas de engenharia de baixo custo: redução da velocidade do tráfego de passagem com sinalização vertical intensa de advertência e regularização; sinalização horizontal não convencional pintada na pista e faixas para a travessia de pedestres; sonorizadores associados à sinalização vertical de advertência; faixas transversais à via com tachas refletivas; construção de calçadas ao longo da via com fechamento de acessos irregulares; uso de defensas e cercas para canalizar travessias em local adequado; proibir estacionar; construção de baias para parada de ônibus; campanhas educativas. O DNER 
(1998) aponta também que há soluções de grande porte como a construção de passarelas e projetos especiais.

\subsection{METODOLOGIA DE GERENCIAMENTO DE RISCOS}

\subsubsection{ASPECTOS CONCEITUAIS}

Apresenta-se a seguir a os principais conceitos da Metodologia de Gerenciamento de Riscos, conforme considerações que tem como fonte o trabalho desenvolvido pelo pesquisador junto com o INST para o Programa de Desenvolvimento de Segurança Rodoviária da concessionária Centrovias Sistemas Rodoviários S/A, no ano 1999.

O conceito de "gerenciamento de risco" é amplamente utilizado no setor empresarial relacionado à segurança dos trabalhadores, consistindo basicamente na identificação prévia de riscos potenciais de acidentes e na adoção de atitudes preventivas para eliminação desses riscos. A engenharia de tráfego tem adotado e aplicado esse conceito para todas as ações envolvidas na implantação e operação de sistemas rodoviários.

A metodologia de gerenciamento de riscos aplicada a rodovias é composta por ações a serem desenvolvidas de forma integrada pelos órgãos e entidades com jurisdição sobre a via e as comunidades intervenientes - usuária e lindeira -, levando em consideração todos os aspectos relevantes nas rodovias, tais como:

- Competência jurídica dos órgãos / entidades sobre a mesma;

- Projeto e execução de obras;

- Operação, manutenção e fiscalização: normas, órgãos envolvidos e atribuições;

- Interface das rodovias com áreas urbanas;

- Subordinação dos agentes envolvidos a chefias diferenciadas;

- Uso do solo nas áreas lindeiras;

- População usuária: transporte coletivo, de cargas e particular: expectativas, crenças e valores, comportamento;

- População lindeira: expectativas, crenças e valores, comportamentos;

- Serviços de apoio oferecido ao usuário.

A metodologia permite, através de uma análise de situação, identificar os principais riscos e, a partir daí, propor ações que possibilitam o gerenciamento desses riscos. Essa 
metodologia, por incorporar o aspecto comportamental às propostas de ações, proporciona resultados que refletem na qualidade de vida de toda a comunidade.

O processo é contínuo e permanente, devendo abranger a cada instante todas as ações em desenvolvimento na via: projetos, manutenção, operação, fiscalização, etc.

$\mathrm{Na}$ Figura 2.1 é apresentado o fluxo de atividades a serem desenvolvidas para aplicação dessa metodologia no estudo das rodovias, as quais são descritas brevemente na sequencia.

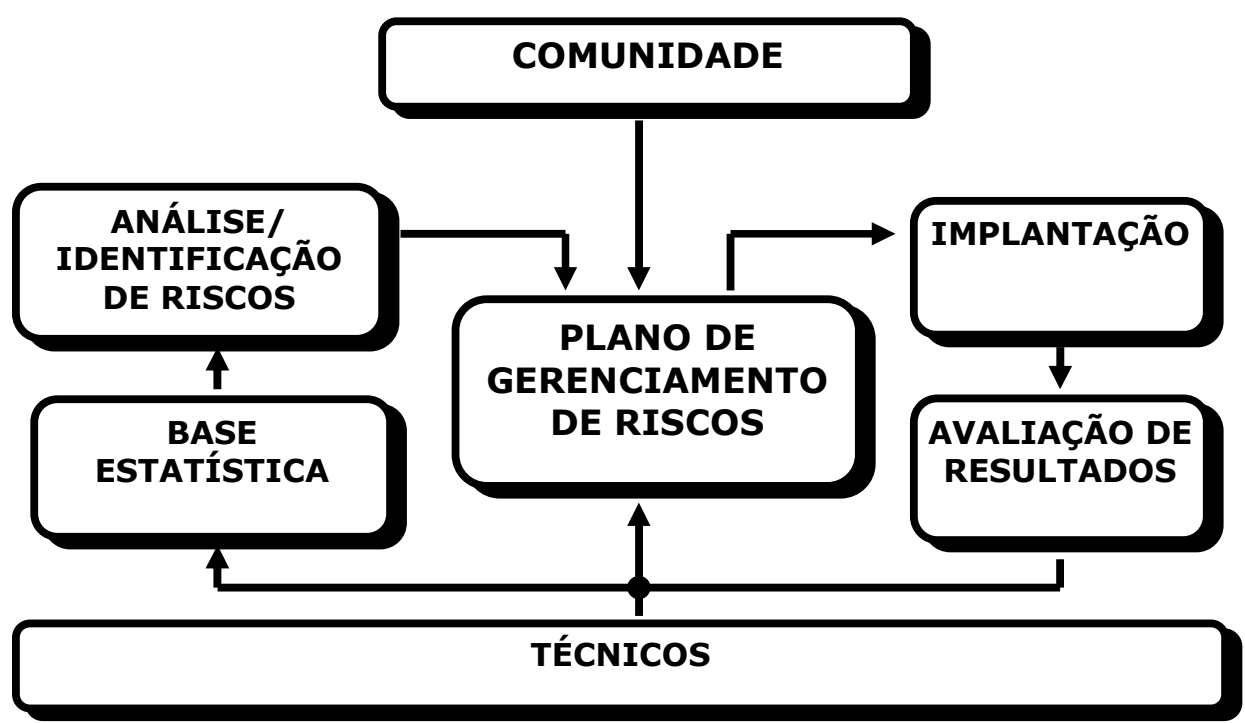

Figura 2. 1 - Fluxograma de atividades.

Fonte: INST (1999)

A primeira etapa envolve o Levantamento de dados existentes - Base Estatística

(Conhecer) que leva a um conhecimento da realidade da entidade em analise, em especial quanto a:

- Características das vias nos trechos (volume, número de acessos, número de faixas de rolamento, raios de curvatura, declividade, drenagem etc.);

- Características do uso do solo lindeiro às vias, dos acessos oferecidos e do controle desses acessos;

- Identificação dos pontos críticos;

- Identificação dos órgãos envolvidos na gestão e na operação, manutenção e fiscalização das vias e das áreas lindeiras;

- Rotinas e esquemas especiais de operação, manutenção e fiscalização das vias; 
- Características da população usuária das vias e da população lindeira às mesmas;

- Identificação das entidades ligadas aos usuários das vias e das lideranças das comunidades locais;

- Levantamento dos índices de acidente.

A segunda etapa abrange uma Análise de Dados e Identificação de Riscos (Analisar) visando:

- Identificação dos principais fatores de riscos;

- Propostas de ações para gerenciamento dos riscos identificados.

A terceira etapa é a Definição de um Plano de Gerenciamento de Riscos (Planejar) composta por ações que poderão envolver:

- Intervenções em pontos críticos;

- Medidas operacionais;

- Serviços de manutenção;

- Atividades de fiscalização;

- Comunicação social e campanhas;

- Segurança veicular e de pedestres;

- Monitoramento e serviços ao usuário.

Neste momento é fundamental a participação da comunidade e dos órgãos técnicos envolvidos na discussão das medidas previstas e a forma de implantá-las para que a o Plano de Ações atinja os resultados desejados.

A quarta etapa é a Implementação do Programa (Agir) com:

- Definição de atribuições dos órgãos e comunidade;

- Cronograma de implantação das ações;

- Acompanhamento da implantação.

A quinta etapa prevê a avaliação de resultados (monitorar) através de:

- Acompanhamento de situações "antes e depois" das implantações;

- Monitoramento constante dos dados referentes às vias, com permanente avaliação de comportamento dos envolvidos, como parte do processo dinâmico de análise e readequação de medidas e incorporação de novas, se necessário.

Este processo contínuo se complementa, e por sua vez necessita de um sistema de Auditoria de Segurança Viária (ASV), definido por Ferraz et al (2008), como uma análise formal, do ponto de vista da segurança do trânsito, de uma via, elemento viário ou esquema de 
circulação, existente ou projetado, por uma equipe de examinadores qualificados e independentes.

A auditoria de segurança visa basicamente:

- Minimizar o risco e a severidade dos acidentes de trânsito motivados por falhas de projeto;

- Minimizar a necessidade de obras complementares corretivas após a construção e operação;

- Melhorar as práticas de segurança nos projetos por parte de todos os envolvidos no planejamento, projeto, construção, manutenção e operação do sistema viário.

A Auditoria de Segurança Viária deve ser prevista em cada ou em todos os estágios de um projeto viário. Assim, a técnica pode ser introduzida nos seguintes estágios:

- Estudos de Viabilidade: nesta etapa do projeto, a auditoria pode influenciar na seleção das diretrizes de traçado, dos padrões de projeto e analisando também o impacto da nova via na malha viária; é especialmente importante nesta fase a verificação da existência e a análise da adequação de normas e procedimentos de projeto.

- Anteprojeto ou Projeto Básico: nesta etapa, pré-detalhamento do projeto, a auditoria de segurança, interagindo com equipes de projeto, analisa o processo verificando o atendimento às normas e procedimentos, a previsão de sinalizações específicas, os procedimentos, a previsão de sinalização especificas, o dimensionamento de equipamentos, análise do uso do solo, estacionamento, parâmetros geométricos, etc.

- Detalhamento de Projeto: nesta etapa é feita uma análise detalhada do projeto; envolve a verificação de todos os desenhos do projeto (geometria, sinalização, iluminação, pavimento, drenagem etc.), verificando a uniformidade das normas e procedimentos adotados para cada trecho da via ou região.

- Obras de Implantação: nesta etapa é feita uma análise sobre qual o impacto da realização de obras na via. Verifica-se a observação de todas as normas e procedimentos para obras, de forma que a intervenção/ocupa da pista não produza situações de riscos; além disso, verifica-se a necessidade de eventuais adequações do projeto para atendimento de situações específicas. 
- Operações, Manutenção e Fiscalização do Projeto implantado: nesta etapa é feita uma análise sobre ocorrências de acidentes, normas e procedimentos operacionais, interações das equipes externas e internas, serviços prestados aos motoristas etc.

Para ilustrar a metodologia de gerenciamento de risco seguem os conceitos principais usados e o roteiro que deve ser seguido na aplicação da mesma.

\subsubsection{CARACTERIZAÇÃO DOS ACIDENTES DE TRÂNSITO}

$\mathrm{Na}$ análise das ocorrências registradas num determinado segmento da rodovia, é fundamental a caracterização do tipo de acidente predominante. A partir dessa caracterização e de outros fatores determinantes para a ocorrência do acidente podem ser indicadas as possíveis soluções para o caso em analise.

Há muito tempo, dados relativos aos incidentes de tráfego ocorridos na malha viária, registrados através dos boletins de ocorrência lavrados pelos policiais militares rodoviários, vêm contribuindo na obtenção de informações importantes, e que possibilitam a identificação, nas rodovias, dos principais pontos críticos ou áreas de alto risco (conhecidos também como pontos negros), bem como a caracterização dos principais problemas e deficiências existentes.

Os relatórios editados pela Polícia Rodoviária mostrados na Figura 2.2 contêm informações relevantes, tais como:

- Natureza dos acidentes;

- Caracterização da frota, incluindo espécies e categoria dos veículos;

- Consequência dos acidentes;

- Tipos de acidente;

- Horário dos acidentes;

- Dias da semana, etc.

Os principais tipos de acidentes contemplados nos boletins acima citados são:

- Colisão Frontal: é o impacto entre dois veículos que trafegam em sentidos opostos;

- Colisão Traseira: é o impacto entre dois veículos que trafegam no mesmo sentido (ou excepcionalmente em sentidos contrários, mas em marcha a ré);

- Engavetamento: é a colisão traseira entre três ou mais veículos;

- Abalroamento Lateral: é o impacto lateral entre dois veículos que trafegam no mesmo sentido; 
- Abalroamento Transversal: é o impacto entre dois veículos que se cruzam em angulo de aproximadamente $90^{\circ}$;

- Choque: é o impacto entre um veículo contra um obstáculo fixo (poste, árvore, muro, veículo estacionado ou parado);

- Capotamento: é o acidente em que o teto do veículo toca o pavimento em algum momento;

- Tombamento: é o acidente em que a lateral do veículo fica em contato com o pavimento;

- Atropelamento: é o acidente em que um pedestre ou um animal é atingido por um veículo;
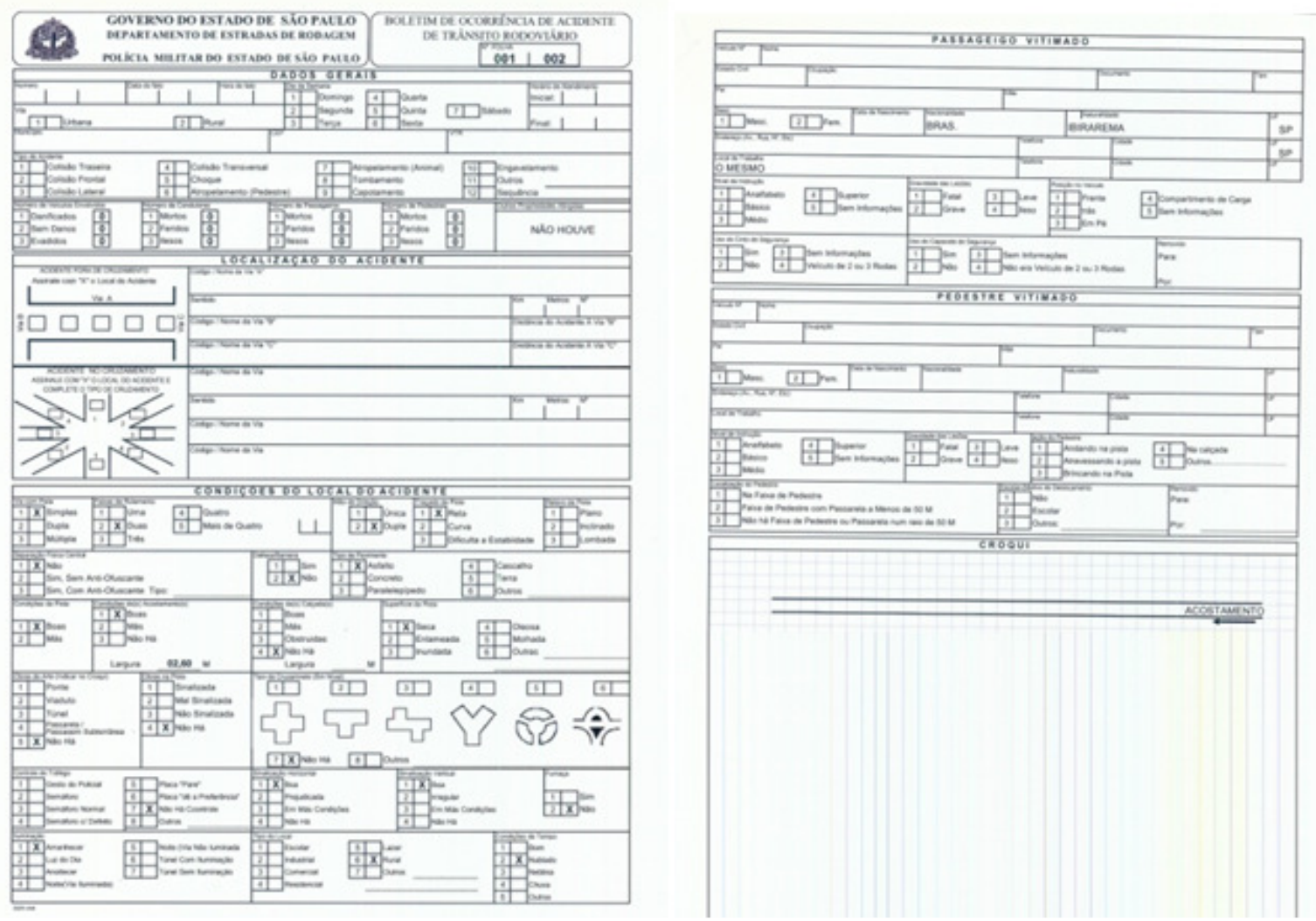

Figura 2. 2 - Boletim de Ocorrência (BO).

Fonte: INST (1999).

A informação desta importante base de dados apresenta pelo menos dois problemas importantes que merecem mencionar-se e que desestimulam seu uso. Primeiramente, a própria sistemática utilizada para a apresentação e distribuição das informações (documentação impressa) contribui na geração de atrasos para recebimento dos dados pela parte interessada 
(entidade que realiza a gestão operacional da rodovia), sendo comum nos processos normais de circulação da informação, o não recebimento de informações por erro de destinatário, extravio de correspondência, morosidade dos processos de protocolo, elevados custos para cópia e correio, etc.

Outro aspecto a ser mencionado refere-se ao questionamento sobre confiabilidade dos dados disponíveis, uma vez que a forma de lançamento e o esforço demandado para sua consecução podem levar à perda de parte significativa das informações. Isto acontece geralmente pelas simplificações sucessivas nos tipos e quantidades de dados a serem coletados ou por inconsistências surgidas pela introdução de dados incorretos, decorrentes, principalmente, de erros de preenchimento de tabela.

É importante destacar o esforço que vem realizando o governo no sentido de promover a sistematização das informações com a emissão de Boletins de Ocorrência on-line, que propiciam a obtenção de bases de dados digitais que facilitam o manuseio e processamento das informações, tornando-as mais úteis na utilização de sistemas de gestão como o de gerenciamento de riscos aqui apresentado.

A partir dos dados que são coletados dos registros dos postos da Polícia Militar Rodoviária monta-se uma central de controle operacional que representará o centro nervoso de todo o gerenciamento de tráfego do sistema. Nessa central, está instalado o computador principal, o software de cadastro e processamento de dados e demais equipamentos operacionais necessários, e será responsável pelo recebimento, controle, processamento e análise de todos os dados e informações de campo e, consequentemente, pela geração, manutenção do banco de dados de acidentes e elaboração das recomendações técnicas.

A possibilidade de posterior incorporação de um Sistema de Informações Georeferenciadas - SIG permitiria a visualização gráfica na tela do computador central da malha rodoviária, com os respectivos dados das ocorrências nos pontos e/ou trechos crítico.

Com a disponibilização deste banco de dados e uma adequada infraestrutura de gerenciamento dos recursos, o gerenciamento de riscos pode ser aplicado deforma eficiente e eficaz. Estará constituído por uma série de atividades gerenciais voltadas ao direcionamento correto e eficaz do planejamento estratégico, tomadas de decisão, ações e intervenções necessárias à correção e manutenção do tráfego da malha viária, dentro de limites e padrões de segurança e confiabilidade estabelecidos ou recomendados internacionalmente.

Como recurso indispensável para facilitar as atividades de gerenciamento recomendase usar algum software de processamento das Informações de Acidentes de Trânsito. Com 
esta ferramenta é possível a obtenção de uma melhora significativa nos tipos e quantidades de dados, pela introdução de novas séries de informações relevantes que possam vir a serem cadastradas, que irão resultar, consequentemente, no surgimento de novos indicadores e

parâmetros de controle, que até então não se encontravam disponíveis. Desta forma, o processamento permitirá a obtenção de conclusões importantes, tais como locais críticos; dias e datas críticas; horários críticos; acidentes-padrão; veículos envolvidos; efeitos das condições climáticas e do estado da via; etc.

\subsubsection{ANÁLISE DOS ACIDENTES DE TRÂNSITO E DIAGNÓSTICO DAS CAUSAS}

Os acidentes de trânsito geralmente são resultado de uma soma de fatores, os que podem ser classificados em três tipos:

- Fator humano (comportamento dos condutores e pedestres)

- Fator veículo (condições de projeto e manutenção dos veículos)

- Fator via/meio ambiente (condições da via, engenharia de tráfego, clima, etc.).

Um acidente típico pode acontecer como consequência de fatores de um, dois ou todos estes tipos. Um exemplo de um acidente simples, de um único fator, seria um condutor cansado e com sonho que perde o controle de seu automóvel novo a baixíssima velocidade e sai da pista, viajando em um trecho reto de uma via em excelente estado durante um dia de tempo bom. O acidente foi causado por um único fator, do tipo "fator humano": a sonolência do condutor.

Por outro lado ocorrem acidentes nos quais aparecem todos os tipos de fatores, incluso alguns deles repetidos. Pode-se citar como exemplo um acidente no qual um condutor alcoolizado e consequentemente com reações lentas (fator humano 1), dirigindo seu automóvel com pneus carecas (fator veículo 1) numa via à noite e com chuva (fator via/meio ambiente 1), derrapou e não evitou bater com um ônibus com defeito nos faróis (fator veículo 2), quando seu condutor, cansado após dirigir muitas horas sem parar (fator humano 2), tentou frear tarde demais ao adentrar na via através de um acesso sem sinalização horizontal, recentemente recapeamento (fator via/meio ambiente 2). Neste acidente percebe-se um total de 6 fatores, sendo 2 de cada tipo.

Em pesquisa feita na Inglaterra pelo Transport and Road Research Laboratory TRRL, citada pelo INST (1999), 91,5\% dos acidentes apresentaram "fator humano" ou mais 
simplesmente falhas no comportamento de um ou mais usuários. Fatores do tipo "fator via", ou defeitos na engenharia de tráfego e/ou condições adversas do tempo, contribuíram em 32\% dos acidentes e "fator veículo", ou condições inadequadas dos freios, pneus etc. de pelo menos um dos veículos envolvidos, em 24,5\%. Este resultado é resumido na Tabela $2.1 \mathrm{e}$ ilustrado na Figura 2.3:

Tabela 2. 1 - Causas Multifatores de Acidentes de Trânsito

\begin{tabular}{ccccc}
\hline $\begin{array}{c}\text { N. }{ }^{\circ} \text { de Tipos de } \\
\text { Fatores } \\
\text { Simultâneos }\end{array}$ & $\begin{array}{c}\text { Fator } \\
\text { Humano }\end{array}$ & $\begin{array}{c}\text { Fator } \\
\text { Veículo }\end{array}$ & $\begin{array}{c}\text { Fator Via / } \\
\text { Meio } \\
\text { Ambiente }\end{array}$ & $\begin{array}{c}\text { \% dos } \\
\text { Acidentes }\end{array}$ \\
\hline 1 & $\mathrm{X}$ & $\mathrm{X}$ & & 50,0 \\
1 & & & $\mathrm{X}$ & 3,0 \\
1 & $\mathrm{X}$ & $\mathrm{X}$ & & 0,5 \\
2 & $\mathrm{X}$ & & $\mathrm{X}$ & 15,0 \\
2 & & $\mathrm{X}$ & $\mathrm{X}$ & 5,0 \\
2 & $\mathrm{X}$ & $\mathrm{X}$ & $\mathrm{X}$ & 1,5 \\
3 & $\mathbf{9 1 , 5}$ & $\mathbf{2 4 , 5}$ & $\mathbf{3 2 , 0}$ & $\mathbf{1 0 0 , 0}$ \\
\% Total & & & & \\
\hline
\end{tabular}

Fonte: TRRL Apud INST (1999)

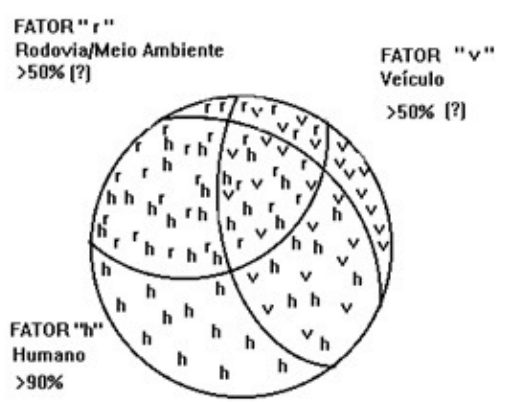

Figura 2. 3 - Causas Multi-Fatores de Acidentes de Trânsito.

Fonte: INST (1999).

As causas de acidentes normalmente identificadas em boletins de ocorrência policiais ou relatórios de acidentes elaborados por diversas outras autoridades de trânsito podem ser classificadas como "causas diretas", no sentido que denominam o que obviamente ocorreu. Por exemplo: "o condutor passou sinal vermelho" (causa direta, tipo fator humano), ou "o veículo derrapou em função de pneus carecas" (causa direta, tipo fator veículo), ou "a sinalização horizontal não era visível" (causa direta, tipo fator via/meio ambiente). 
Embora sirvam para apontar os "culpados", as causas diretas não têm tanta utilidade para trabalhos objetivos visando à redução e prevenção de acidentes. Para este fim, torna-se necessário analisar mais profundamente os acidentes, identificando as "causas indiretas". Voltando aos exemplos no parágrafo anterior: "o condutor passou sinal vermelho". Más por quê? As possíveis respostas, que representam as possíveis causas indiretas, são várias. Entre elas: passou de propósito porque estava com pressa; não viu o sinal vermelho; viu o sinal vermelho, mas tarde demais; passou mal na direção e estava desmaiado; pretendeu parar normalmente, mas derrapou devido a pneus carecas, pista lisa e água de chuva; e depois de ficar parado há muito tempo no sinal vermelho achou que estava enguiçado.

Obviamente as várias causas indiretas requerem medidas corretivas ou preventivas diferentes. Algumas requerem até mais estudo. Por exemplo, no caso de um condutor que não viu o sinal vermelho, porque o não viu? Estava encoberto? A posição do sinal não é adequada? O condutor deveria estar usando óculos e não estava? Alguma propaganda luminosa ofuscava os condutores?

Devem-se analisar em profundidade estes aspectos visando evitar dois perigos que se sucedem com frequência: o de não identificar as raízes do problema e o de desperdiçar recursos, investindo em medidas que não resultarão na redução desejada de acidentes. Por exemplo, de nada adiantaria mudar as posições dos grupos focais semafóricos visando tornálos mais visíveis, se os acidentes estão ocorrendo devido à condição derrapante da pista.

Pode-se afirmar então, que os acidentes podem ser reduzidos e prevenidos por meio da identificação e eliminação sistemáticas dos multifatores contribuintes (causas diretas) que os geram, o que por sua vez significa a busca e eliminação das causas indiretas.

A eliminação de qualquer um dos fatores contribuintes, de qualquer dos três tipos, tem o efeito de redução da probabilidade de ocorrência dos acidentes. Por exemplo, no acidente de seis fatores, apresentado anteriormente, a simples eliminação do cansaço do condutor do ônibus (fator humano 2) aumentaria muito suas chances de perceber o início da via e também o automóvel que se aproximava com antecedência suficiente para permitir uma frenagem normal, com pouco risco de acidente, mesmo mantendo-se os demais cinco fatores de risco. Pode-se perceber que, da mesma forma, a eliminação de qualquer um dos seis fatores, sem a eliminação dos demais, reduziria significativamente a probabilidade de ocorrência do acidente.

A eliminação sucessiva de mais fatores contribuintes diminui cada vez mais a probabilidade de ocorrência dos acidentes, o que obviamente resulta em menos ocorrências. 
Quando o objetivo é a elaboração de programas de redução e prevenção de acidentes de trânsito não interessa a identificação dos "culpados". O que interessa é a identificação dos meios de se evitar os acidentes, eliminando progressivamente os multifatores contribuintes, sempre que seja possível. Não sendo possível a eliminação de determinados fatores contribuintes, pode-se ainda reduzir a probabilidade de ocorrência dos acidentes, ou suas consequências, por meio de medidas que compensam os efeitos negativos destes fatores. A utilização de defensas em curvas e de tratamento antiderrapante para minimizar as consequências de acidentes devido ao excesso de velocidade, sem eliminação do excesso de velocidade, seriam exemplos de compensação.

Normalmente os programas de redução e prevenção de acidentes de trânsito propiciam, consciente ou inconscientemente, metas de priorizar em primeiro lugar a redução de vítimas fatais, em segundo lugar a redução da frequência e gravidade dos ferimentos sofridos pelas vítimas não fatais e, por último, a redução de danos materiais. É comprovado que as características dos acidentes com vítimas fatais diferem das dos acidentes com vítimas não fatais e que as características de ambos diferem das dos acidentes sem vítimas que resultam em somente danos materiais. Pode se observar diferenças significativas nas distribuições temporais, geográficas e por tipo de acidente (colisão entre veículos, atropelamento de pedestres, choque contra objeto fixo etc.). Assim pode-se perceber a importância de dimensionamento correto dos trabalhos de acordo com as metas.

A análise dos dados sobre os acidentes tem como objetivo geral a identificação dos riscos que resultaram nos acidentes, visando possibilitar a avaliação dos prováveis efeitos gerais das rodovias sobre esses riscos e visando também identificar as medidas necessárias, físicas e operacionais, para minimizar a frequência dos acidentes de trânsito e a gravidade das suas consequências.

Esta analise dos dados se realiza de forma sistemática conforme estabelece a metodologia de gerenciamento de riscos, onde os dados se levantam diretamente dos arquivos dos boletins de ocorrência da Polícia Militar Rodoviária para um período de tempo mínimo de 1 ano e desejável de 3 anos. Forma-se um banco de dados em planilha de cálculo facilmente processável. Estes registros, contendo todas as informações disponíveis, permitem identificar e salientar as características principais dos acidentes de trânsito ocorridos no período em estudo. A análise dos dados se realiza com a ajuda de quadros e gráficos que cumprem o objetivo de apresentar os resultados de diversas formas destacando em cada caso alguma particular característica do acidente. Por exemplo, a porcentagem de participação dos veículos 
envolvidos nos acidentes; distribuição dos acidentes por tipo, dia e horário, $\mathrm{n}^{\circ}$ de vítimas, por período de ocorrência.

Ainda, em áreas urbanas deve-se complementar o estudo com análise de atropelamentos fatais e acidentes fatais sem envolvimento de pedestres, e suas distribuições ao longo do trecho.

Os acidentes sem vítima, embora normalmente em maior número do que os com vítimas, são de importância relativamente menor, uma vez que não resultam em danos pessoais, mas somente danos materiais. Ainda mais, é fato notório que, ao contrário dos acidentes com vítima, muitos dos acidentes sem feridos não chegam a ser registrados pelo policiamento, em face de acordos feitos no local entre as partes. Isso ocorre especialmente em relação aos acidentes com poucos danos.

A partir da analise crítica de cada um destes elementos, e seu permanente monitoramento, poderemos chegar a um diagnóstico da situação com um melhor entendimento da mecânica e motivos dos acidentes, sendo de valiosa ajuda para a definição da solução ou remédio a aplicar ao problema.

Para completar e verificar o diagnóstico das causas dos acidentes, se realiza uma série de vistorias técnicas na rodovia, enfocando-se determinados sub-trechos e locais, que se destacaram pela alta concentração de ocorrência de acidentes durante o ano de referência.

Finalmente deve-se comentar que os acidentes de trânsito apresentam um comportamento dinâmico ao longo do tempo e são influenciados por diversos fatores como características do tráfego, taxa de motorização, política econômica, características da via, condições dos condutores, nível de educação, legislação sobre o trânsito, desenvolvimento urbano das regiões que a rodovia atravessa e, principalmente pela política de segurança adotada no gerenciamento da rodovia, elementos estes que transformam a técnica de análise assunto para especialistas na matéria.

As possíveis medidas para solucionar a falta de segurança em um determinado trecho de uma rodovia guardam uma relação direta com o acidente-padrão registrado.

Existem várias propostas que sugerem medidas corretivas para os diferentes tipos de acidentes, e que podem vir a ajudar ao profissional. O INST apresenta no se trabalho uma lista de medidas aplicáveis conforme o problema a resolver. Existem outros que apresentam medidas moderadoras de velocidades comentando casos e seus resultados como ARAUJO CUPOLILLO (2006). 


\subsubsection{CUSTOS DOS ACIDENTES}

O custo de um acidente de trânsito para a sociedade vai muito além dos custos diretos representados pela reparação dos veículos e das despesas hospitalares com as vítimas.

Os custos sociais dos acidentes de trânsito englobam também todos os recursos consumidos, desde a ocorrência até o final do processo de recuperação total dos danos materiais e pessoais. Esses custos incluem, entre outros aspectos:

- Danos aos veículos;

- Danos à sinalização viária;

- Danos aos equipamentos urbanos;

- Danos às propriedades;

- Perdas de cargas;

- Atendimento policial;

- Serviço de resgate de vítimas;

- Atendimento médico em hospitais;

- Reabilitação de pessoas feridas e traumatizadas;

- Processos judiciais;

- Tempo perdido em congestionamentos;

- Combustível queimado em congestionamentos;

- Perdas de produção;

- Pensões e indenizações;

- Fabricação de equipamentos para deficientes físicos;

- Limpeza de pista.

A determinação precisa desses custos é extremamente trabalhosa e certamente abrangerá aspectos subjetivos, exigindo exagerados esforços em comparação com a utilidade dos resultados.

A CET- Companhia de Engenharia de Tráfego, de São Paulo, determina valores médios para utilização em avaliações econômicas de projetos. Esses valores estão apresentados na Tabela 2.2.

O DNER publica, e atualiza anualmente, estimativa dos custos sociais dos acidentes de trânsito ocorridos nas rodovias federais. Para o ano de 1995 os custos foram os indicados na Tabela 2.3, com atualização segundo a variação do dólar no período. 
Tabela 2. 2 - Custos de Acidentes em São Paulo

\begin{tabular}{lcc}
\hline \multicolumn{1}{c}{ Tipo de Acidente } & $\begin{array}{c}\text { Custo Médio } \\
\text { (US\$ de 1997) }\end{array}$ \\
\hline Sem vítima & 1.410 \\
Com vítima leve & 3.530 \\
Com vítima grave & 17.630 \\
Com vítima fatal & 141.000 \\
\hline Fonte: CET/SP apud Gold (1998) & \\
\multicolumn{1}{c}{ Tabela 2. 3 - Custos de Acidentes } \\
\multicolumn{2}{c}{ Tipo de Acidente } & Custo Médio \\
& (R\$) & (US\$) (*) \\
\hline Sem vítima & 6.188 & 2.036 \\
Com vítima & 90.780 & 29.862 \\
Com vítima fatal & 374.811 & 123.293
\end{tabular}

Fonte: DNIT (2004) - Obs.: (*) conversão US \$ 1,00 = R \$ 3,04

Os custos estimados pelo DNIT em dólares são superiores que os da CET. A justificativa está no fato que os acidentes considerados pela CET ocorrem em áreas urbanas, onde normalmente os veículos estão em baixa velocidade, enquanto os do DNIT se referem a acidentes em rodovias, quase sempre em alta velocidade e, consequentemente, resultando em maiores danos materiais e pessoais.

O IPEA (Instituto de Pesquisa Econômica Aplicada) realizou junto com o DENATRAN sua pesquisa "Impactos sociais e econômicos dos acidentes de trânsito nas rodovias brasileiras" IPEA/DENATRAN (2006), com o objetivo identificar e mensurar os custos provocados pelos acidentes de trânsito nas rodovias brasileiras, visando fornecer subsídios para a elaboração e avaliação de políticas públicas. A Tabela 2.4 fornece os custos médios por tipo de acidente.

Tabela 2. 4 - Custos de Acidentes

\begin{tabular}{lc}
\hline \multicolumn{1}{c}{ Tipo de Acidente } & $\begin{array}{c}\text { Custo Médio } \\
(\mathbf{R} \$ \mathbf{)}\end{array}$ \\
\hline Sem vítima & 16.840 \\
Com vítima & 86.032 \\
Com vítima fatal & 418.341 \\
\hline Fonte: IPEA/DENATRAN (2006)
\end{tabular}

A maioria das rodovias possui trechos com características tipicamente rurais e outros com características urbanas ou mistas. Assim podem-se esperar custos médios dos acidentes 
entre os da cidade de São Paulo e os do DNIT. Contudo, os relatórios de acidentes raramente possuem informações precisas sobre a gravidade dos ferimentos. Por este motivo o INST sugere-se a adoção de valores médios que representem o conjunto dos acidentes registrados, que constam na Tabela 2.5 .

Tabela 2. 5 - Custo de acidentes - Valores Médios Sugeridos

\begin{tabular}{lc}
\hline \multicolumn{1}{c}{ Tipo de Acidente } & Custo Médio (US\$) \\
\hline Sem vítima & 7.200 \\
Com vítima & 16.800 \\
Com vítima fatal & 141.000 \\
\hline
\end{tabular}

Fonte: INST (1999)

Com os elementos contribuintes às causas do acidente bem identificados, caracterizados e analisados em detalhe, têm-se condições de desenvolver as etapas seguintes do método de gerenciamento de risco: o Planejar, o seja a definição de um plano de gerenciamento de riscos; e o Agir, ou seja, executar o programa definido. Estas etapas são próprias de cada situação em estudo, motivo pelo qual se omitem neste estudo e se procede a comentar a respeito da última etapa, que se aplica para todos os programas de gerenciamento de riscos.

\subsubsection{AVALIAÇÃO DE RESULTADOS}

As principais atividades desta etapa são o acompanhamento de situações "antes e depois" das implantações e o monitoramento constante dos dados referentes aos segmentos viários, como parte do processo dinâmico de análise e readequação de medidas e incorporação de novas, se necessário.

Embora o foco principal deste estudo seja a aplicação do método do "antes - depois" para medir a eficácia de soluções aplicadas, devem-se apresentar alguns dos indicadores e paramentos comumente usados pela técnica para monitorar o desempenho das mesmas. São eles:

- $\quad$ Índices de Acidentes: $\quad I a=\frac{N^{\circ} \text { acid. } x 10^{6}}{E(\operatorname{Km}) \times V D M \times N^{\circ} \text { dias periodo. }}$ periodo=mensal e anual.

- Índice de Severidade: $\quad I s=\frac{\left(N^{\circ} \text { Acd.S } / \text { Vit } x 1+N^{\circ} \text { Acd.Fer. } x 5+N^{\circ} \text { Acd.Mort. } x 13\right) x 10^{6}}{E(\mathrm{~km}) x V D M x N^{\circ} \text { dias periodo. }}$ 
O indicador Índice de Severidade consolida os distintos tipos de acidentes ponderando-os conforme sua gravidade, e permitindo avaliar a eficiência das ações implantadas quanto à obtenção de menores índices, embora se registre elevado Ia.

$$
\text { - Índice de Mortos: } \quad \operatorname{Im}=\frac{N^{\mathrm{o}} \text { Mort. } \times 10^{6}}{E(\mathrm{Km}) \times V D M \times N^{\mathrm{o}} \text { dias periodo. }}
$$

$$
\text { periodo = anual e mensal. }
$$

Este último indicador é o de maior impacto social e repercussão na mídia, motivo pelo qual é adotado sempre como meta a atingir num programa de redução de acidentes, por qualquer entidade responsável pela administração da infraestrutura viária.

Existem outros indicadores que são acompanhados periodicamente pelo sistema DENATRAM/RENAEST em anuário estatístico e que visa disponibilizar informações básicas de acidentes de todos os estados da federação para as comunidades interessadas, o que se realiza através do site www.denatran.gov.br, do Portal RENAEST, os quais se apresentam na Tabela 2.6.

Indicadores similares a estes são monitorados pelos governos em todo o mundo de forma de contar com estatísticas comparáveis com outros países e analisar a marcha das políticas de segurança desenvolvidas.

A ARTESP tem implantado um programa de monitoramento dos acidentes de trânsito nas rodovias sob concessão no Estado de São Paulo, que permite realizar um acompanhamento sistemático dos principais índices de acidentes e definir metas a serem perseguidas com os programas de redução de acidentes anuais. Todas as concessionárias enviam os dados dos acidentes registrados nos segmentos rodoviários que administram permitindo a formação de uma base de dados uniforme e completa para o sistema viário concessionado. Esta extensa base de dados foi usada neste trabalho, considerando os seguintes indicadores:

- DM - Acidentes com Danos Materiais $\left(\mathrm{n}^{\circ}\right)$

- FE - Acidentes com Feridos $\left(\mathrm{n}^{\circ}\right)$

- $\mathrm{MO}$ - Acidentes com Mortos $\left(\mathrm{n}^{\mathrm{o}}\right)$

- TO - Acidentes Total $\left(n^{\circ}\right)$

Com estas estadísticas e a extensão dos trechos (adotando o valor mínimo de $1 \mathrm{~km} \mathrm{e}$ máximo de cada segmento homogêneo), são calculados os seguintes indicadores visando determinar segmentos críticos a serem considerados nos programas de segurança.

- Ipm - Índice de Acidentes Médio Ponderado do Trecho Homogêneo ou da Rodovia 
- Ip - Índice de Acidentes Ponderado por Quilômetro

- Ic - Índice Crítico

Tabela 2. 6 - Resumo dos indicadores de acidentalidade do Anuário Estatístico QUADRO 45 - RESUMO DE ANOS ANTERIORES - BRASIL

\begin{tabular}{|c|c|c|c|c|}
\hline ITENS & 1998 & 1999 & 2000 & 2001 \\
\hline População & 161.790 .311 & 163.947 .554 & 169.590 .693 & 172.385 .826 \\
\hline Frota & 30.939 .466 & 32.318 .646 & $29.503 .503 * * *$ & 31.913 .003 \\
\hline Acidentes com Vítimas & 262.374 & 376.589 & $286.994 * *$ & 307.287 \\
\hline Vítimas Fatais & 20.020 & $20.178 *$ & 20.049 & 20.039 \\
\hline Vítimas Não Fatais & 320.733 & $325.729 *$ & $358.762 * *$ & $374.557 * *$ \\
\hline Veículos/100 Habitantes & 19,1 & 19,7 & 17,4 & 18,5 \\
\hline Vítimas Fatais/100.000 Habitantes & 12,4 & $13,9 *$ & 11,8 & 11,6 \\
\hline Vítimas Fatais/10.000 Veículos & 6,5 & $7,0 *$ & 6,8 & 6,3 \\
\hline Vítimas Não Fatais/10.000 Veículos & 103,7 & $111,8 *$ & $124,1 * *$ & $119,8^{* *}$ \\
\hline Acidentes com Vítimas/10.000 Veículos & 84,8 & 116,5 & $99,3 * *$ & 96,2 \\
\hline ITENS & 2003 & 2004 & 2005 & 2006 \\
\hline População & 176.871 .437 & 181.581 .024 & 184.184 .264 & 186.770 .562 \\
\hline Frota & 36.658 .501 & 39.240 .875 & 42.071 .961 & 45.370 .640 \\
\hline Acidentes com Vítimas & 333.689 & 348.583 & 383.371 & 322.919 \\
\hline Vítimas Fatais & 22.629 & 25.526 & 26.409 & 19.910 \\
\hline Vítimas Não Fatais & 439.065 & 474.244 & 513.510 & 407.685 \\
\hline Veículos/100 Habitantes & 20,7 & 21,6 & 22,8 & 24,3 \\
\hline Vítimas Fatais/100.000 Habitantes & 12,8 & 14,1 & 14,3 & 10,7 \\
\hline Vítimas Fatais/10.000 Veículos & 6,2 & 6,5 & 6,3 & 4,4 \\
\hline Vítimas Não Fatais/10.000 Veículos & 119,8 & 120,9 & 122,1 & 89,9 \\
\hline Acidentes com Vítimas/10.000 Veículos & 91,0 & 88,8 & 91,1 & 71,2 \\
\hline
\end{tabular}

Fonte: DENATRAN/ RENAEST (2006)

\subsubsection{TRAVESSIAS URBANAS DE RODOVIAS - PROBLEMAS DE TRÁFEGO A CONSIDERAR}

Os principais pontos críticos de acidentes de trânsito das rodovias brasileiras se localizam em regiões de travessias urbanas as quais já foram caracterizados no item 2.1 deste estudo. Resumindo pode-se dizer que apresentam elevados volume de tráfego, intensa ocupação das faixas lindeiras, muitas vezes desordenada, com modificações traumáticas no uso do solo, resultando num alto índice de acidentes e problemas para a comunidade usuária da região.

O tratamento dessas regiões exige uma solução integrada com participação das esferas de governo envolvidas para a adoção de medidas de modo a minimizar a ocorrência de acidentes. Essa solução contempla não somente medidas de engenharia de tráfego e educação de trânsito, mas também medidas de planejamento urbano, envolvendo todas as instâncias da 
administração pública e, principalmente, à comunidade usuária e lindeira, em todas as fases da implantação.

Os estudos devem-se nortear por algumas diretrizes consideradas essenciais para a viabilidade de adoção das medidas sugeridas, considerando que:

- A proposição e definição de medidas deverão ser feitas com a participação da comunidade, que se dará desde a análise do local até a avaliação e acompanhamento da efetividade de resultados da implantação;

- As medidas deverão atender tanto à necessidade rodoviária, garantindo padrões de segurança e fluidez, quanto à da comunidade local;

- Deverão ser respeitadas ao máximo as atribuições e competências do quadro institucional vigente;

- A articulação das diferentes instâncias de governo, entre si e com as entidades locais, é fator decisivo para implantação de medidas e para integralização dos investimentos necessários.

Para a elaboração do estudo, deverão ser desenvolvidas as seguintes atividades:

- Identificação das características da região, em especial quanto ao uso do solo, configuração física, legislação específica, equipamentos existentes (sociais, sinalização, comunicação) e usuários (a nível local e de passagem);

- Verificação de existência de transporte público;

- Delimitação das áreas de influência direta e indireta da rodovia;

- Identificação dos órgãos e entidades envolvidas na jurisdição, operação e fiscalização;

- Levantamento da existência de planos e projetos para o local, tanto de tráfego e de transporte como de uso do solo, saúde, educação, habitação, abastecimento e lazer;

- Levantamento junto à comunidade e às equipes responsáveis pela operação e fiscalização de dados sobre o local, de expectativas e de sugestões;

- Levantamento das condições de tráfego atuais e futuras, com contagem de veículos, pesquisa de origem-destino dos usuários, identificação dos polos geradores de tráfego, pesquisa de acidentes;

- Análise dos dados levantados e identificação de riscos;

- Estudo de medidas para gerenciamento de riscos do tipo físico-operacionais, institucionais e comportamentais; 
- Apresentação e discussão das medidas sugeridas com órgãos, entidades e comunidade envolvida;

- Montagem de um programa de ação para implantação, acompanhamento e monitoramento das medidas.

O assunto de maior importância nestes segmentos rodoviários é a circulação de pedestres. Deve-se avaliar a existência da demanda de pedestres ao longo do trecho, caracterizando as concentrações em determinados locais, dias e horários.

A caracterização do tráfego de pedestres, para fins de análise de condições de segurança viária, abrange duas características principais e distintas dos fluxos de pedestres: caminhando paralelamente ao eixo da via e atravessando-a.

Os locais de demanda de pedestres para travessia da rodovia estão concentrados principalmente nos acessos de vias locais para a rodovia. Dois fatores explicam essa concentração de demanda:

- Vias transversais urbanas dão acesso às áreas lindeiras à rodovia;

- Existência de bloqueios físicos naturais (topografia acidentada) ou restrições impostas de acesso à rodovia.

A forma mais segura de organização da travessia de uma rodovia por pedestres é a separação de nível dos pedestres e do tráfego veicular. Assim não há interação física entre pedestres e veículos e, consequentemente, não há risco de atropelamento, nem de qualquer outro tipo de acidente veicular. A travessia da rodovia por pedestres, com separação de níveis, pode ser criada de duas maneiras básicas: por cima do fluxo veicular; ou por baixo do fluxo veicular.

Uma alternativa intermediária é a travessia em nível com separação física de sentidos dos fluxos veiculares através de canteiro central, que proporciona uma área de espera para pedestres entre as travessias das duas pistas. Assim os pedestres enfrentariam um sentido de tráfego motorizado por vez. Desde que o volume de veículos apresente brechas com frequência e duração suficiente no momento da travessia, essa pode ser feita com relativa segurança. Um dos problemas com essa alternativa ocorre quando coincide a demanda para travessia com o fluxo alto de veículos motorizados, sem brechas de duração adequadas para a travessia, ou com brechas adequadas, mas de frequência baixa, ultrapassando os limites de tolerância de espera dos pedestres e ciclistas. Outro problema é o efeito da grande variedade de velocidades veiculares e de ultrapassagens, o que dificultariam a avaliação das brechas por parte dos pedestres, especialmente as crianças e os idosos. 
A pior alternativa é a travessia em nível sem separação física dos sentidos dos fluxos veiculares. Os pedestres enfrentam os fluxos veiculares nos dois sentidos simultaneamente, o que torna praticamente impossível a identificação das brechas adequadas para travessia, o que por sua vez aparecem com frequência muito menor do que no caso anterior, de separação física das pistas dos dois sentidos.

Em relação ao movimento no sentido paralelo ao eixo da rodovia, o fluxo de pedestres acontece quando não há vias marginais que permitam o seu deslocamento. Podem ainda, ocorrer situações em que vias marginais existentes não disponham de passeios pavimentados ou ainda que o tipo de pavimento existente apresente um nível muito alto de desconforto (pisos ou materiais irregulares), fazendo com que a rodovia seja mais atrativa.

São observados ainda pedestres caminhando ao longo dos acostamentos da rodovia ou nos canteiros entre a rodovia e as vias marginais. Em muitos casos este movimento é de pouca distância, fazendo parte do ato de travessia da rodovia. Outras vezes, são resultado dos percursos erráticos que realizam os "andarilhos", indivíduos que habitam na faixa de domínio das estradas em precárias condições de saúde e segurança.

As soluções para estes problemas são várias, de diversos custos e benefícios: construção de passarelas, de passagens inferiores e melhorias das condições das passagens em nível; iluminação das calçadas e das áreas de percursos dos pedestres; tratamentos especiais em pontos de ônibus; restrição da velocidade máxima; e a aplicação de medidas operacionais e de fiscalização apropriadas à situação.

Finalmente pode-se afirmar que para alcançar resultados efetivos, as medidas devem ser direcionadas para os tipos de acidentes que se deseja reduzir e devem ser efetivadas nos dias e horários de maior incidência.

\subsubsection{O PROBLEMA DA DETERMINAÇÃO DA VELOCIDADE IDEAL NA TRAVESSIA URBANA}

Conforme documento técnico do DER/SP, disponibilizado a este pesquisador em conjunto com dados de acidentes de trânsito em travessias onde se implantaram restrições de velocidade e outras medidas de segurança visando à redução dos mesmos, os estudos realizados e as análises de trabalhos técnicos mostram que não existe uma "fórmula mágica" que permita a imediata determinação das velocidades ideais a partir dos dados disponíveis. 
Sendo assim, o documento propõe o estabelecimento de uma metodologia auxiliar, que permita uma boa aproximação dessa velocidade ideal, ficando a critério do técnico responsável o ajuste final da velocidade a ser implantada, com base nos fatores locais que são particulares para cada caso.

A metodologia apresenta conceitos e parâmetros como a "velocidade de projeto" maior velocidade com que um veículo padrão poderá percorrer a rodovia com segurança e conforto, mesmo com piso molhado, quando o veículo estiver submetido apenas às limitações das características geométricas, sem influência do tráfego, que deve ser o primeiro parâmetro a ser observado quando da regulamentação da velocidade da rodovia, e seu valor nunca deve ser ultrapassado pela velocidade regulamentada.

A Portaria SUP/DER-61, do Departamento de Estradas de Rodagem do Estado de São Paulo - DER/SP - de 30 de setembro de 2002 estabelece limites estatutários em rodovias do Estado. Entre seus artigos estabelece no seu artigo $2^{\circ}$ que "As velocidades máximas permitidas para as demais rodovias de Pista Dupla ficam fixadas na seguinte conformidade:

a) $110 \mathrm{~km} / \mathrm{h}$ para automóveis, utilitários e motocicletas; e

b) $90 \mathrm{~km} / \mathrm{h}$ para ônibus e caminhões.

Para as rodovias de Pista Simples as velocidades máximas permitidas ficam fixadas, no artigo $3^{\circ}$, em 100 e $80 \mathrm{~km} / \mathrm{h}$, respectivamente.

Em trechos de rodovias cujas características funcionais de ocupação, uso da área lindeira e condições geométricas exijam e justificam a sua limitação, o artigo $6^{\circ}$ delega nos Diretores das Divisões Regionais a competência de estabelecer velocidades abaixo das discriminadas.

Finalmente, o artigo $7^{\circ}$ estabelece que, para o caso de rodovias concedidas, compete à concessionária interessada propor ao DER/SP, através da ARTESP - Agência Reguladora de Serviços Públicos Delegados de Transporte do Estado de São Paulo - o estabelecimento de velocidades inferiores às anteriormente fixadas, mediante justificativa e apresentação do respectivo projeto de sinalização.

Um critério quase geral e universal para o estabelecimento da regulamentação é a chamada V85, ou velocidade $85^{\circ}$ percentil. Essa velocidade é aquela até a qual $85 \%$ dos motoristas realizam se percurso, desprezando-se os $15 \%$ mais velozes, admitindo que a maior parte dos condutores $(85 \%)$ já trafegue dentro das velocidades de maior conforto e melhor relação entre tempo de viagem e segurança. 
Deve-se observar que esse índice já aparece na Resolução nº 599 do CONTRAN, e é apresentado em praticamente todos os trabalhos internacionais sobre o assunto velocidade, como sendo o parâmetro inicial para a regulamentação das velocidades.

Partindo-se da legislação vigente e da velocidade de projeto da rodovia, o fator V85 deve ser o próximo parâmetro a ser respeitado na determinação das velocidades a serem estabelecidas.

Existem outros fatores que também condicionam a regulamentação de velocidade em alguns sub-trechos de rodovias, geralmente menores às estabelecidas pelos critérios previstos nas normas vigentes:

- Eventuais deficiências geométricas (pontos críticos de acidentes);

- Variantes, interferências;

- Praças de pedágio;

- Ocorrência de neblina, chuva ou outros fenômenos climáticos;

- Urbanização e tráfego de pedestres;

- Danos à superfície do pavimento e acostamentos que possam prejudicar a segurança.

A partir destes conceitos básicos o DER/SP propõe aplicar Fatores de Correção para o V85. Argumentando que pesquisas efetuadas mostraram que em parte dos locais a velocidade V85 se mostra muito elevada, muito além da regulamentação de velocidade já existente, e visando a redução do número de acidentes propõe aplicar um fator de redução para o V85, de acordo com os indicadores de acidentes nas rodovias.

O processo de análise de estudo de velocidades se estrutura em base aos passos seguintes:

- Escolha de pontos ou trechos homogêneos no que diz respeito a suas características técnicas, físicas e demográficas;

- Verificação da velocidade de projeto e adequação à legislação existente;

- Elaboração de pesquisas de campo para apuração das velocidades praticadas nas rodovias ou trechos de rodovias analisados;

- Análise dos dados da pesquisa de velocidade de campo, onde serão determinadas as velocidades médias dos veículos leves e pesados, bem como a velocidade $85 \%$ para os mesmos, e a velocidade $85 \%$ média geral; 
- Levantamento estatístico das rodovias ou trechos analisados, e verificação dos índices de acidentes com vítimas $\left(\mathrm{I}_{\mathrm{av}}\right)$ das mesmas;

Considerando-se os índices de acidentes com vítimas nos trechos da rodovia analisada, determina-se o Fator de Correção (redução) a ser multiplicado pela Velocidade Média (85\%) dos veículos gerais:

$$
\mathrm{V}_{\text {id }}=\mathrm{V}_{85} \text { Média Geral x FC }
$$

Sendo,

$\mathrm{V}_{\mathrm{id}}=$ Velocidade ideal;

$\mathrm{V}_{85}$ Média Geral $=$ Média de velocidade de $85 \%$ dos veículos leves e pesados;

$\mathrm{FC}=$ Fator de correção (redução) que considera o índice de acidentes com vitimas $\left(\mathrm{I}_{\mathrm{av}}\right)$ das rodovias ou trechos de rodovias analisados.

Para os casos em que o $\mathrm{I}_{\mathrm{av}}$ do trecho em análise supera aos índices estabelecidos, recomenda estudo específico para o local por tratar-se de ponto crítico com necessidade de redução de velocidade ou de alternativas dentro da área de Engenharia de Tráfego.

Ainda, estabelece convenções e oferece informações importantes:

- Para rodovias de mais de uma faixa de rolamento por sentido, adotar a fórmula de velocidade para veículos leves e para veículos pesados;

- Para rodovias de uma faixa de rolamento por sentido adotar o $\mathrm{V}_{85}$ de velocidades gerais;

- Após o cálculo de $\mathrm{V}_{\mathrm{id}}$, o valor deverá ser arredondado para baixo em múltiplo de 10 .

- Após a implantação da nova regulamentação de velocidade, de acordo com a metodologia proposta neste trabalho, recomenda-se o constante monitoramento dos índices de acidentes.

- Recomenda-se acompanhar a redução do índice de mortos - IM (n. ${ }^{\circ}$ de mortos em acidentes x 108 / VDM x extensão $(\mathrm{km})$ x período (365)), e somente quando esse índice for inferior a dois, deve-se fazer nova análise para se aumentar a velocidade regulamentada.

- Recomenda-se que somente se aumente a velocidade regulamentada nos casos em que o índice de mortos - IM for inferior a dois.

Nas rodovias paulistas, os dados requeridos nessas verificações, tais como velocidade de projeto e índice de acidentes, estão disponíveis no DER/SP. 


\subsubsection{O PROBLEMA DA MEDIÇÃO DA EFICÁCIA DE AÇÕES APLICADAS PARA A PREVENÇÃO DE ACIDENTES}

Conforme cita Ferraz et al (2008) apud Ogden (1996), são três os métodos normalmente usados na avaliação da eficácia das ações implementadas visando à redução dos acidentes no trânsito:

- Comparação "antes - depois": consiste em comparar os valores absolutos dos acidentes ou os indicadores derivados destes antes e depois da implementação da ação, tomando períodos de tempo suficientemente longos para que os resultados sejam estadisticamente confiáveis, verificando sempre que os valores usados não estejam sofrendo a influencia de outros fatores que tornam inadequada a comparação pretendida.

- Comparação usando locais de referência: aqui se comparam os acidentes dos locais onde se aplicou uma intervenção com aqueles observados em locais onde não ocorreram mudanças, que vem se denominar local de referência. Como os fatores genéricos que influenciam na acidentalidade de maneira ampla afeta igualmente aos locais tratados e não tratados, neste caso não se precisa expurgar os efeitos dos mesmos na avaliação que se realize.

- Comparação da tendência ao longo do tempo: neste caso se procede a desenvolver um modelo de predição dos valores futuros em base aos dados de uma série histórica anterior à intervenção os que se comparam com os efetivamente ocorridos após a mesma.

O DNER (1998) apresenta outro método para medir a eficácia dos tratamentos utilizando métodos estatísticos que podem ser considerados como não adequados, pois aplica estatística de grupos de controle e não de comparação e não levam em consideração as variações do volume de tráfego. Estes conceitos de utilização de grupos de controle e comparação e de uso do VDM serão descrita no próximo capítulo.

A partir desta revisão bibliográfica, se está em condições de aprofundar os aspectos específicos da análise da eficácia mediante a escolha de um dos métodos disponibilizados pela técnica, o que se apresentará conceitualmente no próximo capítulo, para depois ser aplicado a casos concretos. 


\section{ASPECTOS CONCEITUAIS DA METODOLOGIA DO TIPO "ANTES-DEPOIS"}

Apresenta-se a seguir a Metodologia do "antes - depois", conforme considerações que tem como fonte Ferraz et al (2008) e Hauer (1997).

Para o desenvolvimento de planos e projetos voltados para a segurança viária é importante estabelecer de alguma forma uma estimativa do potencial das diversas ações propostas na redução da acidentalidade, preferencialmente com valores desagregados por tipo de acidente quanto à gravidade: sem vítimas, com vítimas não fatais e com vítimas fatais. Essas informações são fundamentais para direcionar estes planos e projetos a serem desenvolvidos e para selecionar aqueles que apresentem maior potencial de redução da acidentalidade e proporcionar os maiores benefícios econômicos.

Para as ações que atuam de forma direta, a confiabilidade das estimativas é maior; nas indiretas, como aquelas que se situam no campo político-administrativo, os erros na previsão são usualmente maiores. As estimativas resultam em geral, mais precisas quando feitas com base nos resultados de ações similares realizadas na mesma cidade ou região, pois fatores como o nível educacional, a cultura, o clima, as características do sistema viário, os tipos de veículos utilizados, etc. influem no grau de eficácia das ações.

Nos países desenvolvidos, onde há o monitoramento das ações voltadas para a segurança no trânsito e muitos estudos e pesquisas são realizados, existe disponibilidade de dados (locais, regionais e nacionais) confiáveis sobre o impacto das principais ações na redução da acidentalidade. Nos países não desenvolvidos, em geral, esse tipo de informação é escassa, sendo muitas vezes utilizados dados obtidos em países desenvolvidos, com consequente aumento do nível de incerteza da eficácia das ações.

A dificuldade para o monitoramento das ações reside em vários fatores: definição do que é acidente, propensão em reportar acidentes, registro incompleto dos acidentes, identificação dos acidentes alvos do tratamento, mudanças de governo que cambiam a 
metodologia de registro de acidentes, regressão para a média, inclusão de outros fatores contribuintes para os acidentes, entre outros.

Também relevante é o fato de que a segurança viária muda com o tempo. Não se pode assumir que não tendo sido aplicado o tratamento (uma ação voltada para a segurança viária), a segurança no período "depois" poderia ter sido a mesma que no período "antes". Portanto, para avaliar o efeito do tratamento na segurança de alguma entidade é preciso comparar o que poderia ter sido a segurança da entidade no período antes se o tratamento não tivesse sido aplicado, com o que foi a segurança da entidade tratada no período depois. Assim, a lógica básica para qualquer pergunta acerca do efeito de qualquer tratamento está na comparação apresentada na Figura 3.1.

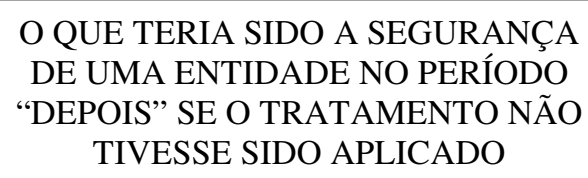

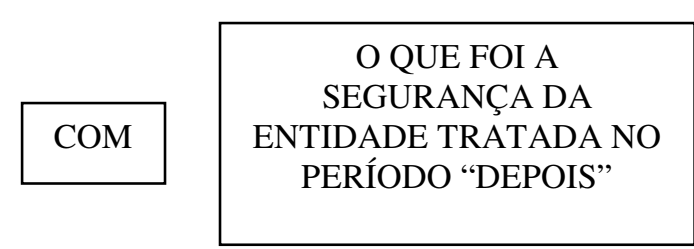

Figura 3. 1 - Comparação da segurança.

Fonte: Hauer (1997).

Outra dificuldade no monitoramento é que os estudos do tipo antes e depois são observacionais por natureza, isto é, são analisados após o evento e não podem ser reproduzidos em laboratório.

Segundo Hauer (1997), os estudos observacionais têm duas características essenciais:

- O objetivo é estudar os efeitos causais de certos agentes, procedimentos, tratamentos, ou programas.

- Por uma razão ou outra, o pesquisador não pode usar a experimentação controlada, isto é, ele não pode impor sobre um objeto, ou retirar do objeto, um procedimento ou tratamento cujos efeitos na segurança se desejam descobrir, ou não pode designar aleatoriamente o objeto a procedimentos diferentes.

Dessa forma, para a realização de um estudo do tipo antes e depois é necessário prever o que teria sido a segurança de uma entidade no período depois se o tratamento não tivesse sido aplicado com o que foi a segurança no período depois.

Existem vários métodos de previsão para a avaliação do impacto na segurança de intervenções viárias, sendo que cada um deles resulta em valores diferentes para a previsão o que poderá levar a resultados antagônicos. 
Segundo Hauer (1997), a existência de muitos métodos diferentes de predição, e correspondentemente de muitas estimativas de mudança na segurança, é desconcertante. Esta é uma das razões do porque a literatura profissional abunda com achados conflitantes. Qual método é mais válido, qual é o mais confiável? Seria útil ser claro sobre os méritos e as falhas de cada método de predição para então ser capaz de julgar quais resultados serão mais confiáveis e qual método será preferível utilizar. Para Hauer o melhor método é aquele que prediz melhor. Para predizer bem devem ser respondidas várias questões estratégicas:

- (a) Como levar em conta os fatores causais que afetam a segurança, que são mensurados e a influência que têm ou que pode ser conhecido. Com isso, por exemplo, sabe-se que o volume afeta a segurança. Para alguns casos têm-se uma ideia da relação entre o volume e a segurança. Se a informação sobre o volume está disponível antes e depois do tratamento, deve ser considerada quando se quer predizer o que teria sido a segurança no período depois se o tratamento não tivesse sido aplicado. Esta abordagem é uma modelagem.

- (b) Como considerar os fatores remanescentes que afetam a segurança mais que não foram mensurados ou a influência não é conhecida. A influência desses fatores pode ser considerada através da extrapolação da tendência ao longo do tempo e utilizando os grupos de comparação. A esperança é que, com o aumento do conhecimento, através de pesquisas e de estudos dos fatores que afetam a segurança, mais fatores que hoje são considerados na questão "b" sejam considerados no futuro na questão "a".

- (c) Como considerar uma tendência selecionada. O histórico de acidentes durante o período antes é uma pista importante do que teria sido a segurança no período depois. Entretanto, o mesmo histórico de acidentes pode também ser uma das razões pelas quais o tratamento foi aplicado. Isto faz com que as predições estejam sujeitas a uma tendência, a qual tem uma característica: regressão para a média.

- (d) Como considerar as mudanças no registro dos acidentes. O grau pelo qual os acidentes são reportados, muda de tempos em tempos, de lugar para lugar. A menos que a mudança seja estimada, não se pode separar o efeito do tratamento do efeito nas mudanças de registro dos acidentes.

Neste contexto, os métodos de previsão mais conhecidos no âmbito da engenharia de tráfego são: utilizar o número de acidentes do último ano do período anterior; utilizar a média dos últimos três anos do período anterior; tendo uma série temporal relativamente longa 
utilizar uma equação de regressão para o ano posterior; e o estado da arte que é a utilização de modelos de regressão. Cada um desses métodos possui pontos positivos e negativos. A utilização de um ou outro método depende da disponibilidade de recursos e dados, bem como da finalidade e precisão que se pretende.

Nesta dissertação serão utilizados dois métodos de previsão propostos por Hauer (1997): Método antes - depois ingênuo e Método usando grupos de comparação. Esses métodos são descritos a seguir.

\subsection{MÉTODO “ANTES - DEPOIS INGÊNUO”}

Um estudo observacional "antes - depois" consiste em comparar, para uma entidade, o número de acidentes (ou índices de acidentes) do período "antes" com o número de acidentes do período "depois". A contagem de acidentes do período "antes" é usada para prever o que teria sido a contagem esperada de acidentes do período "depois" se o tratamento não tivesse sido implementado. Esta forma de prever reflete uma crença ingênua e geralmente irreal de que a passagem do tempo (a partir do período "antes" para o "depois") não estava associada com mudanças que afetaram a segurança da entidade que está em observação. Consequentemente, este será chamado de estudo "antes - depois ingênuo". Apesar da sua falha óbvia, o estudo "antes - depois" ingênuo merece minuciosa discussão. Primeiro, porque o método é um ponto de partida natural para o debate, podendo-se discutir seus méritos e deficiências com clareza. Segundo, porque ele ainda é muito frequentemente encontrado na literatura especializada. Terceiro, porque ele é um limite superior útil, nenhum outro projeto de estudo pode alcançar à precisão estatística que é atingível em um estudo "antes - depois ingênuo".

Alguns fatores, como a demografia de condutores ou a frota de veículos, mudam apenas gradualmente. Portanto, quanto menores os períodos "antes" e "depois", menor seria a influência de tais mudanças gradual, e mais claramente discernível o efeito do tratamento. $\mathrm{O}$ mesmo não é verdadeiro para fatores como: condições climáticas, greves policiais ou do transporte público, grandes eventos, falhas de energia elétrica e similares, os quais podem ser muito diferentes em anos sucessivos. O uso de curtos períodos "antes" e "depois" não diminui a preocupação com a influência de fatores que mudam inesperadamente.

Deveria, portanto, ser óbvio que o estudo "antes - depois" ingênuo estima uma mistura do que é devido ao tratamento e o que é causado por outras influências. Isso deve ser 
explicitado sempre que os resultados de um estudo "antes - depois ingênuo" são publicados, porque a maioria dos leitores não é especialista em pesquisa de avaliação.

A metodologia "antes - depois" ingênuo utiliza as seguintes variáveis:

- $\pi$ : número esperado de acidentes de uma entidade específica, em um período "depois" se não tivesse sido tratada; é o que tem que ser previsto;

- $\lambda$ : número esperado de acidentes da entidade no período "depois", é o que tem que ser estimado.

O efeito do tratamento sobre a segurança é avaliado pela comparação de $\lambda$ e $\pi$. Para comparar os dois, deve-se analisar:

$$
\begin{aligned}
& \delta=\pi-\lambda \\
& \theta=\lambda / \pi
\end{aligned}
$$

Sendo:

- $\delta$ : redução do período "depois" do número esperado de acidentes ou severidade do acidente;

- $\theta$ : razão entre o que a segurança foi com o tratamento e a que teria sido sem o tratamento ("índice de eficácia”).

Quando algum tratamento é implementado em entidades, elas são numeradas 1, 2,.., $\mathrm{j}, \ldots$, n. Durante os períodos "antes" as contagens de acidente são chamadas $\mathrm{K}(1), \mathrm{K}(2), \ldots$, $\mathrm{K}(\mathrm{n})$ e durante os períodos "depois" as contagens de acidente são chamadas $\mathrm{L}(1), \mathrm{L}(2), \ldots$, L(n). A duração dos períodos "antes" e "depois" pode ser diferente de entidade para entidade, o qual precisa ser considerado na aplicação da metodologia. Por este motivo define-se a "razão de durações" como:

$$
r_{d}(j)=\frac{\text { Duração do período depois para a entidade } j}{\text { Duração do período antes para a entidade } j}
$$

As estimativas $\hat{\lambda}, \hat{\pi}, V \hat{A} R\{\hat{\lambda}\}$ e $V \hat{A} R\{\hat{\pi}\}$ para um estudo ingênuo são apresentadas nas Tabelas 3.1 e 3.2. É preciso comentar que se usa o acento circunflexo acima do símbolo de cada variável para identificar que se trata de um valor estimado da mesma.

O método está estruturado em base a quatro etapas, onde são estimadas, previstas e calculadas as variáveis usadas na determinação da eficácia do tratamento aplicado. 
Tabela 3.1 - Estimativa quando nem todos os rd(j) são os mesmos

\begin{tabular}{cc}
\hline Estimativas dos parâmetros & Estimativas das variâncias \\
Etapas 1 & Etapa 2 \\
\hline$\hat{\lambda}=\Sigma L(j)$ & $V \hat{A} R\{\hat{\lambda}\}=\Sigma L(j)$ \\
$\hat{\pi}=\Sigma r d(j) K(j)$ & $V \hat{A} R\{\hat{\pi}\}=\Sigma r_{d}(j)^{2} K(j)$ \\
\hline
\end{tabular}

Fonte: Hauer (1997).

Tabela 3. 2 - Estimativa quando todos os rd(j) são os mesmos

\begin{tabular}{cc}
\hline $\begin{array}{c}\text { Estimativas dos parâmetros } \\
\text { Etapas } 1\end{array}$ & Estimativas das variâncias \\
\hline$\hat{\lambda}=\Sigma L(j)$ & $V \hat{A} R\{\hat{\lambda}\}=\Sigma L(j)$ \\
$\hat{\pi}=r d \Sigma K(j)$ & $V \hat{A} R\{\hat{\pi}\}=r d^{2} \Sigma K(j)$ \\
\hline
\end{tabular}

Fonte: Hauer (1997)

Sendo que a $V \hat{A} R\{\}$ - variância ou coeficiente de variação de uma variável aleatória é uma medida da sua dispersão estatística indicando quão longe em geral os seus valores se encontram do valor esperado. Acostuma representar-se como $\sigma^{2}$ e é definida como a esperança de acontecer o quadrado do desvio desta variável a respeito da sua média. A sua unidade de medida é o quadrado da unidade de medida da variável estatística que representa, motivo pelo qual é usual adotar para medir esta dispersão a sua raiz quadrada conhecida como $\sigma$ ou desvio padrão.

Comenta-se também que o método considera que os acidentes acontecem conforme uma distribuição de Poisson, motivo pelo qual podemos adotar $V \hat{A} R\{\hat{\lambda}\}=\hat{\lambda}$. A Tabela 3.3 seguinte apresenta as fórmulas para as etapas 3 e 4.

Tabela 3. 3 - Etapas 3 e 4

$\delta=\pi-\lambda$
$\operatorname{VAR}\{\hat{\delta}\}=\operatorname{VAR}\{\hat{\pi}\}+\operatorname{VAR}\{\hat{\lambda}\}$
$\hat{\theta}=(\lambda / \pi) /\left[1+\operatorname{VAR}\{\hat{\pi}\} / \pi^{2}\right]$
$\operatorname{VAR}\{\hat{\theta}\} \approx \theta^{2}\left[\left(\operatorname{VAR}\{\hat{\lambda}\} / \lambda^{2}\right)+\left(\operatorname{VAR}\{\hat{\pi}\} / \pi^{2}\right)\right] /\left[1+\operatorname{VAR}\{\hat{\pi}\} / \pi^{2}\right]^{2}$

Fonte: Hauer (1997) 
A respeito de $\hat{\theta}$, considera-se a expressão acima ao invés da anterior $\theta=\lambda / \pi$. Embora $\hat{\lambda}$ e $\hat{\pi}$ sejam estimativas independentes de $\lambda$, a razão entre eles é uma variável dependente. A expressão acima elimina esta condição.

Assim como a duração dos períodos de contagem dos acidentes nos períodos "antes depois", existem fatores conhecidos e mensuráveis que influenciam diretamente no número de acidentes registrado e que, consequentemente, poderiam ser considerados no estudo, se disponíveis. Tal é o caso do fluxo de tráfego existente no segmento rodoviário em análise. Este fator é considerado afetando as variáveis estimadas de um novo fator de correção denominado $\boldsymbol{r}_{\boldsymbol{f t}}$, que podemos definir como a razão ou ratio entre o fluxo de tráfego do período "depois" e o correspondente do período "antes".

$$
\hat{r}_{f t}=\widehat{D}_{m} / \hat{A}_{m}
$$

Onde $\hat{A}_{m}$ e $\widehat{D}_{m}$ são os valores médios estimados do fluxo de tráfego dos períodos antes e depois para cada entidade em estudo.

Esta razão pode calcular-se na prática tão detalhadamente como possível, mediante a análise da função que rege a relação entre o volume de tráfego registrado e o número de acidentes esperado, que poderia ser denominada como função de desempenho de segurança de um determinado segmento de estrada. Neste estudo e perante a falta de uma expressão de aplicação, foi considerado que existe uma relação linear entre estas variáveis para a qual é válida a expressão acima de $r_{f t}$.

A partir da consideração deste novo fator de ajuste, o número esperado de acidentes de uma entidade específica, em um período "depois" se não tivesse sido tratada é calculado pela expressão seguinte, para cada entidade individual (por simplicidade não se indica a entidade específica com seu denominador (j)), e para o conjunto de entidades:

$$
\hat{\pi}=r_{d} \hat{r}_{f t} K
$$

Neste caso, a $V \hat{A} R(\hat{\pi})$ esperada adota a forma de:

$$
V \hat{A} R(\hat{\pi})=\left(r_{d}\right)^{2}\left[\left(\hat{r}_{f t}\right)^{2} K+K^{2} V \hat{A} R\left\{\hat{r}_{f t}\right\}\right]
$$

Onde:

$$
\operatorname{VAR}\left(\hat{r}_{f t}\right)=r_{f t}^{2}\left(v^{2}\left\{\widehat{D}_{m}\right\}+v^{2}\left\{\hat{A}_{m}\right\}\right)
$$

Sendo:

$v\left\{\widehat{D}_{m}\right\}$ e $v\left\{\hat{A}_{m}\right\}=$ coeficientes de variação, números que dependem do período de duração da contagem. Existem algumas tabelas que fornecem estes valores assim como 
estudos que apresentam fórmulas para seu cálculo, como a expressão proposta de Vallurupalli, comentada e apresentada por Hauer (1997), adotada como válida para este trabalho por simplificação.

\subsubsection{RETRATAÇÕES A SEREM FEITAS NA UTILIZAÇÃO DOS ESTUDOS OBSERVACIONAIS INGÊNUOS}

O método ingênuo descrito anteriormente não incorpora outros fatores contribuintes para os acidentes de trânsito, tais como: tráfego (composição da frota de veículos), meteorologia (condições climáticas), comportamento dos motoristas, custos da reparação de veículos, etc., na análise e, por isso, retratações devem ser feitas ao se apresentar os resultados, de modo a se tornar evidente que os achados podem ser resultados de outras ações e outros fatores e não devidos unicamente ao tratamento (intervenção) realizado na via.

Por essa razão, Hauer (1997) propõe duas retratações quando se apresentam os resultados desse tipo de estudo e que são descritas a seguir.

\section{$\underline{\text { Retratação No } 1}$}

"A mudança notada na segurança reflete não apenas o efeito de ...(nome do

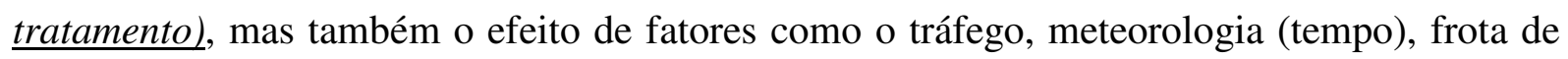
veículos, comportamento do motorista, custo da reparação de automóveis, etc. Não se sabe que parte da mudança pode ser atribuída a ... (nome do tratamento) e que parte se deve às várias outras influências."

Ainda, se existe a mais leve suspeita de que a decisão de tratar as entidades foi influenciada por seu registro de acidentes passado, bom ou mau, e que o mesmo registro de acidentes passado foi utilizado como parte dos dados de "antes", deve-se acrescentar:

\section{$\underline{\text { Retratação No } 2}$}

"A mudança notada em segurança pode ser, em parte, devido à regressão espontânea para a média e não devido a ... (nome do tratamento)."

\subsection{MÉTODO ANTES - DEPOIS UTILIZANDO GRUPOS DE COMPARAÇÃO}

O objetivo desse método é fornecer uma abordagem unificada para a interpretação estatística de todas as variáveis do estudo observacional "antes e depois". Neste caso é possível considerar o efeito de fatores desconhecidos ou de difícil mensuração como 70 
precipitação, frota de veículos, condições econômicas, medidas de segurança, registro de acidentes, etc.

A ideia central é identificar um grupo de entidades que permaneceu sem tratamento, e que são semelhantes às entidades tratadas. As entidades tratadas formam o "grupo de tratamento". As entidades não tratadas são o "grupo de comparação". A esperança é que a mudança na segurança de "antes" para "depois" do grupo de comparação seja um indicativo de como a segurança no grupo de tratamento poderia ter mudado. Esta esperança é baseada em duas suposições:

1. "Que os diversos fatores que afetam a segurança tenham mudado do período “antes" para "depois" da mesma maneira em ambos os grupos - o tratado e o de comparação e,

2. Que esta mudança nos diversos fatores influencia a segurança do grupo tratado e do grupo de comparação da mesma forma.

Define-se:

- $r_{C}$ : "razão de comparação"; a razão entre o número esperado de acidentes no período "depois" e o número esperado de acidentes no período "antes”, no grupo de comparação;

- $\pi=K$ (número esperado de acidentes "antes" no grupo de tratamento) $\mathrm{x} r_{C}$

Neste método a atribuição de entidades de comparação para o grupo de tratamento não é feita aleatoriamente. Mesmo com grupos de entidades grandes não há nenhuma garantia de que o número esperado de acidentes de um grupo de tratamento teria mudado da mesma maneira que no grupo de comparação. É prudente falar sempre de "estudos observacionais" e de "grupos de comparação (G-C)".

Em um estudo observacional "antes - depois" envolvendo um grupo de tratamento e um de comparação, as letras $K, L, M e N$, da Tabela 3.4 a seguir, denotam a contagem de acidentes que corresponde aos títulos das linhas e das colunas. Os valores esperados destas contagens de acidente são indicados pelas correspondentes letras gregas $\kappa, \lambda, \mu e v$.

Tabela 3. 4 - Contagens de acidentes e valores esperados GRUPO DE TRATAMENTO GRUPO DE COMPARAÇÃO

\begin{tabular}{lll}
\hline ANTES & $K, \boldsymbol{K}$ & $M, \mu$ \\
\hline DEPOIS & $L, \lambda$ & $N, v$
\end{tabular}

Fonte: Hauer (1997) 
O método G-C é baseado na esperança de que, na ausência de tratamento, a razão entre o número esperado de acidentes "antes" e "depois" seria a mesma nos grupos de tratamento e de comparação. É preciso distinguir entre a razão $r_{c}$ definida pelo grupo de comparação e uma paralela, mas distinta, razão para o grupo de tratamento. Assim, definida:

$$
\begin{aligned}
& r_{C}=v / \mu \\
& r_{T}=\pi / \kappa
\end{aligned}
$$

Sendo:

- $r_{C}$ : razão de contagens de acidentes esperados para o grupo de comparação.

- $r_{T}$ : razão de contagens de acidentes esperados para o grupo de tratamento. Observe-se que nesta relação usa-se $\pi$, e não $\lambda$, dado que está sendo analisada a situação hipotética de que a entidade não recebeu tratamento.

A esperança mencionada acima pode agora ser expressa como uma equação. A esperança é aquela que verifica:

$$
r_{T}=r_{C}
$$

O que é equivalente a

$$
\frac{r_{C}}{r_{T}}=1
$$

Da definição de $r_{T}$, segue que

$$
\pi=\mathrm{r}_{\mathrm{T}} \mathrm{\kappa}
$$

Contudo, se a suposição na Equação acima é verdadeira, então é verdade também que

$$
\pi=\mathrm{r}_{\mathrm{C}} \mathrm{K}
$$

Uma vez que a $r_{C}$, pode ser estimada a partir do número de acidentes no grupo de comparação ( $\mathrm{M}$ e $\mathrm{N}$ na Tabela 3.2.4), e $\kappa$ pode ser estimado pelo número de acidentes no grupo de tratamento no período "antes" $(K)$, então $\pi$ pode ser estimado.

Assim como o método Ingênuo repousa sobre uma suposição, o mesmo acontece com o método G-C. Da mesma forma que o pressuposto implícito, o método Ingênuo nunca será exatamente verdadeiro, por isso a suposição básica do método G-C nunca ser totalmente correta.

Não se pode argumentar com convicção que, devido a algumas semelhanças externas entre os grupos tratados e de comparação, o pressuposto é "quase certo" ou "provavelmente verdadeiro". Os dados de inúmeros casos estudados pela técnica mostram que este argumento é inválido, motivo pelo qual deve se construir um argumento mais coerente. 
O único argumento defensável que se pode formar para justificar o uso de um grupo de comparação em um estudo observacional é empírico ou indutivo, a saber: se alguém pode mostrar que em uma série temporal os valores passados de $r_{T}$ e $r_{C}$ foram suficientemente semelhantes então, ciente das limitações usuais de todos os argumentos indutivos, pode-se supor que as similaridades passadas também acontecem para aquele valor específico de $r_{C}$ que é usado em um específico "estudo G-C". Contudo, se este é o argumento sobre o qual repousa o método G-C, deve-se permitir na análise a possibilidade de que o pressuposto de $\frac{r_{T}}{r_{C}}=1$ não é exatamente verdadeiro em qualquer "estudo G-C" específico. É necessário, portanto considerar que a razão $r_{C} / r_{T}$ seja uma variável aleatória a qual em diferentes ocasiões toma diferentes valores, HAUER (1997). A razão $r_{C} / r_{T}$ será chamada de $\omega$, ou seja:

$$
\omega=r_{C} / r_{T}
$$

Considera-se uma longa série temporal de contagens de acidente para um grupo de entidades de tratamento e de comparação. A partir dessas contagens de acidente se forma uma série temporal de tabelas $2 \times 2$, tal como a Tabela 3.4. As quatro contagens de acidente $K, L, M$ e $N$, em cada tabela são para o mesmo conjunto de entidades, exceto que em nenhum momento o tratamento tenha sido aplicado às entidades para o grupo de tratamento. Em cada uma dessas tabelas um valor específico de $\omega$ ocorre. Assim, para cada grupo de entidades de tratamento e de comparação existe uma série temporal de $\omega$ 's. Qualquer sequencia de tal $\omega$ 's tem uma média $E\{\omega\}$ e uma variância $\operatorname{VAR}\{\omega\}$. Para um grupo de comparação ser considerado legítimo, ele deve atender à exigência de que $E\{\omega\}=1$. Se esta exigência não for cumprida, os últimos $r_{C}$ podem ser sistematicamente maiores ou menores do que o $r_{T}$ correspondente. Isso poderia negar completamente a premissa básica do "estudo G-C”.

Encontrado o grupo de comparação adequado o caminho para a análise estatística de um estudo G-C está livre de obstáculos conceituais.

A partir do conceito acima, quando se dispõe de uma série temporal de contagens de acidente-alvo para o grupo específico de tratamento e de comparação, Hauer (1997) orienta a realizar o cálculo da relação $\omega$, que denomina "o" ou "amostra da razão odds", mediante a expressão que segue e que conduz a uma estimativa não enviesada de $\omega$ :

$$
\mathrm{o}=(\mathrm{KN}) /(\mathrm{LM}) /(1+1 / \mathrm{L}+1 / \mathrm{M})
$$

Para tal sequencia de amostra da razão $o d d s$, pode-se encontrar a média da amostra denotada por $\mathrm{m}\{\mathrm{o}\}$, e a variância da amostra denotada como $\mathrm{s}^{2}\{\mathrm{o}\}$, conforme: 


$$
\text { VÂR }\{\omega\}=s^{2}\{o\}-(1 / K+1 / L+1 / M+1 / N) \text { se }>0 \text { e } 0 \text { do contrário }
$$

Em resumo, para julgar se um candidato a grupo de comparação é completamente adequado para um grupo de tratamento específico, tem-se de examinar como os acidentesalvo dos dois grupos seguem um ao outro ao longo do tempo. Isso pode ser feito por uma sequencia de cálculos de "amostras de razão odds" sendo que a média da amostra dessa sequencia tem de ser suficientemente próxima de 1. Caso contrário, o grupo de comparação é inadequado.

Dentre os grupos de comparação disponíveis e que se denotam como adequados devese selecionar aquele em que $1 / \mathrm{N}+1 / \mathrm{M}+\mathrm{VÂ} R\{\omega\}$ é menor.

Ainda pode-se explorar mais um pouco o assunto. Caso os dados de fluxo de tráfego “antes" e "depois" estejam disponíveis para as muitas entidades do grupo de comparação, poder-se-ia optar por considerar diretamente e explicitamente a mudança em fatores causais medidos e compreendidos (o VDM neste caso). Fazer isso implica em modificar o papel do grupo de comparação. O mesmo é agora usado para considerar somente os fatores remanescentes, aqueles que não são considerados explicitamente. Portanto, não é possível estimar a razão de comparação usando somente as contagens brutas de acidente do grupo de comparação, como foi feito anteriormente. Neste caso se propõe uma modificação ao método usando uma nova $r_{C}$ que se denomina $r_{C m}$ ou "razão de comparação modificada", sendo:

$$
\hat{r}_{\mathrm{T}}=\hat{r}_{\mathrm{C}, \bmod }=\left[\mathrm{N} /\left(\mathrm{r}_{\mathrm{tf}} \mathrm{M}\right)\right] /\left[1+1 /\left(\mathrm{r}_{\mathrm{tf}} \mathrm{M}\right)\right]
$$

Com $\boldsymbol{r}_{\boldsymbol{f t}}$ definido como a razão ou ratio entre o fluxo de tráfego do período "depois" e o correspondente do período "antes". E

$$
\pi=\operatorname{rtf} x \mathrm{r}_{\mathrm{C}, \bmod }
$$

Neste, $r_{\mathrm{tf}}$ considera diretamente o efeito do fluxo de tráfego e $\mathrm{r}_{\mathrm{C} \text {,mod }}$ a influência dos demais fatores causais.

Superada a instância de determinar qual o melhor e mais adequado grupo de comparação, este método também consiste em quatro etapas básicas para calcular a eficácia do tratamento, tal qual visto no método "antes - depois" ingênuo. Os resultados para as Etapas 1 e 2 estão listados na Tabela 3.5.

A Tabela 3.6 indica como calcular as etapas 3 e 4. Na sequencia, a Tabela 3.6 apresenta o cálculo da estimativa dos desvios padrão. 
Tabela 3. 5 - Estimativas das ETAPAS 1 e 2 em um "Estudo G-C"

\begin{tabular}{l|l}
\hline $\begin{array}{l}\text { Estimativas dos parâmetros } \\
\text { Etapa } 1\end{array}$ & $\begin{array}{l}\text { Estimativas das variâncias } \\
\text { Etapa 2 }\end{array}$ \\
\hline$\hat{\lambda}=L$ & $\boldsymbol{V A ̂} R\{\hat{\lambda}\}=L$ \\
$\hat{r}_{T}=\hat{r}_{C}=(N / M) /(1+1 / M) \approx N / M$ & $V \hat{A} R\left\{\hat{r}_{T}\right\} / r_{T}^{2} \approx 1 / M+1 / N+V \hat{A} \boldsymbol{R}\{\omega\}$ \\
$\hat{\pi}=\hat{r}_{T} K$ & $V \hat{A} R\{\hat{\pi}\} \approx \hat{\pi}^{2}\left[1 / K+V \hat{A} \boldsymbol{R}\left\{\hat{r}_{T}\right\} / r_{t}^{2}\right]$ \\
\hline
\end{tabular}

Fonte: Hauer (1997)

Tabela 3. 6 - ETAPAS 3 e 4 em um "Estudo G-C"

$$
\begin{aligned}
& \delta=\pi-\lambda \\
& \operatorname{VAR}\{\hat{\delta}\}=\operatorname{VAR}\{\hat{\pi}\}+\operatorname{VAR}\{\hat{\lambda}\} \\
& \hat{\theta}=(\lambda / \pi) /\left[1+\operatorname{VAR}\{\hat{\pi}\} / \pi^{2}\right] \\
& \operatorname{VAR}\{\hat{\theta}\} \approx \boldsymbol{\theta}^{2}\left[\left(\operatorname{VAR}\{\hat{\lambda}\} / \lambda^{2}\right)+\left(\operatorname{VAR}\{\hat{\pi}\} / \pi^{2}\right)\right] /\left[1+\left(\operatorname{VAR}\{\hat{\pi}\} / \pi^{2}\right]^{2}\right.
\end{aligned}
$$

Fonte: Hauer (1997)

Tabela 3. 7 - Estimativa do desvio padrão

\begin{tabular}{l} 
\\
$\qquad \hat{\sigma}\{\hat{\lambda}\}=\sqrt{\hat{\lambda}}$ \\
$\hat{\sigma}\{\hat{\pi}\}=\sqrt{\hat{\pi}}$ \\
$\hat{\sigma}\{\hat{\delta}\}=(\mathrm{VÂA}\{\hat{\pi}\}+\mathrm{VÂR}\{\hat{\lambda}\})^{1 / 2}$ \\
$\hat{\sigma}\{\hat{\theta}\}=\hat{\theta}\left[\left(\mathrm{VÂR}\{\hat{\lambda}\} / \hat{\lambda}^{2}\right)+\left(\mathrm{VÂR}\{\hat{\pi}\} / \hat{\pi}^{2}\right)\right]^{1 / 2} /[1+\mathrm{VÂR}\{\hat{\pi}\}$ \\
\hline
\end{tabular}

Fonte: Hauer (1997)

Hauer (1997) resume as orientações de como escolher o grupo de comparação mencionando que, em termos práticos, um grupo de comparação deve reunir os seguintes requisitos:

1. Os períodos "antes" e "depois" para os grupos de tratamento e de comparação devem ser os mesmos, caso contrário a "Suposição 1", mencionada na página 58, é violada; 
2. Deve haver razão para acreditar que a mudança nos fatores que influenciam a segurança, quaisquer que sejam estes, é semelhante nos grupos de tratamento e de comparação; isso também é necessário para assegurar a "Suposição 1";

3. As contagens de acidente devem ser suficientemente grandes e;

4. Quando uma sequencia de amostras de razões odds é calculada a partir de contagens de históricas de acidente, a média da sua amostra é próxima de 1 e sua variância é pequena. 


\section{COLETA DE DADOS}

Este capítulo aborda como foi realizada a coleta de dados das ações de engenharia realizadas para a redução de acidentes nas travessias urbanas de rodovias para a aplicação do método aos locais estudados.

\subsection{PESQUISA E COLETA DE DADOS}

Definida a metodologia a usar na análise da eficácia, se procedeu à procura dos dados necessários para a aplicação do método.

Os dados reais que dão suporte estatístico ao presente estudo foram obtidos de algumas das concessionárias que administram rodovias do estado de São Paulo sob o sistema de pedágio. Solicitou-se, em pedido específico ao responsável pela área de segurança rodoviária da Agência Reguladora de Serviços Públicos Delegados de Transporte do Estado de São Paulo- ARTESP, informações sobre soluções técnicas implantadas em travessias urbanas de rodovias visando à redução de acidentes. $O$ pedido visava obter de cada concessionária material disponível para os casos mais significativos da sua malha. Requisitouse a informação solicitando que a mesma contivesse necessariamente:

- Identificação do local da travessia urbana: rodovia, $\mathrm{km}$, cidade, entidade específica (exemplo: acesso, passarela, cruzamento, entroncamento, semáforo, etc.);

- Dados dos acidentes de tráfego do maior período de tempo disponível que transformaram o local (ou segmento) em ponto crítico antes da implantação da solução técnica para redução ou mitigação dos acidentes;

- Tipo de solução ou elemento implantado (exemplo: passarela, radar, restrição de velocidade, restrição de movimentos; lombada, sinalização ostensiva, via coletora, combinação das anteriores, etc.), com data do início de operação efetiva de cada uma; 
- Dados dos acidentes de tráfego, do maior período de tempo disponível, após o tratamento do local com a solução técnica escolhida;

E, se disponível:

- Volume de tráfego do local e sua classificação;

- Registro fotográfico do trecho ou local crítico e seus problemas;

Ainda, para a aplicação da metodologia utilizando grupos de comparação, solicitou-se a identificação e informação dos itens acima de outras travessias urbanas de rodovias com similares características operacionais, que não receberam tratamento nos períodos informados, sempre que existentes.

Este pedido foi repassando a todas as concessionárias controladas pela ARTESP.

Simultaneamente foi solicitada igual informação à Coordenadoria de Operações e Estatísticas - COE, do Departamento de Estradas de Rodagem do Estado de São Paulo DER/SP.

Como resposta a estes pedidos se obtiveram os dados usados nesta pesquisa. Deve salientar-se que foram poucas as concessionárias que responderam positivamente ao pedido e se preocuparam em atender estritamente ao requisitado. Dentre as cinco que responderam num primeiro momento, duas delas apresentaram informações que não permitiram seu uso, seja por insuficiência de dados ou por atender ao pedido de forma evasiva. Este fato demandou a insistência do pedido, realizado de forma direta pelo pesquisador exclusivamente com aquelas concessionárias que tinham respondido num primeiro momento. Obtiveram-se respostas aproveitáveis de três delas, com quais se manteve contato permanente até alcançar um nível de informações que puderam dar suporte pleno à aplicação do estudo objeto do trabalho.

O DER/SP apresentou material referente aos critérios aplicados pela entidade na determinação da velocidade máxima em travessias urbanas de rodovias, que foi aproveitado na revisão bibliográfica. As informações recebidas de dois casos de aplicações de redução de velocidade em áreas urbanas, correspondentes aos trechos da Rodovia Mogi-Bertioga (SP098) e da Via Anchieta (SP150), que sofreram alterações nos seus limites de velocidades respectivamente em dezembro de 2005 e em outubro de 2006, e tiveram melhoria concreta na segurança segundo os cálculos realizado pela entidade, foram insuficientes para a aplicação do método "antes - depois" usado neste trabalho. A insistência no pedido de uma base de dados mais extensa não teve resposta, motivo pelo qual finalmente não se utilizou esta informação. 


\subsection{LOCAIS ESTUDADOS E TRATAMENTOS ANALISADOS}

A partir dos dados recebidos num primeiro momento, e após seleção dos locais que apresentavam as melhores informações (dados de períodos antes e depois apropriados, descrição adequada dos tratamentos implantados com data do inicio das operações, consistência dos dados, entre outras) foi possível analisar a eficácia das ações aplicadas de várias travessias urbanas de rodovias. Os tratamentos analisados, por rodovia e numeradas na ordem final adotada no processamento dos dados para cada caso, são os seguintes:

\section{SP310 - Rodovia Washington Luís:}

1. Redução de velocidade de 110 a $90 \mathrm{~km} / \mathrm{h}$ com implantação de radar e aumento das sinalizações verticais e horizontais e dispositivos de segurança, em todo o trecho da travessia rodoviária urbana de Rio Claro, que se estende do Km 172 ao km 177.

2. Construção de Defesa New Jersey elevada em $2 \mathrm{~km}$ e novo sistema de drenagem no trecho do Km 174 ao km 176 da travessia rodoviária urbana de Rio Claro.

3. Construção de mais 1 dispositivo de acesso a desnível no Km 161 da travessia rodoviária urbana de Cordeirópolis, que se estende do Km 159 ao km 161.

4. Construção de Defesa New Jersey elevada no trecho do Km 231 ao km 235 da travessia rodoviária urbana de São Carlos, que se estende do Km 230 ao km 236.

\section{SP300 - Rodovia Marechal Rondon:}

5. Implantação de reforço de sinalização horizontal e vertical de travessia de pedestres a nível, com redução de velocidade de 110 a $80 \mathrm{~km} / \mathrm{h}$, tela de proteção no canteiro central com abertura específica para a passagem, iluminação e radar no km 68+500 ao km 69+500 da travessia rodoviária urbana de Jundiaí, que se estende do $\mathrm{Km} 64$ ao km 79.

6. Construção de Passarela no km 67 da travessia rodoviária urbana de Jundiaí.

7. Construção de Passarela no km 82 da travessia rodoviária urbana de Cabreuva, que se estende do $\mathrm{Km} 78$ ao $\mathrm{Km} 82$.

\section{SP225 - Rodovia Engenheiro Paulo Nilo Romano :}

8. Redução de velocidade de $110 \mathrm{~km} / \mathrm{h}$ para $90 \mathrm{~km} / \mathrm{h}$ em todo o trecho da travessia rodoviária urbana de Jau, conhecido como Contorno de Jau, que se estende do $\mathrm{Km}$ 177 ao $\mathrm{km} 185$. 


\section{SP127 - Rodovia Fausto Santomauro:}

9. Construção de Ciclovia no trecho do $\mathrm{km} 0$ ao $\mathrm{km} 3$ da travessia rodoviária urbana de Rio Claro, que se estende do $\mathrm{km} 0$ ao $\mathrm{km} 5$.

10. Construção de Passarela no km 88 da travessia rodoviária urbana de Cerquilho, que se estende do $\mathrm{km} 88$ ao $\mathrm{km} 91$.

\section{SP075 - Rodovia Santos Dumont:}

11. Tela de proteção no canteiro central e construção de escadas nos viadutos do $\mathrm{km}$ 29 e km 32 da travessia rodoviária urbana de Itu, que se estende do km 29 ao km 32.

12. Implantação de reforço de sinalização horizontal e vertical de travessia de pedestres a nível, com redução de velocidade de 110 a $80 \mathrm{~km} / \mathrm{h}$, tela de proteção no canteiro central com abertura específica para a passagem, iluminação e radar no trecho do km 66 ao km 67, área de influencia do aeroporto de Viracopos, na travessia rodoviária urbana de Campinas, que se estende do km 64 ao km 78.

13. Construção de Passarela no km 64 na travessia rodoviária urbana de Campinas.

\subsection{LOCAIS UTILIZADOS COMO GRUPOS DE COMPARAÇÃO}

A base de dados obtida permitiu identificar diversos segmentos homogêneos que foram usados como grupos de comparação para a aplicação do método. Em total se definiram sete trechos de comparação, sendo:

\section{SP310 - Rodovia Washington Luís:}

(a) Km 228 ao 229 - Travessia Urbana de São Carlos;

(b) Km 230 ao 236 - Travessia Urbana de São Carlos;

(c) Km 237 ao 241 - Travessia Urbana de São Carlos;

(d) Km 167 ao 169 - Travessia Urbana de Santa Gertrudes;

(e) Km 172 ao 176 - Travessia Urbana de Rio Claro.

\section{SP075 - Rodovia Santos Dumont:}

(f) Km 49 ao 55,9 - Travessia Urbana de Indaiatuba;

(g) Km 70 ao 77 - Travessia Urbana de Campinas.

\section{SP127 - Rodovia Fausto Santomauro:}

(h) Km 28 ao 32 - Travessia Urbana de Piracicaba. 
Durante a escolha dos segmentos foi desconsiderado o trecho designado como (e) por verificar-se que o mesmo tinha sido objeto de um tratamento dentro do período analisado (Nov 2008).

\subsection{PROCESAMENTO DE DADOS}

A extensa base de dados usada neste trabalho, informada por três das concessionárias que administram trechos rodoviários controlados pela ARTESP, se apresenta no ANEXO e fornecem os seguintes dados estatísticos:

- Número de Acidentes com Danos Materiais - DM

- Número de Acidentes com Feridos - FE

- Número de Acidentes com Mortos - MO

- Número de Acidentes Total - TO

- Número de Veículos Médio Diário Anual - VDM

Os quais são informados por rodovia, ano, pista ou sentido de circulação (norte/sul ou leste/oeste) e segmento homogêneo (a cada $1 \mathrm{~km}$ e total por segmento homogêneo).

Apresenta também o calculo dos indicadores usados pela ARTESP na determinação dos segmentos críticos a serem atacados com programas de segurança, sendo eles:

- Exposição: valor resultante do produto entre a extensão do segmento e seu VDM:

$$
\text { Exposição }=\text { Ext. } x \text { VDM x 365 }\left(\mathrm{n}^{\circ} \text { dias do ano }\right) / 10^{\wedge} 6
$$

- Acidente ponderado: valor que junta o numero de acidentes e a gravidade dos mesmos aplicando diferentes pesos aos acidentes segundo a sua gravidade, que é também pode ser definido como índice de severidade:

$$
\text { Acidente ponderado }=\mathrm{DM} \times 1+\mathrm{FE} \times 5+\mathrm{MO} \times 13
$$

- Ip: Índice de Acidentes Ponderado por Quilômetro, valor que combina o numero de acidentes com o VDM do segmento, sendo:

$$
\mathrm{Ip}=\text { Acidente ponderado / Exposição }
$$

- Ipm: Índice de Acidentes Médio Ponderado do Trecho Homogêneo ou da Rodovia.

- Ic: Índice Crítico, calculado usando a constante $\mathrm{K}$ igual a 1,645, cujo coeficiente determina um Grau de Confiança de 95,0\%, segundo a expressão 4.4:

$$
\mathrm{Ic}=\mathrm{Ipm}+\mathrm{K} x(\mathrm{Ipm} / \text { Exposição })^{\wedge 1 / 2}-0,5 / \text { Exposição }
$$


Finalmente compara-se o Índice de Acidentes Ponderado para cada quilômetro com o Índice Crítico calculado para o segmento homogêneo, composto por vários quilômetros de similares características operacionais, para determinar quais os locais onde se deverão investir esforços com programas de redução de acidentes, conforme se mostra na Tabela 4.1.

Foram considerados todos os dados recebidos, incorporando-os em uma nova base de dados organizada de forma de permitir seu processamento ordenado com planilhas de calculo Excel. Recalcularam-se os índices de forma de evitar eventuais diferencias de cálculo entre as concessionárias, dado que foram encontrados alguns poucos dados inconsistentes.

As planilhas geradas nesta adequação dos dados constituem uma nova base criada com o propósito de facilitar o processamento dos mesmos, permitir uniformizar critérios e extrapolar dados para os anos onde não se contava com a série anual completa. Ainda, quando detectado certas inconsistências, após consultas com os gestores que os tinham enviados, estes dados foram corrigidos ou complementados com critérios que ficaram descritos em comentários específicos no pé de cada tabela resultante. Na Tabela 4.2 se apresenta a estrutura final desta base de dados, para um segmento de rodovia definido com trecho homogêneo da SP310.

Sempre que realizadas adequações nas bases de dados, as mesmas foram cuidadosamente descritas de forma a se permitir o rastreamento dos dados originais. Estas bases de dados, por serem extensas não foram impressas no presente escrito, mas estão disponibilizadas em arquivo digital e depositadas junto com o documento principal da tese de mestrado. As bases de dados se denominaram: "BD310”; "BD300”; "BD225”; "BD127” e “BD075”. As mesmas apresentam os dados divididos pelos mesmos segmentos homogêneos definidos pela concessionária que os forneceu.

Como foi realizado o estudo usando o método de grupos de comparação gerou-se, ainda, mais uma base de dados com os trechos de rodovias que serviram de suporte para estes grupos. "Os mesmos foram denominados "GC_310”, “GC_300”, “GC_225”, GC_127”, $e$ “GC_075”. A Tabela 4.3 mostra como se resumiram os dados das bases acima citadas. 
TABELA 4. 1 - Tabela de Dados com Índices de Acidentes

Rodovia: SP-310 Norte

$K=$

1,645

\begin{tabular}{|c|c|c|c|c|c|c|c|c|c|c|c|c|c|c|}
\hline \multirow{2}{*}{$\begin{array}{c}\text { TRECHOS } \\
\text { HOMOGÊNEOS }\end{array}$} & \multicolumn{2}{|c|}{ KM } & \multirow{2}{*}{ EXT. } & \multirow{2}{*}{ VDM } & \multicolumn{4}{|c|}{ ACIDENTES } & \multirow{2}{*}{ EXPOSIÇÃO } & \multirow{2}{*}{$\begin{array}{l}\text { ACIDENTES } \\
\text { PONDERADO }\end{array}$} & \multicolumn{3}{|c|}{ ÍNDICES } & \multirow{2}{*}{$\begin{array}{c}\text { Comparação } \\
\text { Ip com Ic }\end{array}$} \\
\hline & INICIAL & FINAL & & & DM & FE & MO & TOT & & & Ip & Ipm & Ic & \\
\hline \multirow{14}{*}{ TRECHO 1} & 227,800 & 228,000 & 0,200 & 15.518 & 1 & 0 & 0 & 1 & 1,1328 & 1 & 0,88 & 2,69 & 4,7778 & - \\
\hline & 228,000 & 229,000 & 1,000 & 15.518 & 3 & 2 & 0 & 5 & 5,6641 & 13 & 2,30 & 2,69 & 3,7307 & - \\
\hline & 229,000 & 230,000 & 1,000 & 15.518 & 5 & 2 & 0 & 7 & 5,6641 & 15 & 2,65 & 2,69 & 3,7307 & - \\
\hline & 230,000 & 231,000 & 1,000 & 15.518 & 1 & 3 & 1 & 5 & 5,6641 & 29 & 5,12 & 2,69 & 3,7307 & CRÍTICO \\
\hline & 231,000 & 232,000 & 1,000 & 15.518 & 4 & 3 & 0 & 7 & 5,6641 & 19 & 3,35 & 2,69 & 3,7307 & - \\
\hline & 232,000 & 233,000 & 1,000 & 15.518 & 1 & 1 & 2 & 4 & 5,6641 & 32 & 5,65 & 2,69 & 3,7307 & CRÍTICO \\
\hline & 233,000 & 234,000 & 1,000 & 15.518 & 2 & 0 & 0 & 2 & 5,6641 & 2 & 0,35 & 2,69 & 3,7307 & - \\
\hline & 234,000 & 235,000 & 1,000 & 15.518 & 1 & 1 & 0 & 2 & 5,6641 & 6 & 1,06 & 2,69 & 3,7307 & - \\
\hline & 235,000 & 236,000 & 1,000 & 15.518 & 8 & 3 & 0 & 11 & 5,6641 & 23 & 4,06 & 2,69 & 3,7307 & CRÍTICO \\
\hline & 236,000 & 237,000 & 1,000 & 15.518 & 2 & 1 & 0 & 3 & 5,6641 & 7 & 1,24 & 2,69 & 3,7307 & - \\
\hline & 237,000 & 238,000 & 1,000 & 15.518 & 1 & 4 & 0 & 5 & 5,6641 & 21 & 3,71 & 2,69 & 3,7307 & - \\
\hline & 238,000 & 239,000 & 1,000 & 15.518 & 0 & 3 & 0 & 3 & 5,6641 & 15 & 2,65 & 2,69 & 3,7307 & - \\
\hline & 239,000 & 240,000 & 1,000 & 15.518 & 0 & 1 & 0 & 1 & 5,6641 & 5 & 0,88 & 2,69 & 3,7307 & - \\
\hline & 240,000 & 241,800 & 1,800 & 15.518 & 0 & 5 & 0 & 5 & 10,1953 & 25 & 2,45 & 2,69 & 3,4814 & - \\
\hline \multicolumn{3}{|c|}{ Subtotal - Trecho 1} & 14,000 & 15.518 & 29 & 29 & 3 & 61 & 79,2970 & 213 & 2,69 & 2,69 & 2,9826 & - \\
\hline
\end{tabular}

Fonte: Concessionário Triângulo do Sol (2010). 
TABELA 4. 2 - EXEMPLO DA ESTRUTURA DA BASE DE DADOS CRIADA

SEG. HOMOG. SP127-Km88a105

\begin{tabular}{|c|c|c|c|c|c|c|c|c|c|c|c|c|c|c|c|c|c|c|c|}
\hline \multirow{3}{*}{ RODOVIA } & \multirow{2}{*}{\multicolumn{2}{|c|}{ ÁREA URBANA }} & \multirow{3}{*}{ SENTIDO } & \multirow{3}{*}{ ANO } & \multirow{3}{*}{\begin{tabular}{|c|} 
T.Hom og \\
№ \\
\end{tabular}} & \multirow{2}{*}{\multicolumn{2}{|c|}{ KM }} & \multirow{3}{*}{ EXT. } & \multirow{3}{*}{ VDM } & \multirow{2}{*}{\multicolumn{4}{|c|}{ ACIDENTES }} & \multirow{3}{*}{\begin{tabular}{|c|} 
EXPOSIÇÃO \\
MENSAL
\end{tabular}} & \multirow{3}{*}{\begin{tabular}{|c|} 
Acid. \\
Ponder.
\end{tabular}} & \multirow{2}{*}{\multicolumn{3}{|c|}{ Índices }} & \multirow{3}{*}{$\begin{array}{l}\text { Com paração } \\
\text { Ip com Ic }\end{array}$} \\
\hline & & & & & & & & & & & & & & & & & & & \\
\hline & $\mathbf{N}^{\circ}$ & NOME & & & & Inicial & Final & & & DM & FE & MO & TO & & & Ip & Ipm & Ic & \\
\hline SP127 & 2 & Cerquilho & $S+N$ & 2003 & 2 & 88 & 89 & 1 & 5.280 & 5 & 8 & - & 13 & 1,9272 & 45 & 23,35 & 7,45 & 10,42 & CRÍTICO \\
\hline SP127 & 2 & Cerquilho & $\mathrm{S}+\mathrm{N}$ & 2003 & 2 & 89 & 90 & 1 & 5.280 & 2 & 2 & - & 4 & 1,9272 & 12 & 6,23 & 7,45 & 10,42 & - \\
\hline SP127 & 2 & Cerquilho & $\mathrm{S}+\mathrm{N}$ & 2003 & 2 & 90 & 91 & 1 & 5.280 & 12 & 2 & - & 14 & 1,9272 & 22 & 11,42 & 7,45 & 10,42 & CRÍTICO \\
\hline SP127 & 2 & Cerquilho & $\mathrm{S}+\mathrm{N}$ & 2003 & 2 & 91 & 92 & 1 & 5.280 & 5 & 1 & - & 6 & 1,9272 & 10 & 5,19 & 7,45 & 10,42 & - \\
\hline SP127 & & & $\mathrm{S}+\mathrm{N}$ & 2003 & 2 & 92 & 93 & 1 & 5.280 & 2 & - & - & 2 & 1,9272 & 2 & 1,04 & 7,45 & 10,42 & - \\
\hline SP127 & & & $\mathrm{S}+\mathrm{N}$ & 2003 & 2 & 93 & 94 & 1 & 5.280 & 3 & 2 & - & 5 & 1,9272 & 13 & 6,75 & 7,45 & 10,42 & - \\
\hline SP127 & & & $\mathrm{S}+\mathrm{N}$ & 2003 & 2 & 94 & 95 & 1 & 5.280 & 2 & - & - & 2 & 1,9272 & 2 & 1,04 & 7,45 & 10,42 & - \\
\hline SP127 & & & $\mathrm{S}+\mathrm{N}$ & 2003 & 2 & 95 & 96 & 1 & 5.280 & 7 & 5 & 2 & 14 & 1,9272 & 58 & 30,10 & 7,45 & 10,42 & CRÍTICO \\
\hline SP127 & & & $\mathrm{S}+\mathrm{N}$ & 2003 & 2 & 96 & 97 & 1 & 5.280 & 3 & 3 & - & 6 & 1,9272 & 18 & 9,34 & 7,45 & 10,42 & - \\
\hline SP127 & & & $\mathrm{S}+\mathrm{N}$ & 2003 & 2 & 97 & 98 & 1 & 5.280 & 2 & 1 & - & 3 & 1,9272 & 7 & 3,63 & 7,45 & 10,42 & - \\
\hline SP127 & & & $\mathrm{S}+\mathrm{N}$ & 2003 & 2 & 98 & 99 & 1 & 5.280 & 3 & 2 & - & 5 & 1,9272 & 13 & 6,75 & 7,45 & 10,42 & - \\
\hline SP127 & & & $\mathrm{S}+\mathrm{N}$ & 2003 & 2 & 99 & 100 & 1 & 5.280 & - & 2 & - & 2 & 1,9272 & 10 & 5,19 & 7,45 & 10,42 & - \\
\hline SP127 & & & $\mathrm{S}+\mathrm{N}$ & 2003 & 2 & 100 & 101 & 1 & 5.280 & - & - & - & - & 1,9272 & - & - & 7,45 & 10,42 & - \\
\hline SP127 & & & $\mathrm{S}+\mathrm{N}$ & 2003 & 2 & 101 & 102 & 1 & 5.280 & 2 & 2 & 1 & 5 & 1,9272 & 25 & 12,97 & 7,45 & 10,42 & CRÍTICO \\
\hline SP127 & & & $\mathrm{S}+\mathrm{N}$ & 2003 & 2 & 102 & 103 & 1 & 5.280 & - & 1 & - & 1 & 1,9272 & 5 & 2,59 & 7,45 & 10,42 & - \\
\hline SP127 & & & $\mathrm{S}+\mathrm{N}$ & 2003 & 2 & 103 & 104 & 1 & 5.280 & 2 & 1 & - & 3 & 1,9272 & 7 & 3,63 & 7,45 & 10,42 & - \\
\hline SP127 & & & $\mathrm{S}+\mathrm{N}$ & 2003 & 2 & 104 & 105 & 1 & 5.280 & 2 & - & - & 2 & 1,9272 & 2 & 1,04 & 7,45 & 10,42 & - \\
\hline SP127 & & & $\mathrm{S}+\mathrm{N}$ & 2003 & 2 & 105 & 105,9 & 0,9 & 5.280 & 1 & 1 & - & 2 & 1,7345 & 6 & 3,46 & 7,45 & 10,57 & - \\
\hline SP127 & & TOTAL & $\mathrm{S}+\mathrm{N}$ & 2003 & 2 & 88 & 105,90 & 17,9 & 5.280 & 53 & 33 & 3 & 89 & 34,4963 & 257 & 7,45 & 7,45 & 8,20 & - \\
\hline SP127 & 2 & Cerquilho & $S+N$ & 2003 & & 88 & 91,00 & 4,00 & 5.280 & 24 & 13 & - & 37 & 7,7087 & 89 & 11,55 & 7,45 & 9,00 & CRÍTICO \\
\hline SP127 & & Resto trecho & $\mathrm{S}+\mathrm{N}$ & 2003 & & 92 & 105,90 & 13,90 & 5.280 & 29 & 20 & 3 & 52 & 26,7877 & 168 & 6,27 & 7,45 & 8,30 & - \\
\hline
\end{tabular}

Fonte: Base de Dados gerada pelo autor (2011). 
Tabela 4. 3 - Dados de um trecho usado como grupo de comparação

\begin{tabular}{|c|c|c|c|c|c|c|c|}
\hline $\begin{array}{c}\text { Rodovia SP310 } \\
\text { Km } 228 \text { ao } 229 \\
\text { GC (a) } \\
\text { Travessia Urbana } \\
\text { de São Carlos }\end{array}$ & ANO & VDM & DM & FE & MO & TO & TO \\
\hline \multicolumn{3}{|c|}{ ESCOLHA DO TIPO DE ACIDENTE PELA GRAVEDADE --> } & 1 & 2 & 3 & 4 & 4 \\
\hline \multirow{9}{*}{ TOTAL } & 2002 & 23.788 & 8 & 6 & 2 & 16 & 16 \\
\hline & 2003 & 23.788 & 16 & 12 & 0 & 28 & 28 \\
\hline & 2004 & 23.788 & 14 & 13 & 1 & 28 & 28 \\
\hline & 2005 & 26.690 & 25 & 8 & 1 & 34 & 34 \\
\hline & 2006 & 25.267 & 20 & 13 & 0 & 33 & 33 \\
\hline & 2007 & 26.745 & 18 & 15 & 4 & 37 & 37 \\
\hline & 2008 & 29.233 & 19 & 16 & 1 & 36 & 36 \\
\hline & 2009 & 29.558 & 22 & 13 & 0 & 35 & 35 \\
\hline & 2010 & 29.883 & 11 & 8 & 1 & 20 & 20 \\
\hline \multirow{9}{*}{ PISTA 1 (S - 0) } & 2002 & 12.131 & 3 & 4 & 0 & 7 & 7 \\
\hline & 2003 & 12.131 & 5 & 8 & 0 & 13 & 13 \\
\hline & 2004 & 12.131 & 5 & 9 & 1 & 15 & 15 \\
\hline & 2005 & 13.546 & 16 & 3 & 0 & 19 & 19 \\
\hline & 2006 & 12.674 & 13 & 7 & 0 & 20 & 20 \\
\hline & 2007 & 13.643 & 9 & 7 & 2 & 18 & 18 \\
\hline & 2008 & 14.404 & 10 & 6 & 1 & 17 & 17 \\
\hline & 2009 & 14.755 & 15 & 9 & 0 & 24 & 24 \\
\hline & 2010 & 14.365 & 3 & 4 & 1 & 8 & 8 \\
\hline \multirow{9}{*}{ PISTA 2 (N - L) } & 2002 & 11.657 & 5 & 2 & 2 & 9 & 9 \\
\hline & 2003 & 11.657 & 11 & 4 & 0 & 15 & 15 \\
\hline & 2004 & 11.657 & 9 & 4 & 0 & 13 & 13 \\
\hline & 2005 & 13.144 & 9 & 5 & 1 & 15 & 15 \\
\hline & 2006 & 12.593 & 7 & 6 & 0 & 13 & 13 \\
\hline & 2007 & 13.102 & 9 & 8 & 2 & 19 & 19 \\
\hline & 2008 & 14.829 & 9 & 10 & 0 & 19 & 19 \\
\hline & 2009 & 14.803 & 7 & 4 & 0 & 11 & 11 \\
\hline & 2010 & 15.518 & 8 & 4 & 0 & 12 & 12 \\
\hline
\end{tabular}

Fonte: Base de Dados gerada pelo autor (2011).

\subsection{DESCRIÇÃO DAS AÇÕES ANALISADAS}

Em base as informações recebidas, foram consolidadas as descrições que se incluem nas Figuras 4.1, 4.2, 4.3, 4.4 e 4.5, todas elas geradas pelo autor, onde se apresentam os tratamentos ou ações analisados e a data de entrada em operação de cada um. 


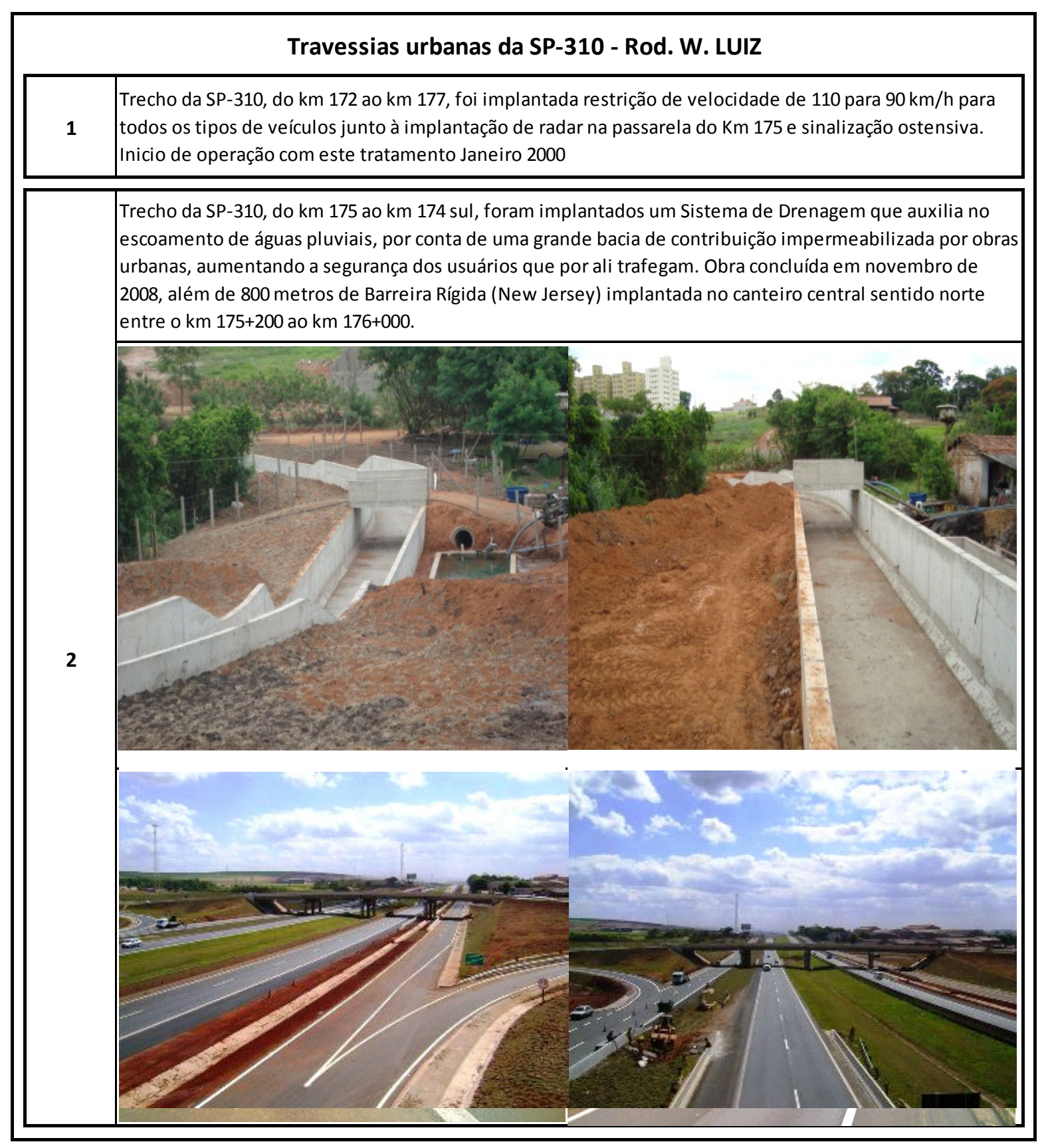

Figura 4. 1 - Descrição das ações aplicadas na SP-310.

Fonte: Base de Dados gerada pelo autor (2011).

(continua na página seguinte) 


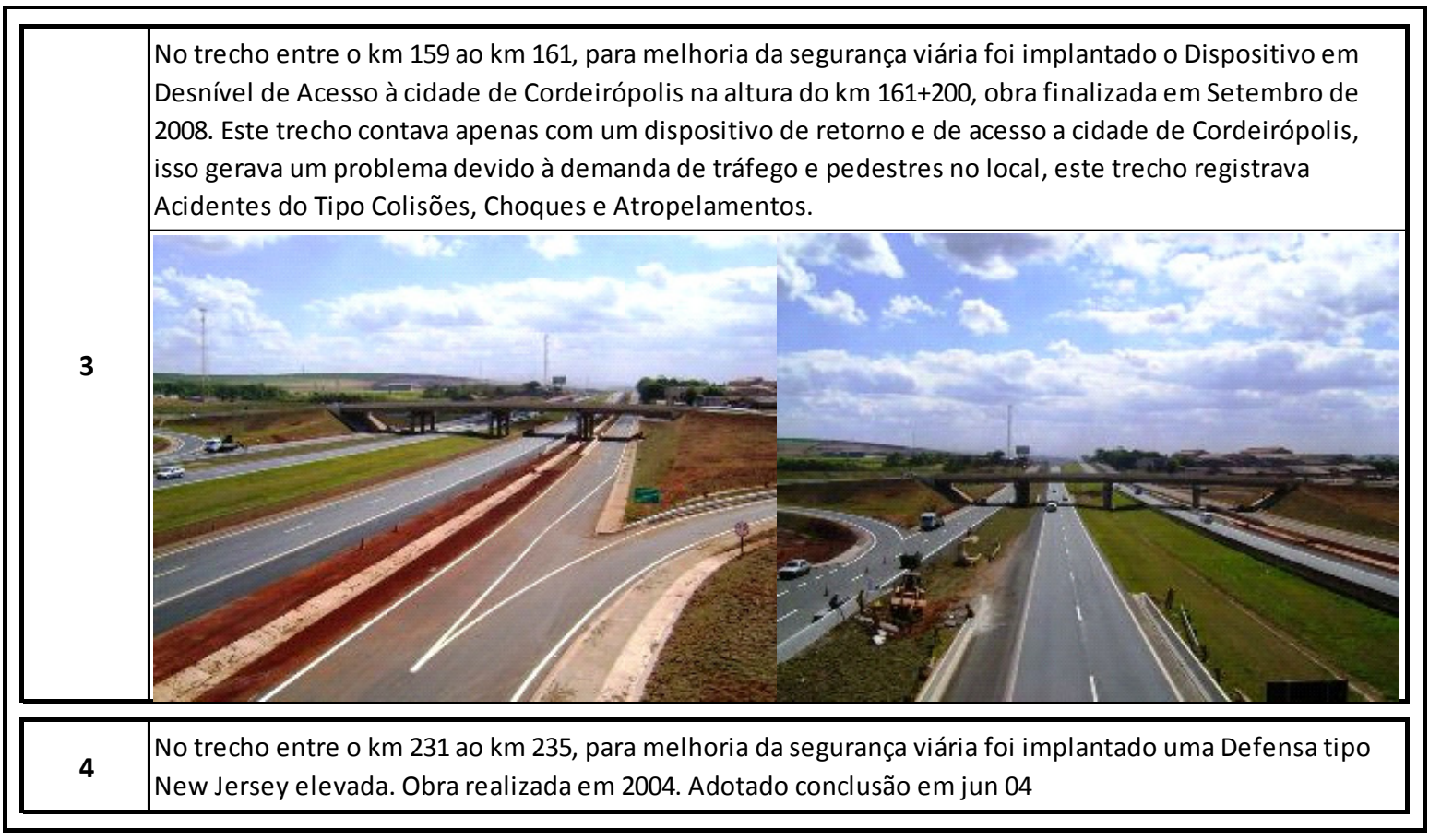

Continuação de Figura 4.1. - Descrição das ações aplicadas na SP-310.

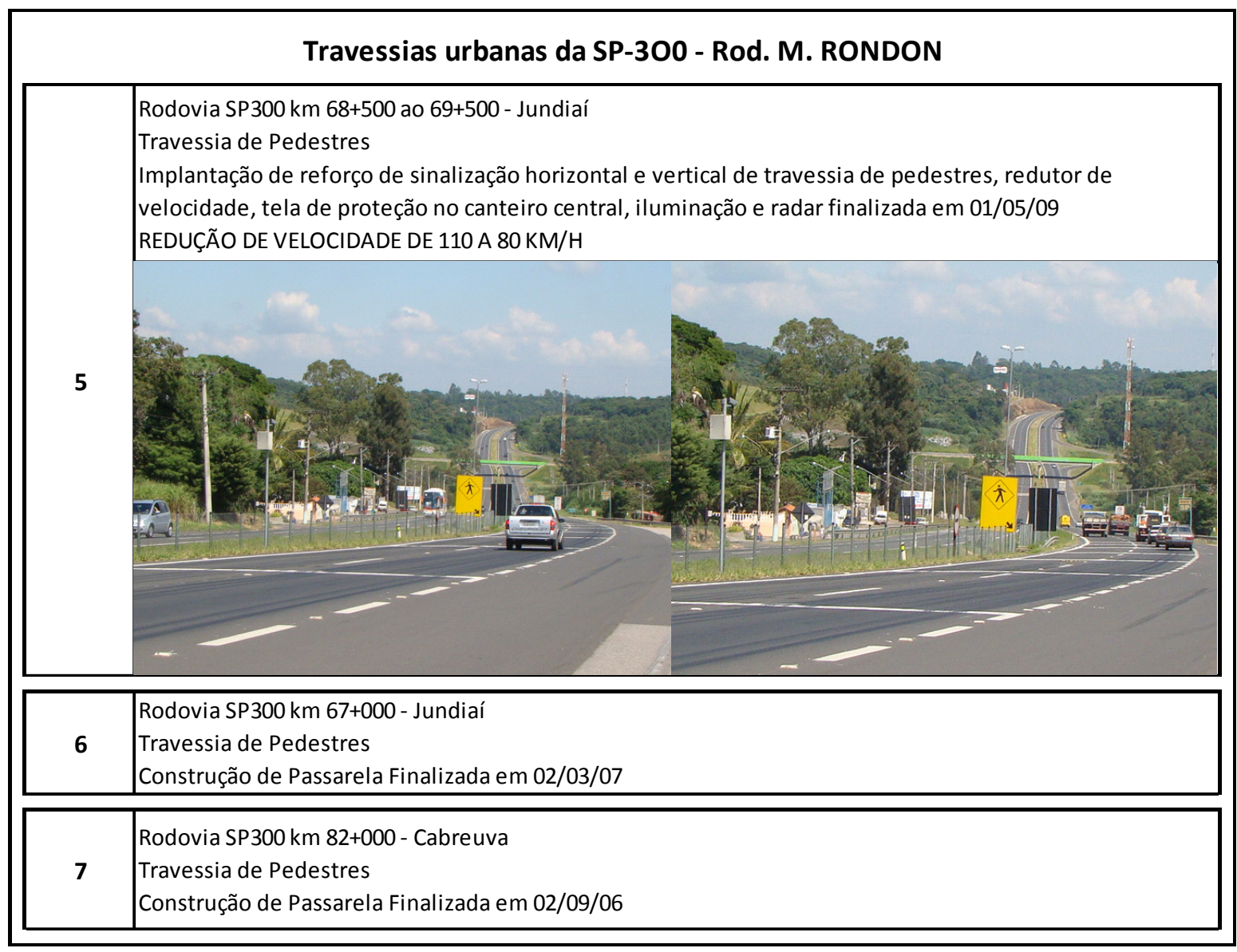

Figura 4. 2 - Descrição das ações aplicadas na SP-300.

Fonte: Base de Dados gerada pelo autor (2011). 
Travessias urbanas da SP-225 - Rod. Engenheiro Paulo Nilo Romano

O perímetro de Jaú compreende o trecho do km 177+600 ao km 185 da SP-225

8

Por solicitude do Ministério Público de Jau, acolhido pela ARTESP, a concessionária realizou estudo

técnico visando definir a conveniência de implantar redução de velocidade no Contorno de Jaú. Em base

ao resultado deste estudo a velocidade foi reduzida de $110 \mathrm{~km} / \mathrm{h}$ para $90 \mathrm{~km} / \mathrm{h}$ em jan/2009.

Figura 4. 3 - Descrição das ações aplicadas na SP-225.

Fonte: Base de Dados gerada pelo autor (2011).

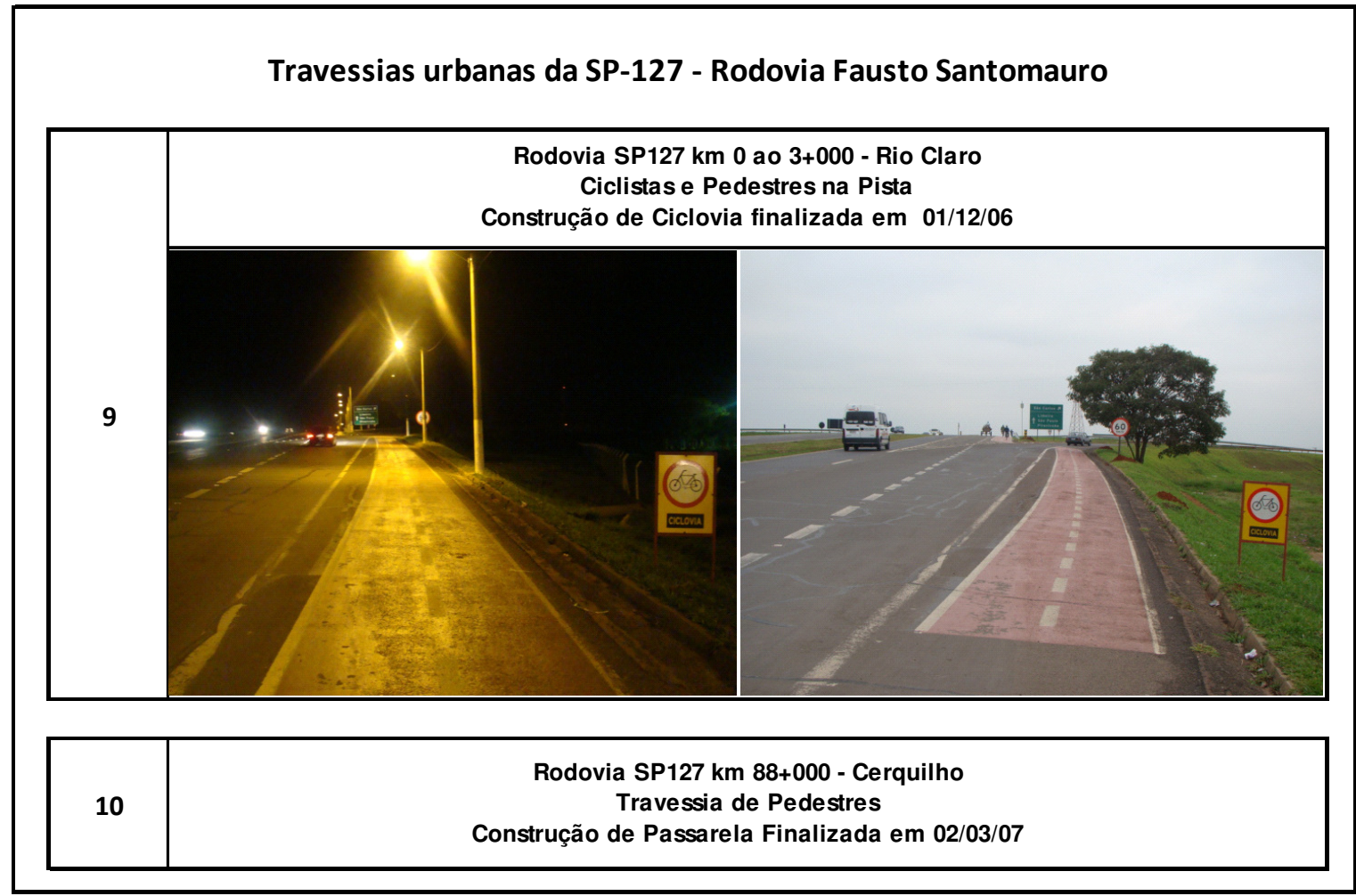

Figura 4. 4 - Descrição das ações aplicadas na SP-127

Fonte: Base de Dados gerada pelo autor (2011). 


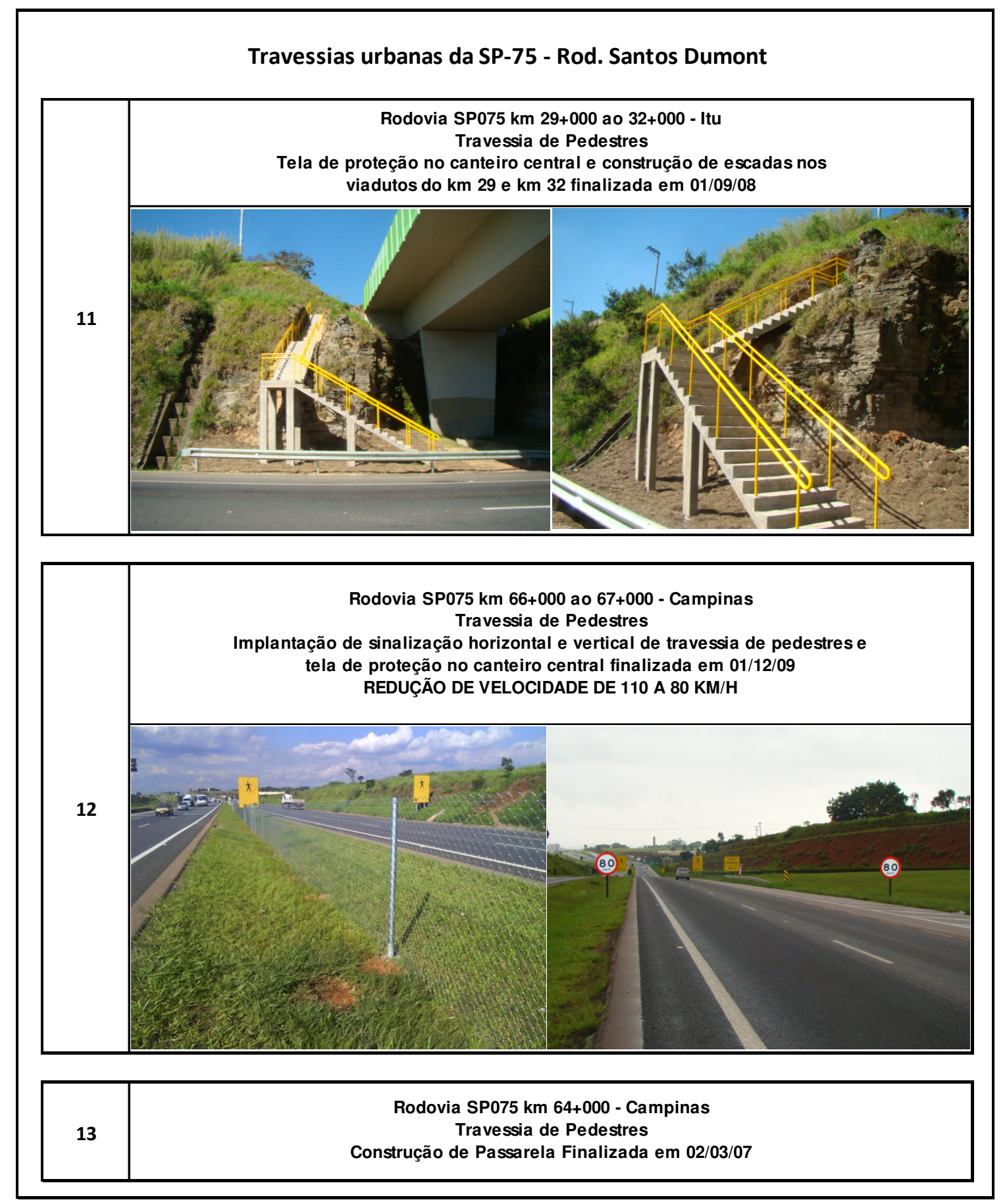

Figura 4. 5 - Descrição das ações aplicadas na SP-075

Fonte: Base de Dados gerada pelo autor (2011). 


\section{ANÁLISE DOS DADOS E RESULTADOS}

\subsection{RESUMO GERAL POR RODOVIA}

Processou-se a informação disponível, aplicando as duas metodologias citadas neste trabalho: método "antes - depois" ingênuo e método de grupos de comparação. As oportunidades de aplicar este segundo método foram menores, dado que o mesmo somente pode ser aplicado se verificada a condição de que a razão $\frac{r_{C}}{r_{T}}$, chamada de $\omega$, atenda à exigência de que sua média $\mathrm{E}\{\omega\}$ seja igual a um.

Para o cálculo se usaram as seguintes variáveis:

- Tempo antes (ano): período de tempo antes da aplicação do tratamento, medido em anos, em que se processaram os acidentes do local;

- Tempo depois (ano): período de tempo depois da aplicação do tratamento, medido em anos, em que se processaram os acidentes do local;

- VDM antes: média dos veículos médios diários anuais do local onde se processaram os acidentes, antes da aplicação do tratamento;

- VDM depois: média dos veículos médios diários anuais do local onde se processaram os acidentes, depois da aplicação do tratamento;

- $\pi$ : número esperado de acidentes de uma entidade específica, em um período “depois" se não tivesse sido tratada; é o valor que tem que ser previsto;

- $\lambda$ : número esperado de acidentes da entidade no período "depois", é o que tem que ser estimado;

- $\delta$ : redução do período "depois" do número esperado de acidentes (ou do índice de severidade do acidente);

- $\theta$ : razão entre o que a segurança foi com o tratamento e a que teria sido sem o tratamento ("índice de eficácia");

- Redução dos acidentes em $\%=1-\theta$; 
- $\sigma(\delta)$ : desvio padrão da redução do número de acidentes no período “depois";

- $\sigma(\theta)$ : desvio padrão do índice de eficácia.

Foram considerados quatro variantes para estimar o valor de $\pi$. Os três primeiros casos correspondem ao método de comparação "antes - depois" ingênuo, e o quarto aplica o critério de grupos de comparação, conforme os casos que se explicam a seguir:

- i: cálculo estatístico considerando $\pi$ como sendo igual ao valor do ano anterior ou, quando disponíveis os dados de pelo menos os últimos três anos, o valor fornecido pela tendência dos mesmos usando a função do Excel que retorna valores em uma tendência linear (ajusta, usando o método de quadrados mínimos, a uma linha os valores conhecidos e os calculados);

- ii: cálculo de $\pi$ considerando a duração do período de tempo com dados disponíveis;

- iii: cálculo de $\pi$ considerando a duração do período de tempo com dados disponíveis e o VDM do trecho em analise;

- iv: cálculo de $\pi$ considerando os dados de grupos de comparação.

Desta forma é possível comparar os resultados da eficácia das ações aplicando diversos critérios de estimação do $\pi$. O primeiro deles, comumente usado pela técnica quando não se dispõe ou se conseguem poucos dados de períodos anteriores para o trecho em estudo, é o que apresenta resultados de menor confiabilidade.

O segundo, embora permita levar em conta uma serie maior de dados e o tempo transcorrido, não considera outros fatores que incidem diretamente nas estatísticas de acidentes como o VDM. Por este motivo, o pesquisador opta por escolher como o melhor resultado dentre os valores comparados aquele denominado com o numeral iii. Quando se refere expressamente aos resultados do estudo, estará fazendo menção sempre a resultados obtidos usando este critério.

Finalmente, o cálculo usando grupos de referencia, que usa dados de comparação de trechos de rodovias de similares características operacionais aos locais em analise, procedentes de bases de dados de uma mesmo origem (concessionárias e ARTESP), apresentam em geral resultados consistentes com os do método ingênuo (critério iii).

Ainda sendo assim, se prefere apresentar os resultados sem pretender enunciar conclusões com os mesmos no entendimento que os estudos deverão ser aprofundados e estendidos a um número maior de tratamentos para então estar em condições de realizá-las. 
Embora não se apresentem junto a este texto todos os resultados obtidos, comenta-se que foi feito o estudo contemplando a desagregação dos acidentes segundo a sua gravidade, sendo: acidentes com danos materiais; acidentes com feridos; acidentes com mortos; acidentes com feridos e com mortos (soma das duas anteriores); e acidentes totais (os resultados aqui apresentados correspondem a este último tipo).

Pode comentar-se que aquele tipo de acidentes mais grave (com feridos e com mortos), por estar calculados em base a poucos casos, conduzem a resultados com elevado desvio-padrão, reduzindo a qualidade dos mesmos. O cálculo e seus resultados podem ser consultados no APÊNDICE e constatados no material digital que acompanha o texto. Estudos posteriores com um número maior de dados podem permitir um analise mais consistente desta situação.

Nas páginas seguintes se apresentam quadros com a descrição dos casos estudados por rodovia e seus correspondentes resultados. 
TABELA 5. 1 - RESULTADOS DA SP310

\begin{tabular}{|c|c|c|c|c|c|c|c|c|c|c|c|c|c|c|c|c|c|c|c|}
\hline \multicolumn{12}{|c|}{ SP 310} & \multicolumn{8}{|c|}{ RESULTADOS } \\
\hline & LOCAL & & MÉTOdo & $\begin{array}{c}\text { Tempo } \\
\text { antes } \\
\text { (ano) }\end{array}$ & $\begin{array}{c}\text { Tempo } \\
\text { depois } \\
\text { (ano) }\end{array}$ & $\begin{array}{c}\text { VDM } \\
\text { antes }\end{array}$ & $\begin{array}{c}\text { VDM } \\
\text { depois }\end{array}$ & $\begin{array}{c}\mathrm{rd}= \\
\mathrm{Td} / \mathrm{Ta}\end{array}$ & $\begin{array}{c}\mathrm{rft}= \\
\mathrm{Vd} / \mathrm{Va}\end{array}$ & $\mathrm{K}$ & $\mathrm{L}$ & $\pi$ & $\lambda$ & $\delta=\pi-\lambda$ & $\begin{array}{c}\theta= \\
\lambda / \pi\end{array}$ & $\theta^{\prime}$ & $\begin{array}{c}\text { Redução } \\
1-\theta^{\prime}\end{array}$ & $\sigma(\delta)$ & $\sigma(\theta)$ \\
\hline \multirow{4}{*}{1} & \multirow{4}{*}{$\begin{array}{c}\text { Rodovia } \\
\text { SP310 } \\
\text { Km } 172 \text { ao } \\
177 \\
\text { Travessia } \\
\text { Urbana de Rio } \\
\text { Claro }\end{array}$} & $i$ & $\begin{array}{l}\text { CALCULO ESTATÍSTICO CONSIDERANDO } \pi \text { COMO IGUAL AO } \\
\text { VALOR DO ANO ANTERIOR }\end{array}$ & & & & & & & & & 71 & 77 & (6) & 1,08 & 1,07 & $-7 \%$ & 12 & 0,1735 \\
\hline & & ii & $\begin{array}{l}\text { CALCULO CONSIDERANDO A DURAÇÃO DO PERÍODO DE } \\
\text { TEMPO CONSIDERADO }\end{array}$ & & & & & & & & & 711 & 667 & 44 & 0,94 & 0,93 & $7 \%$ & 37 & 0,0502 \\
\hline & & iii & $\begin{array}{l}\text { CALCULO CONSIDERANDO A DURAÇÃO DO PERÍODO DE } \\
\text { TEMPO E DO VDM CONSIDERADO }\end{array}$ & 2,00 & 8,83 & 15.274 & 21.461 & 4,42 & 1,41 & 161 & 667 & 999 & 667 & 332 & 0,67 & 0,66 & $34 \%$ & 41 & 0,0332 \\
\hline & & iv & $\begin{array}{l}\text { CALCULO CONSIDERANDO GRUPOS DE COMPARAÇÃO } \\
\text { PARA PERÍODO ANTES DO TRATAMENTO }\end{array}$ & \multicolumn{16}{|c|}{ Não se aplica por falta de dados } \\
\hline \multirow{4}{*}{2} & \multirow{4}{*}{\begin{tabular}{|c} 
Rodovia \\
SP310 \\
Km 174 ao \\
176 \\
Travessia \\
Urbana de Rio \\
Claro
\end{tabular}} & i & $\begin{array}{l}\text { CALCULO ESTATÍSTICO CONSIDERANDO } \pi \text { COMO } \\
\text { TENDENCIA DOS VALORES ANTES DE } 3 \text { ANOS }\end{array}$ & & & & & & & & & 56 & 84 & (29) & 1,51 & 1,51 & $-51 \%$ & 12 & 0,2566 \\
\hline & & ii & $\begin{array}{l}\text { CALCULO CONSIDERANDO A DURAÇÃO DO PERÍODO DE } \\
\text { TEMPO CONSIDERADO }\end{array}$ & & & & & & & & & 107 & 180 & (72) & 1,67 & 1,67 & $-67 \%$ & 17 & 0,2016 \\
\hline & & iii & $\begin{array}{l}\text { CALCULO CONSIDERANDO A DURAÇÃO DO PERÍODO DE } \\
\text { TEMPO E DO VDM CONSIDERADO }\end{array}$ & 6,83 & 2,17 & 22.548 & 27.575 & 0,32 & 1,22 & 339 & 180 & 131 & 180 & (48) & 1,37 & 1,36 & $-37 \%$ & 18 & 0,1554 \\
\hline & & iv & $\begin{array}{l}\text { CALCULO CONSIDERANDO GRUPOS DE COMPARAÇÃ̃ } \\
\text { PARA PERÍODO ANTES DO TRATAMENTO } \\
\end{array}$ & & & & & & & & & 90 & 171 & (81) & 1,95 & 1,95 & $-95 \%$ & 16 & 0,3416 \\
\hline \multirow{4}{*}{3} & \multirow{4}{*}{$\begin{array}{c}\text { Rodovia } \\
\text { SP310 } \\
\text { Km 159 ao } \\
161 \\
\text { Travessia } \\
\text { Urbana de } \\
\text { Cordeirópolis }\end{array}$} & i & $\begin{array}{l}\text { CALCULO ESTATÍSTICO CONSIDERANDO } \pi \text { COMO } \\
\text { TENDENCIA DOS VALORES ANTES DE } 3 \text { ANOS } \\
\end{array}$ & & & & & & & & & 38 & 24 & 14 & 0,63 & 0,62 & $37 \%$ & 8 & 0,1583 \\
\hline & & ii & $\begin{array}{l}\text { CALCULO CONSIDERANDO A DURAÇÃO DO PERÍODO DE } \\
\text { TEMPO CONSIDERADO }\end{array}$ & & & & & & & & & 79 & 75 & 4 & 0,95 & 0,95 & $5 \%$ & 12 & 0,1503 \\
\hline & & iii & $\begin{array}{l}\text { CALCULO CONSIDERANDO A DURAÇÃO DO PERÍODO DE } \\
\text { TEMPO E DO VDM CONSIDERADO }\end{array}$ & 6,75 & 2,25 & 21.309 & 27.386 & 0,33 & 1,29 & 238 & 75 & 102 & 75 & 27 & 0,74 & 0,74 & $26 \%$ & 13 & 0,1107 \\
\hline & & iv & $\begin{array}{l}\text { CALCULO CONSIDERANDO GRUPOS DE COMPARAÇÃO } \\
\text { PARA PERÍODO ANTES DO TRATAMENTO }\end{array}$ & & & & & & & & & 84 & 64 & 20 & 0,78 & 0,78 & $22 \%$ & 12 & 0,1359 \\
\hline \multirow{4}{*}{4} & \multirow{4}{*}{$\begin{array}{c}\text { Rodovia } \\
\text { SP310 } \\
\text { Km 231 ao } \\
235 \\
\text { Travessia } \\
\text { Urbana de São } \\
\text { Carlos }\end{array}$} & i & $\begin{array}{l}\text { CALCULO ESTATÍSTICO CONSIDERANDO } \pi \text { COMO } \\
\text { TENDENCIA DOS VALORES ANTES DE } 3 \text { ANOS }\end{array}$ & & & & & & & & & 46 & 56 & (10) & 1,21 & 10,11 & $-21 \%$ & 66 & 0,0328 \\
\hline & & ii & $\begin{array}{l}\text { CALCULO CONSIDERANDO A DURAÇÃO DO PERÍODO DE } \\
\text { TEMPO CONSIDERADO }\end{array}$ & & & & & & & & & 300 & 391 & (90) & 1,30 & 26,28 & $-30 \%$ & 1.171 & 0,0183 \\
\hline & & iii & $\begin{array}{l}\text { CALCULO CONSIDERANDO A DURAÇão DO PERÍODO DE } \\
\text { TEMPO E DO VDM CONSIDERADO }\end{array}$ & 2,50 & 6,50 & 23.788 & 27.309 & 2,60 & 1,15 & 116 & 391 & 345 & 391 & (46) & 1,13 & 27,12 & $-13 \%$ & 1.420 & 0,0139 \\
\hline & & iv & $\begin{array}{l}\text { CALCULO CONSIDERANDO GRUPOS DE COMPARAÇÃ̃ } \\
\text { PARA PERÍODO ANTES DO TRATAMENTO } \\
\end{array}$ & Não se co & onseguiu ur & Im GC ade & equado & & & & & & & & & & & & \\
\hline \multicolumn{20}{|c|}{$\begin{array}{l}\text { Considerações importantes } \\
\text { Os dados dos acidente }\end{array}$} \\
\hline
\end{tabular}

Fonte: Base de Dados gerada pelo autor (2011) 
TABELA 5. 2 - RESULTADOS DA SP300

\begin{tabular}{|c|c|c|c|c|c|c|c|c|c|c|c|c|c|c|c|c|c|c|c|}
\hline \multicolumn{12}{|c|}{ SP 300} & \multicolumn{8}{|c|}{ RESULTADOS } \\
\hline & LOCAL & & MÉTODO & $\begin{array}{c}\text { Tempo } \\
\text { antes } \\
\text { (ano) }\end{array}$ & $\begin{array}{c}\text { Tempo } \\
\text { depois } \\
\text { (ano) }\end{array}$ & $\begin{array}{c}\text { VDM } \\
\text { antes }\end{array}$ & $\begin{array}{c}\text { VDM } \\
\text { depois }\end{array}$ & $\begin{array}{c}\mathrm{rd}= \\
\mathrm{Td} / \mathrm{Ta}\end{array}$ & $\begin{array}{c}\mathrm{rft}= \\
\mathrm{Vd} / \mathrm{Va}\end{array}$ & K & L & $\pi$ & $\lambda$ & $\delta=\pi-\lambda$ & $\begin{array}{c}\theta= \\
\lambda / \pi\end{array}$ & $\theta^{\prime}$ & $\begin{array}{c}\text { Redução } \\
1-\theta\end{array}$ & $\sigma(\delta)$ & $\sigma(\theta)$ \\
\hline \multirow{4}{*}{5} & \multirow{4}{*}{$\begin{array}{l}\text { Rodovia } \\
\text { SP300 km } \\
68+500 \text { ao } \\
69+500- \\
\text { Jundiai } \\
\text { Travessia de } \\
\text { Pedestres }\end{array}$} & $\mathrm{i}$ & $\begin{array}{l}\text { CALCULO ESTATÍ́STICO CONSIDERANDO } \pi \text { COMO } \\
\text { TENDENCIA DOS VALORES ANTES DE } 3 \text { ANOS }\end{array}$ & & & & & & & & & 25 & 10 & 15 & 0,40 & 0,35 & $65 \%$ & 6 & 0,1247 \\
\hline & & ii & $\begin{array}{l}\text { CALCULO CONSIDERANDO A DURAÇÃO DO PERÍODO DE } \\
\text { TEMPO CONSIDERADO }\end{array}$ & & & & & & & & & 25 & 15 & 11 & 0,58 & 0,57 & $43 \%$ & 6 & 0,1807 \\
\hline & & iii & $\begin{array}{l}\text { CALCULO CONSIDERANDO A DURAÇÃO DO PERÍODO DE } \\
\text { TEMPO E DO VDM CONSIDERADO }\end{array}$ & 6,33 & 1,67 & 26.717 & 20.069 & 0,26 & 0,75 & 96 & 15 & 19 & 15 & 4 & 0,77 & 0,76 & $24 \%$ & 6 & 0,2516 \\
\hline & & iv & $\begin{array}{l}\text { CALCULO CONSIDERANDO GRUPOS DE COMPARAÇÃ̃ } \\
\text { PARA PERÍODO ANTES DO TRATAMENTO }\end{array}$ & \multicolumn{16}{|c|}{ Não se conseguiu um GC adequado } \\
\hline \multirow{4}{*}{6} & \multirow{4}{*}{$\begin{array}{l}\text { Rodovia } \\
\text { SP300 } \\
\text { km } 67+000 \\
\text { Jundiai } \\
\text { Travessia de } \\
\text { Pedestres }\end{array}$} & i & $\begin{array}{l}\text { CALCULO ESTATÍSTICO CONSIDERANDO } \pi \text { COMO } \\
\text { TENDENCIA DOS VALORES ANTES DE } 3 \text { ANOS }\end{array}$ & & & & & & & & & 27 & 34 & (7) & 1,26 & 1,25 & $-25 \%$ & 8 & 0,3108 \\
\hline & & ii & $\begin{array}{l}\text { CALCULO CONSIDERANDO A DURAÇÃO DO PERÍODO DE } \\
\text { TEMPO CONSIDERADO }\end{array}$ & & & & & & & & & 103 & 107 & (4) & 1,04 & 1,03 & $-3 \%$ & 14 & 0,1407 \\
\hline & & iii & $\begin{array}{l}\text { CALCULO CONSIDERANDO A DURAÇÃO DO PERÍODO DE } \\
\text { TEMPO E DO VDM CONSIDERADO }\end{array}$ & 4,17 & 3,83 & 29.169 & 23.775 & 0,92 & 0,82 & 112 & 107 & 84 & 107 & (23) & 1,27 & 1,26 & $-26 \%$ & 14 & 0,1819 \\
\hline & & iv & $\begin{array}{l}\text { CALCULO CONSIDERANDO GRUPOS DE COMPARAÇÃO } \\
\text { PARA PERÍODO ANTES DO TRATAMENTO }\end{array}$ & & & & & & & & & 63 & 82 & (19) & 1,31 & 1,35 & $-35 \%$ & 12 & 0,2779 \\
\hline \multirow{4}{*}{7} & \multirow{4}{*}{$\begin{array}{c}\text { Rodovia } \\
\text { SP300 } \\
\text { km } 82+000 \\
\text { Cabreuva } \\
\text { Travessia de } \\
\text { Pedestres }\end{array}$} & i & $\begin{array}{l}\text { CALCULO ESTATÍSTICO CONSIDERANDO } \pi \text { COMO } \\
\text { TENDENCIA DOS VALORES ANTES DE } 3 \text { ANOS } \\
\end{array}$ & & & & & & & & & 17 & 20 & (3) & 1,16 & 0,92 & $8 \%$ & 6 & 0,2847 \\
\hline & & ii & $\begin{array}{l}\text { CALCULO CONSIDERANDO A DURAÇÃO DO PERÍODO DE } \\
\text { TEMPO CONSIDERADO }\end{array}$ & & & & & & & & & 99 & 72 & 27 & 0,73 & 0,72 & $28 \%$ & 13 & 0,1098 \\
\hline & & iii & $\begin{array}{l}\text { CALCULO CONSIDERANDO A DURAÇÃO DO PERÍODO DE } \\
\text { TEMPO E DO VDM CONSIDERADO }\end{array}$ & 3,67 & 4,33 & 10.255 & 12.274 & 1,18 & 1,20 & 84 & 72 & 119 & 72 & 47 & 0,61 & 0,60 & $40 \%$ & 14 & 0,0887 \\
\hline & & iv & $\begin{array}{l}\text { CALCULO CONSIDERANDO GRUPOS DE COMPARAÇÃO } \\
\text { PARA PERÍODO ANTES DO TRATAMENTO }\end{array}$ & & & & & & & & & 101 & 64 & 1.709 & 0,64 & 0,74 & $26 \%$ & 13 & 0,2732 \\
\hline \multicolumn{20}{|c|}{$\begin{array}{l}\text { sideraç̃es importantes } \\
\text { Os dados dos acident }\end{array}$} \\
\hline
\end{tabular}

Fonte: Base de Dados gerada pelo autor (2011) 
TABELA 5. 3 - RESULTADOS DA SP225

\begin{tabular}{|c|c|c|c|c|c|c|c|c|c|c|c|c|c|c|c|c|c|c|c|}
\hline \multicolumn{12}{|c|}{ SP 225} & \multicolumn{8}{|c|}{ RESULTADOS } \\
\hline & LOCAL & & MÉTODO & \begin{tabular}{c|c} 
Tempo \\
antes \\
(ano)
\end{tabular} & $\begin{array}{c}\text { Tempo } \\
\text { depois } \\
\text { (ano) }\end{array}$ & $\begin{array}{c}\text { VDM } \\
\text { antes }\end{array}$ & $\begin{array}{c}\text { VDM } \\
\text { depois }\end{array}$ & $\begin{array}{c}\mathrm{rd}= \\
\mathrm{Td} / \mathrm{Ta}\end{array}$ & $\begin{array}{c}\mathrm{rft}= \\
\mathrm{Vd} / \mathrm{Va}\end{array}$ & K & $\mathrm{L}$ & $\pi$ & $\lambda$ & $\delta=\pi-\lambda$ & $\theta=\lambda / \pi$ & $\theta^{\prime}$ & $\begin{array}{c}\text { Redução } \\
1-\theta^{\prime}\end{array}$ & $\sigma(\delta)$ & $\sigma(\theta)$ \\
\hline \multirow{4}{*}{8} & \multirow{4}{*}{$\begin{array}{c}\text { Rodovia SP } 225 \\
\text { Km } 177 \text { ao } 185 \\
\text { Travessia } \\
\text { Urbana de Jau }\end{array}$} & $i$ & $\begin{array}{l}\text { CALCULO ESTATÍ́STICO CONSIDERANDO } \pi \text { COMO } \\
\text { TENDENCIA DOS VALORES ANTES DE } 3 \text { ANOS }\end{array}$ & & & & & & & & & 98 & 90 & 8 & 0,92 & 0,91 & $9 \%$ & 14 & 0,1316 \\
\hline & & $\mathrm{ii}$ & \begin{tabular}{|c|} 
CALCULO CONSIDERANDO A DURAČ̃̃O DO PERÍODO DE \\
TEMPOO CONSIDERADO
\end{tabular} & & & & & & & & & 154 & 183 & (29) & 1,19 & 1,19 & $-19 \%$ & 18 & 0,1292 \\
\hline & & iii & $\begin{array}{l}\text { CALCULO CONSIDERANDO A DURAÇ̃̃O DO PERÍODO DE } \\
\text { TEMPO E DO VDM CONSIDERADO }\end{array}$ & 7,00 & 2,00 & 16.786 & 28.014 & 0,29 & 1,67 & 538 & 183 & 257 & 183 & 74 & 0,71 & 0,71 & $29 \%$ & 21 & 0,0686 \\
\hline & & iv & $\begin{array}{l}\text { CALCULO CONSIDERANDO GRUPOS DE COMPARAÇÃO } \\
\text { PARA PERÍODO ANTES DO TRATAMENTO }\end{array}$ & & & & & & & & & 232 & 183 & 49 & 0,79 & 0,81 & $19 \%$ & 20 & 0,1336 \\
\hline \multicolumn{20}{|c|}{$\begin{array}{l}\text { Os dados dos acidentes recebidos que não contemplavam um ano inteiro foram anualizados proporcionalmente para os meses faltantes; } \\
\text { Quando não se contava com dados ANTES de três ou mais anos, se adotou como tendência o mes mo valor do ano anterior } \\
\text { Os estudos com referencia i, ii, iii, correspondem ao método de comparação "antes - depois ingênuo" } \\
\text { Os estudos com referencia iv, correspondem ao método de comparacão us ando locais de referencia ou grupos de comparacão }\end{array}$} \\
\hline
\end{tabular}

Fonte: Base de Dados gerada pelo autor (2011) 


\section{TABELA 5. 4 - RESULTADOS DA SP127}

\begin{tabular}{|c|c|c|c|c|c|c|c|c|c|c|c|c|c|c|c|c|c|c|c|}
\hline \multicolumn{12}{|c|}{ SP 127} & \multicolumn{8}{|c|}{ RESULTADOS } \\
\hline & LOCAL & & MÉTOdO & $\begin{array}{c}\text { Tempo } \\
\text { antes } \\
\text { (ano) }\end{array}$ & $\begin{array}{c}\text { Tempo } \\
\text { depois } \\
\text { (ano) }\end{array}$ & $\begin{array}{l}\text { VDM } \\
\text { antes }\end{array}$ & $\begin{array}{l}\text { VDM } \\
\text { depois }\end{array}$ & $\begin{array}{c}\mathrm{rd}= \\
\mathrm{Td} / \mathrm{Ta}\end{array}$ & $\begin{array}{c}\mathrm{rft}= \\
\mathrm{Vd} / \mathrm{Va}\end{array}$ & $\mathrm{K}$ & L & $\pi$ & $\lambda$ & $\delta=\pi-\lambda$ & $\begin{array}{l}\theta= \\
\lambda / \pi\end{array}$ & $\theta^{\prime}$ & $\begin{array}{c}\text { Redução } \\
1-\theta\end{array} \mid$ & $\sigma(\delta)$ & $\sigma(\theta)$ \\
\hline \multirow{4}{*}{9} & \multirow{4}{*}{\begin{tabular}{|c} 
Rodovia SP127 \\
$\mathrm{km} 0$ ao $3+000$ \\
Rio Claro \\
Cilistas e \\
Pedestres na \\
Pista
\end{tabular}} & $\mathrm{i}$ & $\begin{array}{l}\text { CALCULO ESTATÍSTICO CONSIDERANDO } \pi \text { COMO } \\
\text { TENDENCIA DOS VALORES ANTES DE } 3 \text { ANOS }\end{array}$ & & & & & & & & & 55 & 57 & (3) & 1,05 & 0,97 & $3 \%$ & 11 & 0,1810 \\
\hline & & ii & $\begin{array}{l}\text { CALCULO CONSIDERANDO A DURAÇÃO DO PERÍODO DE } \\
\text { TEMPO CONSIDERADO }\end{array}$ & & & & & & & & & 242 & 235 & 6 & 0,97 & 0,97 & $3 \%$ & 22 & 0,0884 \\
\hline & & iii & $\begin{array}{l}\text { CALCULO CONSIDERANDO A DURAÇÃO DO PERÍODO DE } \\
\text { TEMPO E DO VDM CONSIDERADO }\end{array}$ & 3,92 & 4,08 & 6.754 & 9.427 & 1,04 & 1,40 & 232 & 235 & 337 & 235 & 102 & 0,70 & 0,69 & $31 \%$ & 24 & 0,0588 \\
\hline & & iv & $\begin{array}{l}\text { CALCULO CONSIDERANDO GRUPOS DE COMPARAÇÃO } \\
\text { PARA PERÍODO ANTES DO TRATAMENTO }\end{array}$ & & & & & & & & & 301 & 231 & 70 & 0,77 & 0,88 & $12 \%$ & 23 & 0,2977 \\
\hline \multirow{4}{*}{10} & \multirow{4}{*}{$\begin{array}{c}\text { Rodovia SP127 } \\
\text { km 88+000 - } \\
\text { Cerquilho } \\
\text { Travessia de } \\
\text { Pedestres }\end{array}$} & $\mathrm{i}$ & $\begin{array}{l}\text { CALCULO ESTATÍSTICO CONSIDERANDO } \pi \text { COMO } \\
\text { TENDENCIA DOS VALORES ANTES DE } 3 \text { ANOS }\end{array}$ & & & & & & & & & 11 & 4 & 7 & 0,35 & 0,33 & $67 \%$ & 4 & 0,1788 \\
\hline & & ii & $\begin{array}{l}\text { CALCULO CONSIDERANDO A DURAÇÃO DO PERÍODO DE } \\
\text { TEMPO CONSIDERADO }\end{array}$ & & & & & & & & & 42 & 20 & 22 & 0,47 & 0,46 & $54 \%$ & 8 & 0,1232 \\
\hline & & iii & $\begin{array}{l}\text { CALCULO CONSIDERANDO A DURAÇÃO DO PERÍODO DE } \\
\text { TEMPO E DO VDM CONSIDERADO }\end{array}$ & 4,17 & 3,83 & 4.893 & 7.003 & 0,92 & 1,43 & 45 & 20 & 60 & 20 & 40 & 0,33 & 0,32 & $68 \%$ & 9 & 0,0824 \\
\hline & & iv & $\begin{array}{l}\text { CALCULO CONSIDERANDO GRUPOS DE COMPARAÇÃO } \\
\text { PARA PERÍODO ANTES DO TRATAMENTO }\end{array}$ & & & & & & & & & 58 & 21 & 37 & 0,36 & 0,40 & $60 \%$ & 9 & 0,1378 \\
\hline
\end{tabular}

Considerações importantes

Os dados dos acidentes recebidos que não contemplavam um ano inteiro foram anualizados proporcionalmente para os meses faltantes;

Quando não se contava com dados ANTES de três ou mais anos, se adotou como tendência o mes mo valor do ano anterior

Os estudos com referencia i, ii, iii, correspondem ao método de comparação "antes - depois ingênuo"

Fonte: Base de Dados gerada pelo autor (2011) 
TABELA 5. 5 - RESULTADOS DA SP075

\begin{tabular}{|c|c|c|c|c|c|c|c|c|c|c|c|c|c|c|c|c|c|c|c|}
\hline \multicolumn{12}{|c|}{ SP 075} & \multicolumn{8}{|c|}{ RESULTADOS } \\
\hline & LOCAL & & MÉTOdO & $\begin{array}{c}\text { Tempo } \\
\text { antes } \\
\text { (ano) }\end{array}$ & $\begin{array}{c}\text { Tempo } \\
\text { depois } \\
\text { (ano) } \\
\end{array}$ & $\begin{array}{c}\text { VDM } \\
\text { antes }\end{array}$ & $\begin{array}{l}\text { VDM } \\
\text { depois }\end{array}$ & $\begin{array}{c}\mathrm{rd}= \\
\mathrm{Td} / \mathrm{Ta}\end{array}$ & $\begin{array}{c}\mathrm{rft}= \\
\mathrm{Vd} / \mathrm{Va}\end{array}$ & $\mathrm{k}$ & $\mathrm{L}$ & $\pi$ & $\lambda$ & $\delta=\pi-\lambda$ & $\begin{array}{c}\theta= \\
\lambda / \pi\end{array}$ & $\theta^{\prime}$ & $\begin{array}{c}\text { Redução } \\
1 \text { - } \theta\end{array}$ & $\sigma(\delta)$ & $\sigma(\theta)$ \\
\hline \multirow{4}{*}{11} & \multirow{4}{*}{$\begin{array}{c}\text { Rodovia SP075 } \\
\text { km 29+000 ao } \\
32+000-\text { ttu } \\
\text { Travessia de } \\
\text { Pedestres }\end{array}$} & $\mathrm{i}$ & $\begin{array}{l}\text { CALCULO ESTATÍSTICO CONSIDERANDO } \pi \text { COMO } \\
\text { TENDENCIA DOS VALORES ANTES DE } 3 \text { ANOS }\end{array}$ & & & & & & & & & 83 & 85 & (2) & 1,02 & 0,98 & $2 \%$ & 13 & 0,1495 \\
\hline & & $\mathrm{ii}$ & $\begin{array}{l}\text { CALCULO CONSIDERANDO A DURAÇÃO DO PERÍODO DE } \\
\text { TEMPO CONSIDERADO }\end{array}$ & & & & & & & & & 154 & 177 & (23) & 1,15 & 1,14 & $-14 \%$ & 18 & 0,1251 \\
\hline & & iii & $\begin{array}{l}\text { CALCULO CONSIDERANDO A DURAÇ̃̃O DO PERÍODO DE } \\
\text { TEMPO E DO VDM CONSIDERADO }\end{array}$ & 5,67 & 2,33 & 24.062 & 31.249 & 0,41 & 1,30 & 375 & 177 & 201 & 177 & 24 & 0,88 & 0,88 & $12 \%$ & 19 & 0,0903 \\
\hline & & iv & $\begin{array}{l}\text { CALCULO CONSIDERANDO GRUPOS DE COMPARAÇÃO } \\
\text { PARA PERÍODO ANTES DO TRATAMENTO }\end{array}$ & & & & & & & & & 158 & 156 & 2 & 0,99 & 1,03 & $-3 \%$ & 18 & 0,2149 \\
\hline \multirow{4}{*}{12} & \multirow{4}{*}{$\begin{array}{c}\text { Rodovia SP075 } \\
\text { km } 66+000 \text { ao } \\
67+000- \\
\text { Campinas } \\
\text { Travessia de } \\
\text { Pedestres }\end{array}$} & $\mathrm{i}$ & $\begin{array}{l}\text { CALCULO ESTATÍSTICO CONSIDERANDO } \pi \text { COMO } \\
\text { TENDENCIA DOS VALORES ANTES DE } 3 \text { ANOS }\end{array}$ & & & & & & & & & 116 & 99 & 17 & 0,86 & 0,83 & $17 \%$ & 15 & 0,1126 \\
\hline & & ii & $\begin{array}{l}\text { CALCULO CONSIDERANDO A DURAÇÃO DO PERÍODO DE } \\
\text { TEMPO CONSIDERADO }\end{array}$ & & & & & & & & & 117 & 107 & 10 & 0,91 & 0,91 & $9 \%$ & 15 & 0,1207 \\
\hline & & iii & $\begin{array}{l}\text { CALCULO CONSIDERANDO A DURAÇ̃̃O DO PERÍODO DE } \\
\text { TEMPO E DO VDM CONSIDERADO }\end{array}$ & 6,92 & 1,08 & 36.514 & 47.201 & 0,16 & 1,29 & 749 & 107 & 152 & 107 & 45 & 0,71 & 0,70 & $30 \%$ & 16 & 0,0884 \\
\hline & & iv & $\begin{array}{l}\text { CALCULO CONSIDERANDO GRUPOS DE COMPARAÇÃO } \\
\text { PARA PERÍODO ANTES DO TRATAMENTO } \\
\end{array}$ & & & & & & & & & 116 & 99 & 17 & 0,86 & 0,87 & $13 \%$ & 15 & 0,1438 \\
\hline \multirow{4}{*}{13} & \multirow{4}{*}{$\begin{array}{c}\text { Rodovia SP075 } \\
\text { km 64+000 - } \\
\text { Campinas } \\
\text { Travessia de } \\
\text { Pedestres }\end{array}$} & i & $\begin{array}{l}\text { CALCULO ESTATÍ́STICO CONSIDERANDO } \pi \text { COMO } \\
\text { TENDENCIA DOS VALORES ANTES DE } 3 \text { ANOS }\end{array}$ & & & & & & & & & 29 & 19 & 10 & 0,66 & 0,64 & $36 \%$ & 7 & 0,1813 \\
\hline & & ii & $\begin{array}{l}\text { CALCULO CONSIDERANDO A DURAÇÃO DO PERÍODO DE } \\
\text { TEMPO CONSIDERADO }\end{array}$ & & & & & & & & & 99 & 89 & 10 & 0,90 & 0,89 & $11 \%$ & 14 & 0,1287 \\
\hline & & iii & $\begin{array}{l}\text { CALCULO CONSIDERANDO A DURAÇ̃̃o DO PERÍODO DE } \\
\text { TEMPO E DO VDM CONSIDERADO }\end{array}$ & 4,17 & 3,83 & 18.581 & 23.377 & 0,92 & 1,26 & 108 & 89 & 125 & 89 & 36 & 0,71 & 0,71 & $29 \%$ & 15 & 0,0974 \\
\hline & & iv & $\begin{array}{l}\text { CALCULO CONSIDERANDO GRUPOS DE COMPARAÇÃO } \\
\text { PARA PERÍODO ANTES DO TRATAMENTO }\end{array}$ & & & & & & & & & 363 & 273 & 90 & 0,75 & 0,78 & $22 \%$ & 25 & 0,1585 \\
\hline Consic & $\begin{array}{l}\text { iderações import } \\
\text { Os dados dos ac } \\
\text { Quando não se } \\
\text { Os estudos com } \\
\text { Os estudos com }\end{array}$ & $\begin{array}{l}\text { tantes } \\
\text { cident } \\
\text { conta } \\
\text { irefer } \\
\text { irefer }\end{array}$ & $\begin{array}{l}\text { st } \\
\text { tes recebidos que não contemplavam um ano inteiro fora } \\
\text { ava com dados ANTES de três ou mais anos, se adotou com } \\
\text { rencia i, ii, iii, correspondem ao método de comparação "a } \\
\text { rencia iv, correspondem ao método de comparação usand }\end{array}$ & $\begin{array}{l}\mathrm{m} \text { anualiz } \\
\text { no tendênc } \\
\text { antes - de } \\
\text { lo locais }\end{array}$ & $\begin{array}{l}\text { ados prop } \\
\text { cia o mesm } \\
\text { pois ingên } \\
\text { te referenc }\end{array}$ & $\begin{array}{l}\text { orcionalm } \\
\text { no valor do } \\
\text { uo" } \\
\text { ia ou grup }\end{array}$ & $\begin{array}{l}\text { nente para } \\
\text { o ano ante }\end{array}$ & $\begin{array}{l}\text { os meses } \\
\text { rior }\end{array}$ & faltantes; & & & & & & & & & & \\
\hline
\end{tabular}

Fonte: Base de Dados gerada pelo autor (2011) 
A partir destes resultados pode se inferir as seguintes considerações gerais:

- Não foi possível extrair conclusões ou resultados por rodovia, pois os casos analisados de cada uma diferem uns dos outros. Por este motivo optou-se por agrupar os resultados por tipo de solução aplicada, os que se apresentam nos itens seguintes.

- Verifica-se que o critério de cálculo do valor estimado de $\pi$ (número esperado de acidentes de uma entidade específica, em um período "depois" se não tivesse sido tratada) determina ou condiciona de forma significativa o resultado, motivo pelo qual é necessária a aplicação rigorosa do método.

- Quando mais variáveis medíveis sejam consideradas no cálculo, mais confiável será o resultado. Nas tabelas que apresentam de forma comparativa os diversos critérios utilizados na avaliação, se destacou na cor amarela o método que se considera como o de maior precisão para os dados processados. $\mathrm{O}$ mesmo se corresponde ao critério iii do método "antes - depois" ingênuo, o seja "Cálculo considerando a duração do período de tempo e o VDM considerado”.

- O cálculo baseado em grupos de comparação conduz a resultados consistentes com o método "antes - depois" ingênuo, porém com valores um pouco menores se medidos com a variável "redução de acidentes":

- Para todos os casos, o desvio-padrão para o método de grupos de comparação apresenta valores maiores que o do método ingênuo; isto devido a que no primeiro se introduz uma nova variável com sua correspondente variância: $r_{C}$.

\subsection{RESULTADOS DO MÉTODO “ANTES - DEPOIS” INGÊNUO}

Neste capitulo se apresentam os resultados específicos de cada tratamento analisado. Embora as intervenções aplicadas difiram ligeiramente umas de outras devido a que provem de diversas concessionárias, com seus correspondentes responsáveis técnicos e autonomia para aplicá-las conforme o critério de cada um, as mesmas se agruparam em função da solução mais importante dentre todas as medidas que, em conjunto, constituem a solução aplicada para resolver o problema de segurança do segmento rodoviário. 


\subsubsection{RESULTADOS PARA A SOLUÇÃO DO TIPO 1 - REDUÇÃO DE VELOCIDADE E OUTRAS MEDIDAS}

Se começa por aquele tratamento que deu origem ao tema da pesquisa, a Redução de velocidade, cujos resultados se apresentam na Tabela 5.6, seguidos dos comentários pertinentes. Salienta-se que este tipo de tratamento sempre vem acompanhado de outras ações complementárias que visam o real comprimento da nova velocidade regulamentada, as quais podem diferir ligeiramente caso a caso, conforme descritas no item 4.5.

TABELA 5. 6 - RESULTADOS PARA REDUÇÃO DE VELOCIDADE

\begin{tabular}{|c|c|c|c|c|c|c|c|c|c|c|c|c|c|c|c|c|c|}
\hline \multicolumn{11}{|c|}{ RESUMO POR TIPO DE SOLUÇÃO APLICADA } & \multicolumn{7}{|c|}{ RESULTADO MÉTODO "ANTES-DEPOIS" INGÊNUO } \\
\hline & LOCAL & TRATAMENTO & $\begin{array}{c}\text { Tempo } \\
\text { antes } \\
\text { (ano) }\end{array}$ & \begin{tabular}{|l|} 
Tempo \\
depois \\
(ano)
\end{tabular} & \begin{tabular}{|c|} 
VDM \\
antes
\end{tabular} & \begin{tabular}{|c|} 
VDM \\
depois
\end{tabular} & $\begin{array}{c}\mathrm{rd}= \\
\mathrm{Td} / \mathrm{Ta}\end{array}$ & $\begin{array}{c}\mathrm{rtt}= \\
\mathrm{Vd} / \mathrm{Va}\end{array}$ & $\mathrm{k}$ & $\mathrm{L}$ & $\pi$ & $\lambda$ & $\delta=\pi-\lambda$ & $\theta^{\prime}$ & $\begin{array}{c}\text { Redução } \\
1-\theta^{\prime}\end{array}$ & $\sigma(\delta)$ & $\sigma(\theta)$ \\
\hline 1 & $\begin{array}{c}\text { Rodovia SP310 } \\
\text { Km 172 ao } 177 \\
\text { Travessia } \\
\text { Urbana de Rio } \\
\text { Claro }\end{array}$ & $\begin{array}{c}\text { REDDCÇĀO DE VELOCIDADE DE } \\
1110 \text { A } 90 \text { KM/H } \\
\text { Realizado em Janoo }\end{array}$ & 2,00 & 8,83 & 15.274 & 21.461 & 4,42 & 1,41 & 161 & 667 & 999 & 667 & 332 & 0,66 & $33,6 \%$ & 41 & 0,033 \\
\hline 5 & $\begin{array}{c}\text { Rodovia SP300 } \\
\text { km 68+500 ao } \\
69+500 \text { - Jundiaí } \\
\text { Travessia de } \\
\text { Pedestres }\end{array}$ & 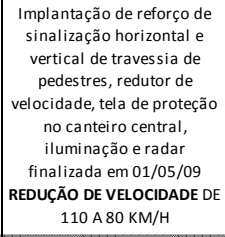 & 6,33 & 1,67 & 26.717 & 20.069 & 0,26 & 0,75 & 96 & 15 & 19 & 15 & 4 & 0,76 & $23,8 \%$ & 6 & 0,252 \\
\hline 8 & $\begin{array}{l}\text { Rodovia SP } 225 \\
\text { Km 177 ao } 185 \\
\text { Travessia } \\
\text { Urbana de Jau }\end{array}$ & $\begin{array}{c}\text { Após estudo óécnico, a } \\
\text { velocidade foi reduzida de } \\
110 \mathrm{~km} / \mathrm{h} \text { para } 90 \mathrm{~km} / \mathrm{h} \mathrm{em} \\
\mathrm{jan} / 2009 .\end{array}$ & 7,00 & 2,00 & 16.786 & 28.014 & 0,29 & 1,67 & 538 & 183 & 257 & 183 & 74 & 0,71 & $28,8 \%$ & 21 & 0,069 \\
\hline 12 & $\begin{array}{c}\text { Rodovia SP075 } \\
\text { km 66+000 ao } \\
67+000- \\
\text { Campinas } \\
\text { Travessia de } \\
\text { Pedestres }\end{array}$ & 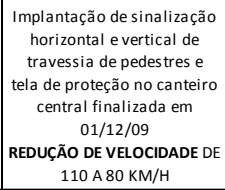 & 6,92 & 1,08 & 36.514 & 47.201 & 0,16 & 1,29 & 749 & 107 & 152 & 107 & 45 & 0,70 & $29,5 \%$ & 16 & 0,088 \\
\hline \multicolumn{9}{|c|}{4,00} & 1.544 & 972 & 1.426 & 972 & 454 & 0,68 & $31,9 \%$ & 49 & 0,028 \\
\hline
\end{tabular}

Fonte: Base de Dados gerada pelo autor (2011)

- Observam-se resultados positivos para todos os casos, com valores variando, se medidos com a variável redução dos acidentes registrados, entre $24 \%$ a $34 \%$. Se calculado este valor para o conjunto dos quatro casos analisados obtemos um valor de redução de acidentes totais de $31,9 \%$ com um desvio padrão de $\pm 2,8$.

- Se forem comparados os resultados destes casos onde se aplicou um tratamento de restrição de velocidade em área urbana, com os dados fornecidos pela bibliografia consultada para este tipo de tratamento - na Tabela 5.7 pode ser observado que se apresenta consiste. No obstante, não se pode comentar este fato como conclusivo. 
Para tanto se deveriam considerar as particularidades de cada estudo, o que foge ao escopo do presente estudo, e contar com um número maior de casos.

- O resultado obtido para a eficácia da redução de velocidade é o esperado. Intuitivamente esperamos um elevado grau de eficácia deste tipo de solução na redução de acidentes. Porém, se desconhecia a sua magnitude. O presente trabalho vem a oferecer números e dados concretos para quatro casos analisados. Espera-se que seja uma contribuição importante para aprofundar análises deste tipo no futuro.

TABELA 5. 7- EFEITO DE DISPOSITIVOS REDUTORES DE VELOCIDADE NA REDUÇÃO DO NÚMERO DE ACIDENTES

\begin{tabular}{|c|c|c|c|}
\hline \multicolumn{4}{|c|}{ Efeito de dispositivos redutores de velocidade nos acidentes } \\
\hline \multirow{2}{*}{$\begin{array}{l}\text { Tratamento } \\
\text { Severidade do acidente }\end{array}$} & \multicolumn{3}{|c|}{ Mudança percentual no número de acidentes } \\
\hline & Tipos de acidentes afetados & $\begin{array}{c}\text { Melhor } \\
\text { estimativa }\end{array}$ & $\begin{array}{c}\text { Intervalo de } \\
\text { confiança de } \\
95 \%\end{array}$ \\
\hline \multicolumn{4}{|l|}{ Lombadas } \\
\hline Acidentes com feridos & $\begin{array}{c}\text { Todos os acidentes em estradas } \\
\text { com lombadas }\end{array}$ & -41 & $(-57 ;-34)$ \\
\hline Acidentes com feridos & $\begin{array}{l}\text { Todos os acidentes em estradas } \\
\text { próximas a estradas com lombadas }\end{array}$ & -7 & $(-14 ;-0)$ \\
\hline \multicolumn{4}{|l|}{ Cruzamentos em desnível } \\
\hline Acidentes com feridos & Acidentes no cruzamento & 5 & $(-34 ;+68)$ \\
\hline $\begin{array}{l}\text { Acidentes com danos } \\
\text { materiais }\end{array}$ & Acidentes no cruzamento & 13 & $(-55 ;+183)$ \\
\hline \multicolumn{4}{|c|}{ Sonorizadores na frente de cruzamentos } \\
\hline Acidentes com feridos & Acidentes no cruzamento & -33 & $(-40 ;-25)$ \\
\hline $\begin{array}{l}\text { Acidentes com danos } \\
\text { materiais }\end{array}$ & Acidentes no cruzamento & -25 & $(-45 ;-5)$ \\
\hline Não especificado & Acidentes no cruzamento & -20 & $(-25 ;-5)$ \\
\hline \multicolumn{4}{|c|}{ Área com restrição de velocidade } \\
\hline Acidentes com feridos & Todos os acidentes & -27 & $(-30 ;-24)$ \\
\hline $\begin{array}{l}\text { Acidentes com danos } \\
\text { materiais }\end{array}$ & Todos os acidentes & -16 & $(-19 ;-12)$ \\
\hline
\end{tabular}

Fonte: ELVIK et AL (2004).

\subsubsection{RESULTADOS PARA A SOLUÇÃO DO TIPO 2 - IMPLANTAÇÃO DE DEFESA NEW JERSEY ELEVADA}

A análise deste tipo de tratamento resultou em valores diferentes aos esperados conforme se apresenta na Tabela 5.8, motivo pelo qual se procurou investigar as causas que 
contribuíram para este resultado. Tratam-se das travessias urbanas da Rodovia SP310 nas cidades de Rio Claro e São Carlos. Ambos locais apresentam ao longo de toda a extensão da defesa, manchas urbanas aos lados da rodovia, comunicadas através de passarelas, passagens inferiores e superiores. Na Figura 5.1 a seguir se mostra a defesa implantada em Rio Claro.

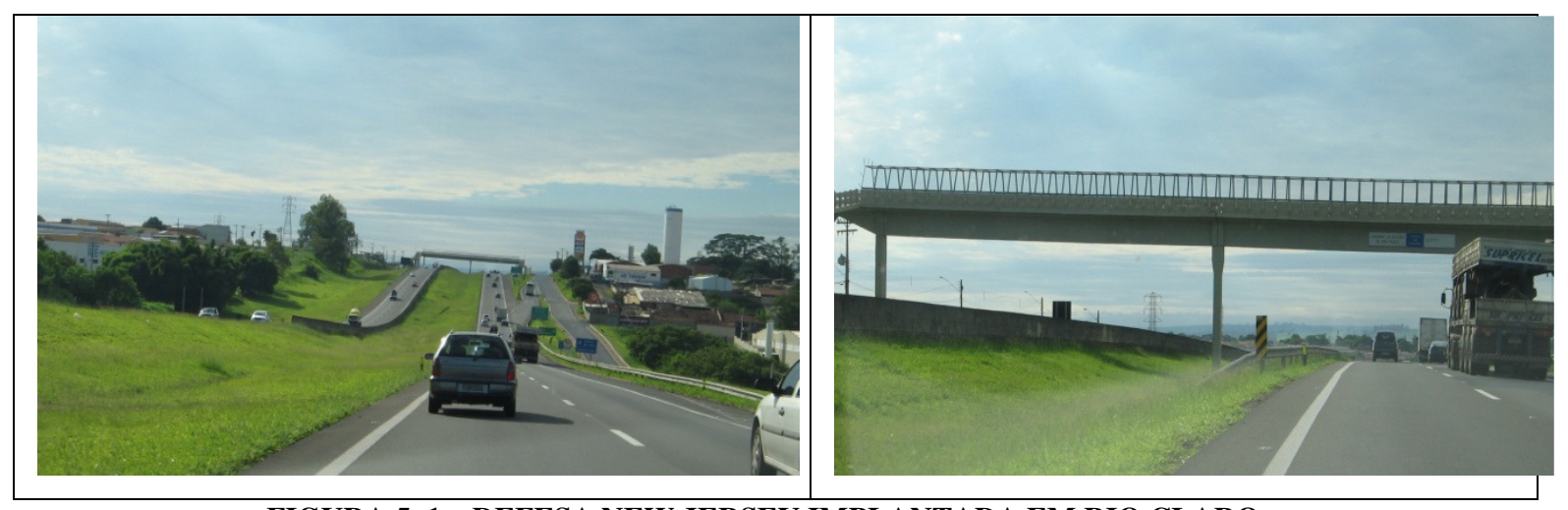

FIGURA 5. 1 - DEFESA NEW JERSEY IMPLANTADA EM RIO CLARO

Fonte: Base de Dados gerada pelo autor (2011)

Embora não se constatou no dia da visita ao local é possível que os vizinhos destas áreas urbanas ainda usem a rodovia para atravessar em nível, saltando a defesa em locais inconvenientes, ou atravessando no local onde a mesma se interrompe, evitando desta forma percursos mais compridos. Esta atitude, que coloca em risco a própria vida do pedestre, pode estar conspirando contra a redução dos acidentes no local. Porém, para confirmar esta suposição, precisa realizar-se uma análise mais detalhada dos acidentes contabilizados, o que foge ao escopo do trabalho. Certamente uma maneira mais correta de esclarecer estes casos seja analisar os acidentes de forma segregada, verificando se existe diminuição dos atropelamentos em desmedro do aumento de outros, comuns em áreas urbanas adjacentes à rodovia (a exemplo de colisões no momento do ingresso de veículos da cidade a baixa velocidade em rodovia que permitem uma elevada velocidade de circulação). 
TABELA 5. 8- RESULTADOS PARA A SOLUÇÃO IMPLANTAÇÃO DE DEFESA NEW JERSEY ELEVADA

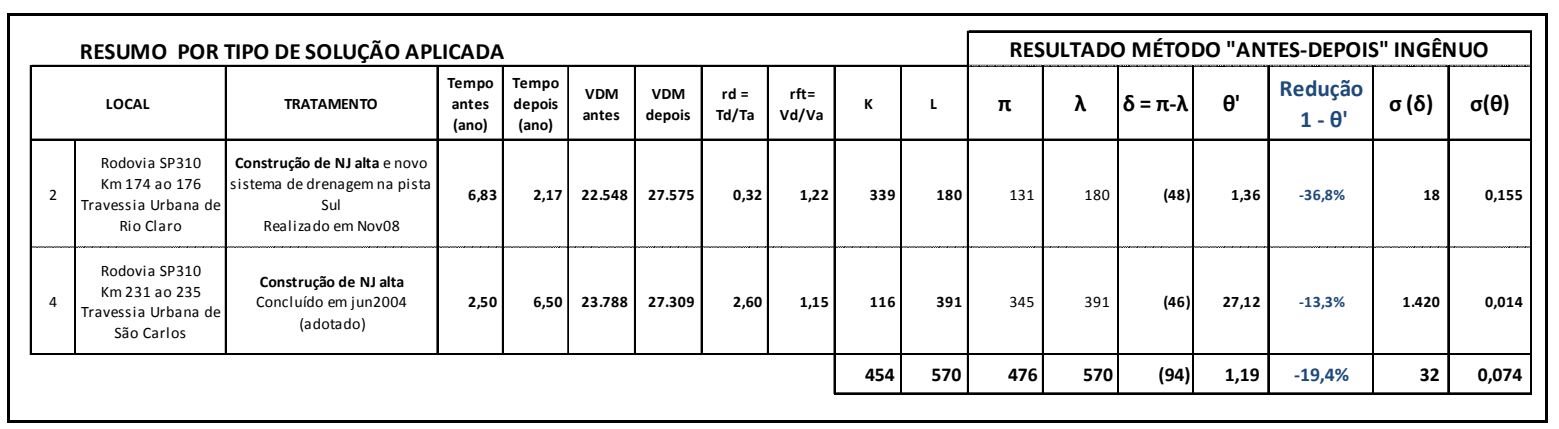

Fonte: Base de Dados gerada pelo autor (2011)

- Considerando o comentário anterior, se conclui que esta solução, analisada a partir do método "antes - depois" ingênuo, apresenta resultados negativos com aumento de $19,4 \%$ e desvio padrão de $\pm 7,4 \%$ para os dois casos analisados, o que significa que longe de ser eficaz, foi contraproducente.

- Deve aprofundar-se a análise antes de emitir parecer firme a respeito desta solução.

- Comenta-se para o caso de Rio Claro, onde junto à implantação da defesa se realizou uma obra de drenagem visando impedir o acumulo de água que chegava a transbordar invadindo a pista e colocando em risco aos usuários do trecho, que esta ação não apresentou melhoria conforme resultados alcançados. Porem, é opinião do autor deste trabalho que a avaliação desta ação deveria ser estudada de forma segregada e restrita a um evento de fortes chuvas, em duração e intensidade, que repetissem a circunstância pela qual a solução foi implementada. Somente nestas condições se poderia aplicar o método de análise "antes - depois" ingênuo sem gerar distorções na análise.

\subsubsection{RESULTADOS PARA A SOLUÇÃO DO TIPO 3 - CONSTRUÇÃO DE NOVO DISPOSITIVO DE ACESSO}

Antes de apresentar o resultado deste caso, se observa que os dados processados e que conduzem aos resultados seguintes são provenientes da soma de acidentes de todo o segmento da travessia urbana de Cordeirópolis, sem maior analise de sua classificação por tipo ou local dentro do mesmo. Isto foi considerado assim pela dificuldade de identificar o beneficio que uma intervenção maior (obra em análise) produz no entorno como um todo e na convicção de 
que esta é a melhor forma de considerá-lo. De fato, o efeito da obra repercute no movimento veicular de toda a cidade que passa a adotar novos percursos oferecidos pela existência da nova opção. Exemplo disto é a diminuição de fluxo de veículos, e com isto do congestionamento, que se verificava no único dispositivo de acesso à cidade que existia antes.

TABELA 5. 9- RESULTADOS PARA A SOLUÇÃO CONSTRUÇÃO DE NOVO DISPOSITIVO DE ACESSO

\begin{tabular}{|c|c|c|c|c|c|c|c|c|c|c|c|c|c|c|c|c|c|}
\hline \multicolumn{11}{|c|}{ RESUMO POR TIPO DE SOLUÇÃO APLICADA } & \multicolumn{7}{|c|}{ RESULTADO MÉTODO "ANTES-DEPOIS" INGÊNUO } \\
\hline & LOCAL & TRATAMENTO & $\begin{array}{c}\text { Tempo } \\
\text { antes } \\
\text { (ano) }\end{array}$ & $\begin{array}{l}\text { Tempo } \\
\text { depois } \\
\text { (ano) }\end{array}$ & $\begin{array}{l}\text { VDM } \\
\text { antes }\end{array}$ & $\begin{array}{l}\text { VDM } \\
\text { depois }\end{array}$ & $\begin{array}{c}\mathrm{rd}= \\
\mathrm{Td} / \mathrm{Ta}\end{array}$ & $\begin{array}{c}\mathrm{rtrt}= \\
\mathrm{va} / \mathrm{va}\end{array}$ & k & $\mathrm{L}$ & $\pi$ & $\lambda$ & $\delta=\pi-\lambda$ & $\theta^{\prime}$ & $\begin{array}{c}\text { Redução } \\
1-\theta^{\prime}\end{array}$ & $\sigma(\delta)$ & $\sigma(\theta)$ \\
\hline 3 & \begin{tabular}{|c} 
Rodovia SP310 \\
Km 159 ao 161 \\
Travessia Urbana \\
de Cordeirópolis
\end{tabular} & \begin{tabular}{|c} 
Construção de mais 1 \\
dispositivo de acesso no \\
Km $161+200$ \\
Concluido em Set08
\end{tabular} & 6,75 & 2,25 & 21.309 & 27.386 & 0,33 & 1,29 & 238 & 75 & 102 & 75 & 27 & 0,74 & $26,1 \%$ & 13 & 0,111 \\
\hline & & & & & & & & & 238 & 75 & 102 & 75 & 27 & 0,74 & $26,1 \%$ & 13 & 0,111 \\
\hline
\end{tabular}

Fonte: Base de Dados gerada pelo autor (2011)

- Obteve-se um resultado satisfatório, de certa forma esperado. O mesmo vem a fornecer valores concretos de redução dos índices de acidentes pela aplicação de investimentos pesados em dispositivos de cruzamentos a distinto nível, com controle de acesso, constituindo uma boa referencia para posteriores analises.

- Observa-se que os períodos antes e depois de analise são extensos o suficiente como para oferecer um resultado representativo e confiável, sendo expressivo também o numero de acidentes processados.

- Verificou que a solução adotada neste caso, seguramente motivada na busca de maior mobilidade para a cidade ao invés de resolver um problema de segurança, teve a virtude de ajudar também neste último requisito resultando numa redução de acidentes da ordem de $26,1 \% \pm 11,1 \%$.

\subsubsection{RESULTADOS PARA A SOLUÇÃO DO TIPO 4 - CRUZAMENTO DE PEDESTRE EM NÍVEL EM ÁREA ESPECIALMENTE DEMARCADA}

O tratamento aqui considerado se corresponde com alguns dos mesmos casos já considerados na solução Tipo 1, sendo que o trabalho realizado para canalizar a passagem dos pedestres por um único local com sinalização ostensiva, que alerta aos condutores dos veículos que se encontram em um local onde pode se encontrar com pedestres cruzando na 
sua frente merece que seja considerado como solução em sim mesmo, desagregada da redução de velocidade (que também acontece como parte importante da solução).

Trata-se de solução que numa primeira impressão poderia ser considerada inadequada. O cruzamento de pedestres em nível em rodovias de pista dupla de alta velocidade não é desejável. A aplicação desta solução é resultado da busca de alternativas técnicas de menor custo para os casos em que o número de pedestres que se valem deste cruzamento é pouco para justificar a realização de um investimento maior do tipo passarela

Em visita realizada pelo autor a trechos onde foi aplicado este tipo de solução verificou-se detalhes a serem melhorados em próximas implementações deste tipo de solução. Trata-se da localização da placa final indicando o local do cruzamento dos pedestres. A mesma, por tamanho e local de instalação, pode vir a ocultar aos mesmos pedestres que se pretende proteger, dificultando a visão dos motoristas em caso que um pedestre intente o cruzamento sem o devido cuidado de esperar o melhor momento para realizá-lo. A Figura 5.2 exemplifica o comentário acima, que se realiza sem animo de crítica, más como melhoria a ser analisada e considerada.

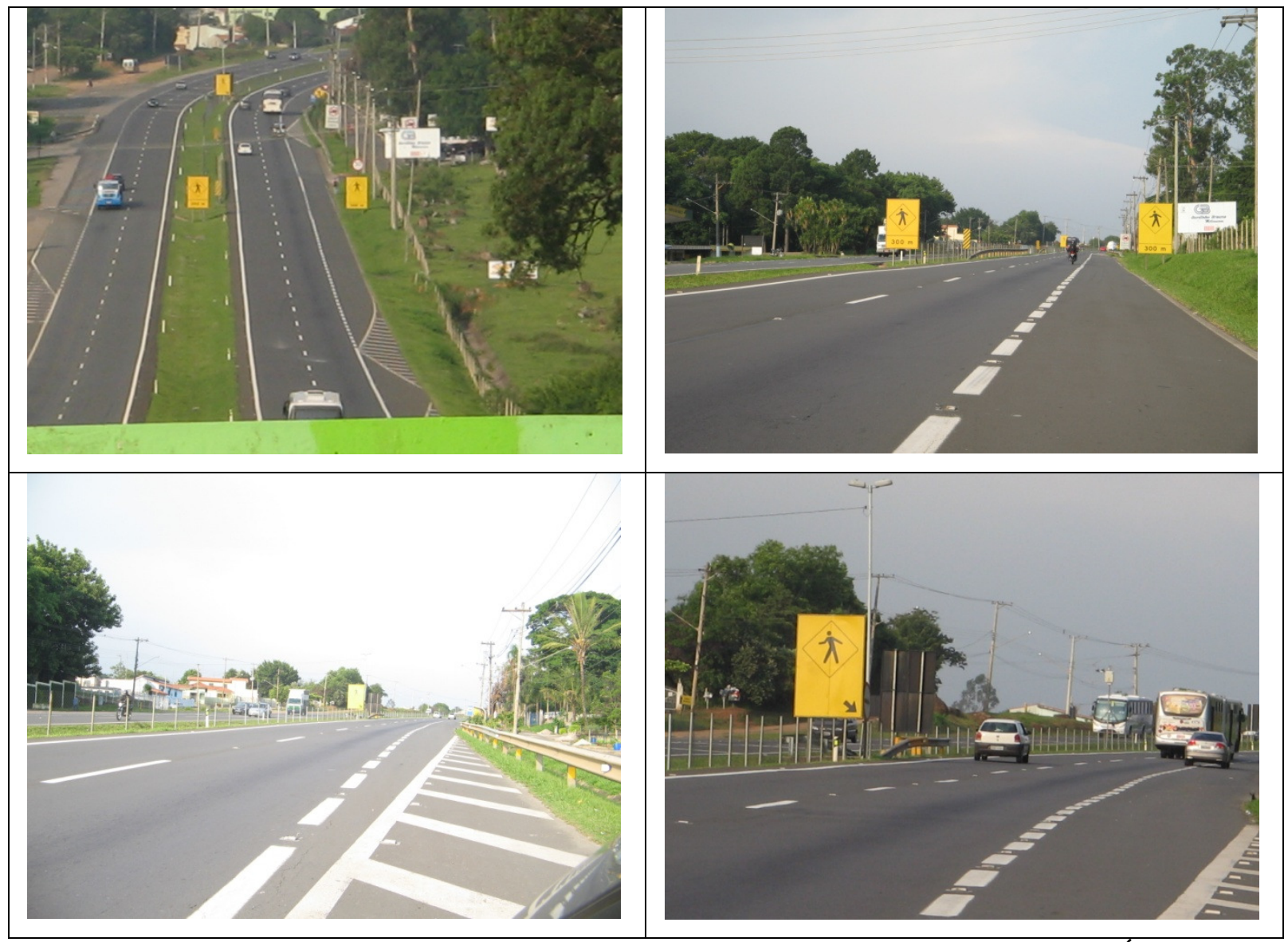

FIGURA 5. 2- LOCAL DE TRATAMENTO PARA CRUZAMENTO DE PEDESTRES EM NÍVEL

Fonte: Base de Dados gerada pelo autor (2011) 


\begin{tabular}{|c|c|c|c|c|c|c|c|c|c|c|c|c|c|c|c|c|c|}
\hline \multicolumn{11}{|c|}{ RESUMO POR TIPO DE SOLUÇÃO APLICADA } & \multicolumn{7}{|c|}{ RESULTADO MÉTODO "ANTES-DEPOIS" INGÊNUO } \\
\hline & LOCAL & TRATAMENTO & \begin{tabular}{|c|} 
Tempo \\
antes \\
(ano)
\end{tabular} & \begin{tabular}{|c|}
$\begin{array}{c}\text { Tempo } \\
\text { depois } \\
\text { (ano) }\end{array}$ \\
\end{tabular} & \begin{tabular}{|c|} 
VDM \\
antes
\end{tabular} & $\begin{array}{c}\text { vDM } \\
\text { depois }\end{array}$ & $\begin{array}{c}\mathrm{rd}= \\
\mathrm{Td} / \mathrm{Ta}\end{array}$ & \begin{tabular}{|l}
$\mathrm{rrt=}$ \\
$\mathrm{vd} / \mathrm{va}$
\end{tabular} & к & $\mathrm{L}$ & $\pi$ & $\lambda$ & $\delta=\pi-\lambda$ & $\theta^{\prime}$ & $\begin{array}{c}\text { Redução } \\
1 \text { - } \theta^{\prime}\end{array}$ & $\sigma(\delta)$ & $\sigma(\theta)$ \\
\hline 5 & \begin{tabular}{|c|} 
Rodovia SP300 km \\
$68+500$ ao $69+500$ \\
Jundiai \\
Travessia de \\
Pedestres
\end{tabular} & 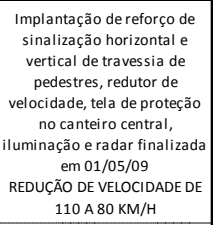 & 6,33 & 1,67 & |26.717 & 20.069 & 0,26 & 0,75 & 96 & 15 & 19 & 15 & 4 & 0,76 & $23,8 \%$ & 6 & 0,252 \\
\hline 12 & \begin{tabular}{|c} 
Rodovia SPO75 km \\
$66+000$ ao $67+000$ \\
Campinas \\
Travessia de \\
Pedestres
\end{tabular} & 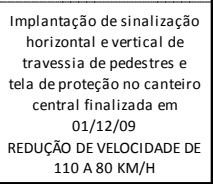 & 6,92 & 1,08 & |36.514 & 47.201 & 0,16 & 1,29 & 749 & 107 & 152 & 107 & 45 & 0,70 & $29,5 \%$ & 16 & 0,088 \\
\hline & & & & & & & & & 845 & 122 & 171 & 122 & 49 & 0,71 & $29,0 \%$ & 17 & 0,084 \\
\hline
\end{tabular}

Fonte: Base de Dados gerada pelo autor (2011)

- Obteve-se um resultado satisfatório com um valor de redução médio de acidentes de $29 \% \pm 8,4 \%$, certamente elevado, se comparado com a expectativa de valores negativos.

- Embora um dos casos apresente valores de redução de $24 \%$, a média melhora muito pelo fato do segundo caso contar com um número maior de dados.

- Sendo os casos analisados, somente dois, e embora ambos apresentem resultados positivos, recomendam-se maiores avaliações antes de manifestar-se pela conveniência técnica desta solução ao problema que se procura resolver.

\subsubsection{RESULTADOS PARA A SOLUÇÃO DO TIPO 5 - IMPLANTAÇÃO DE PASSARELA}

Este tipo de solução é sugerido pela técnica como o melhor para evitar os acidentes derivados do cruzamento de pedestres em vias duplas de alto trânsito. Não obstante isto se observou um resultado negativo para um dos casos analisados. Esta situação muitas vezes acontece na prática porque se descuidam na implantação da solução fatores importantes como a origem e destino das viagens destes pedestres, o acréscimo significativo no percurso a ser desenvolvido pelos pedestres para usar a passarela, a não adoção de elementos que impeçam ou dificultam a passagem em nível, entre outros. Curioso por averiguar os motivos deste resultado para o caso em questão se procedeu a visitar o local, que se mostra Figura 5.3. 
Observa-se que o local de emprazamento da passarela coincide com um dispositivo de entroncamento de duas importantes rodovias: a SP-300 e a Rod. Vice Pref. Hermenegildo Tonoli, que comunica a Itupeva. Permite, ainda, acessar a um bairro populoso em forte crescimento, denominado Eloy Chaves, que pode observar-se na primeira foto da Figura 5.3.

Este entroncamento apresenta um fluxo enorme de veículos e pedestres circulando em todas as direções. Pode-se deduzir que o recente aumento do movimento de veículos neste local, sem captura-se este efeito no VDM considerado, conjuntamente com o maior volume de pedestres, resultado do pujante crescimento populacional do local, também não capturado pelos dados em processamento, tem prejudicado o resultado desta solução. Este caso demandaria uma análise detalhada, que esta fora do escopo deste trabalho. Por este motivo, optou-se por apresentar os resultados médios com e sem este caso.

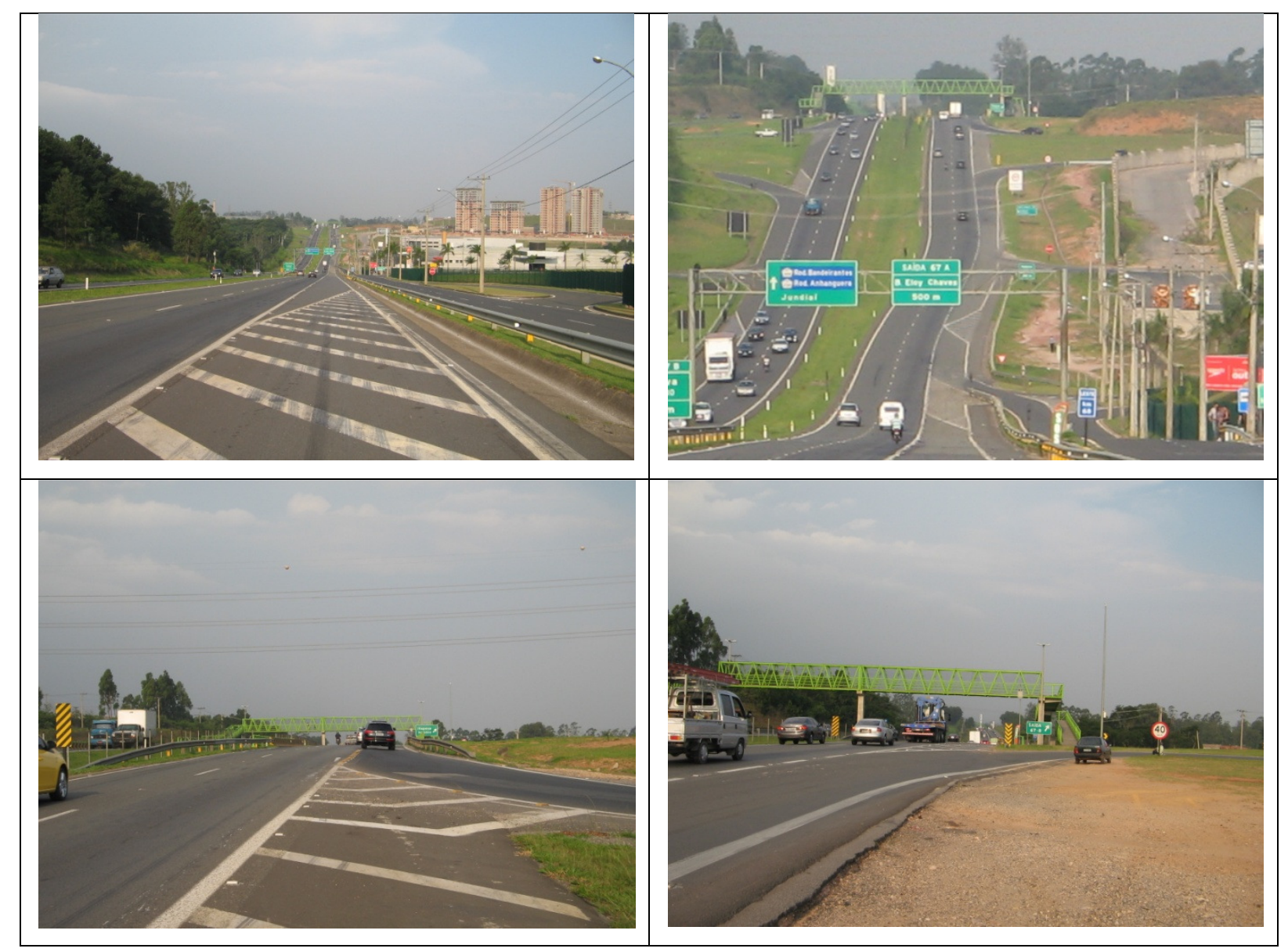

FIGURA 5.3 - PASSARELA DO KM 67 DA SP-300

Fonte: Base de Dados gerada pelo autor (2011) 
TABELA 5. 11 - RESULTADOS PARA A SOLUÇÃO IMPLANTAÇÃO DE PASSARELA

\begin{tabular}{|c|c|c|c|c|c|c|c|c|c|c|c|c|c|c|c|c|c|}
\hline \multicolumn{11}{|c|}{ RESUMO POR TIPO DE SOLUÇÃO APLICADA } & \multicolumn{7}{|c|}{ RESULTADO MÉTODO "ANTES-DEPOIS" INGÊNUO } \\
\hline & LOCAL & TRATAMENTO & \begin{tabular}{|c|} 
Tempo \\
antes \\
(ano)
\end{tabular} & \begin{tabular}{|l|} 
Tempo \\
depois \\
(ano)
\end{tabular} & $\begin{array}{c}\text { VDM } \\
\text { antes }\end{array}$ & \begin{tabular}{|c|} 
VDM \\
depois
\end{tabular} & $\begin{array}{l}\mathrm{rd}= \\
\mathrm{Td} / \mathrm{Ta}\end{array}$ & $\begin{array}{c}\mathrm{rtt}= \\
\mathrm{Vd} / \mathrm{Va}\end{array}$ & $\mathrm{k}$ & $\mathrm{L}$ & $\pi$ & $\lambda$ & $\delta=\pi-\lambda$ & $\theta^{\prime}$ & $\begin{array}{c}\text { Redução } \\
1 \text { - } \theta^{\prime}\end{array}$ & $\sigma(\delta)$ & $\sigma(\theta)$ \\
\hline 6 & $\begin{array}{c}\text { Rodovia SP300 km } \\
67+000-\text { Jundiaí } \\
\text { Travessia de } \\
\text { Pedestres }\end{array}$ & $\begin{array}{l}\text { Construção de Passarela } \\
\text { Finali izada em } 02 / 03 / 07\end{array}$ & 4,17 & 3,83 & 29.169 & 23.775 & 0,92 & 0,82 & 112 & 107 & 84 & 107 & (23) & 1,26 & $-26,3 \%$ & 14 & 0,182 \\
\hline 7 & $\begin{array}{c}\text { Rodovia SP } 300 \mathrm{~km} \\
82+000 \text { - Cabreuva } \\
\text { Travessia de } \\
\text { Pedestres }\end{array}$ & $\begin{array}{l}\text { Construção de Passarela } \\
\text { Finalizada em } 02 / 09 / 06\end{array}$ & 3,67 & 4,33 & 10.255 & 12.274 & 1,18 & 1,20 & 84 & 72 & 119 & 72 & 47 & 0,60 & $40,1 \%$ & 14 & 0,08 \\
\hline 10 & $\begin{array}{c}\text { Rodovia SP127 km } \\
88+000 \text { - Cerquilho } \\
\text { Travessia de } \\
\text { Pedestres }\end{array}$ & $\begin{array}{l}\text { Construção de Passarela } \\
\text { Finali izada em } 02 / 03 / 07\end{array}$ & 4,17 & 3,83 & 4.893 & 7.003 & 0,92 & 1,43 & 45 & 20 & 60 & 20 & 40 & 0,32 & $67,8 \%$ & 9 & 0,082 \\
\hline 13 & $\begin{array}{c}\text { Rodovia SP075 km } \\
64+000 \text { - Campinas } \\
\text { Travessia de } \\
\text { Pedestres }\end{array}$ & $\begin{array}{l}\text { Construção de Passarela } \\
\text { Finalizada em } 02 / 03 / 07\end{array}$ & 4,17 & 3,83 & 18.581 & 23.377 & 0,92 & 1,26 & 108 & 89 & 125 & 89 & 36 & 0,71 & $29,2 \%$ & 15 & 0,097 \\
\hline & & & & & & & & & 349 & 288 & 387 & 288 & 99 & 0,74 & $25,8 \%$ & 26 & 0,058 \\
\hline
\end{tabular}

Fonte: Base de Dados gerada pelo autor (2011)

Os valores obtidos para os quatros casos analisados deste tipo de solução são apresentados na Tabela 5.11, sendo que a Tabela 5.12 apresenta o resultado médio desconsiderando o caso especial acima mencionado.

TABELA 5. 12 - RESULTADOS PARA A SOLUÇÃO IMPLANTAÇÃO DE PASSARELA SEM CASO 6

\begin{tabular}{|c|c|c|c|c|c|c|c|c|c|c|c|c|c|c|c|c|c|}
\hline \multicolumn{11}{|c|}{ RESUMO POR TIPO DE SOLUÇÃO APLICADA } & \multicolumn{7}{|c|}{ RESULTADO MÉTODO "ANTES-DEPOIS" INGÊNUO } \\
\hline & LOCAL & TRATAMENTO & \begin{tabular}{|c|} 
Tempo \\
antes \\
(ano)
\end{tabular} & \begin{tabular}{|c|}
$\begin{array}{c}\text { Tempo } \\
\text { depois } \\
\text { (ano) }\end{array}$ \\
\end{tabular} & $\begin{array}{l}\text { VDM } \\
\text { antes }\end{array}$ & $\begin{array}{l}\text { VDM } \\
\text { depois }\end{array}$ & $\begin{array}{l}\mathrm{rd}= \\
\mathrm{Td} / \mathrm{Ta}\end{array}$ & $\begin{array}{c}\mathrm{rtt} \\
\mathrm{vad} / \mathrm{va}\end{array}$ & $\mathrm{k}$ & $\mathrm{L}$ & $\pi$ & $\lambda$ & $\delta=\pi-\lambda$ & $\theta^{\prime}$ & $\begin{array}{c}\text { Redução } \\
1-\theta^{\prime}\end{array}$ & $\sigma(\delta)$ & $\sigma(\theta)$ \\
\hline 7 & $\begin{array}{c}\text { Rodovia SP } 300 \mathrm{~km} \\
\text { 82+000 - Cabreuva } \\
\text { Travessia de } \\
\text { Pedestres }\end{array}$ & $\begin{array}{l}\text { Construçăo de Passarela } \\
\text { Finalizada em } 02 / 09 / 106\end{array}$ & 3,67 & 4,33 & 10.255 & 12.274 & 1,18 & 1,20 & 84 & 72 & 119 & 72 & 47 & 0,60 & $40,1 \%$ & 14 & 0,085 \\
\hline 10 & $\begin{array}{l}\text { Rodovia SP127 km } \\
88+000 \text { - Cerquilho } \\
\text { Travessia de } \\
\text { Pedestres }\end{array}$ & $\begin{array}{l}\text { Construçöo de Passarela } \\
\text { Finalizada em } 02 / 03 / 07\end{array}$ & 4,17 & 3,83 & 4.893 & 7.003 & 0,92 & 1,43 & 45 & 20 & 60 & 20 & 40 & 0,32 & $67,8 \%$ & 9 & 0,082 \\
\hline 13 & $\begin{array}{c}\text { Rodovia SP075 km } \\
64+000 \text { - Campinas } \\
\text { Travessia de } \\
\text { Pedestres }\end{array}$ & $\begin{array}{l}\text { Construçăo de Passarela } \\
\text { Finalizada em } 02 / 03 / 07\end{array}$ & 4,17 & 3,83 & 18.581 & 23.377 & 0,92 & 1,26 & 108 & 89 & 125 & 89 & 36 & 0,71 & $29,2 \%$ & 15 & 0,097 \\
\hline & & & & & & & & & 237 & 181 & 303 & 181 & 122 & 0,60 & $40,5 \%$ & 22 & 0,0557 \\
\hline
\end{tabular}

Fonte: Base de Dados gerada pelo autor (2011)

- O resultado médio para os quatro casos é de uma redução de $25,8 \%$ no numero de acidentes totais, sendo que este valor se elava para 40,5\%, caso não se considere o caso 6 .

- É opinião do autor que este último dado é o que deve ser considerado como o resultado correto da análise realizada neste trabalho.

- Pode, então, ser verificado que se trata de uma solução conveniente do ponto de vista da segurança. 


\subsubsection{RESULTADOS PARA A SOLUÇÃO DO TIPO 6 - IMPLANTAÇÃO DE CICLOVIA}

Aplicou-se o método "antes - depois" ingênuo a este tipo de solução por que se contava com uma base de dados completa e confiável. Como acontecem com a solução tipo 3,construção de novo dispositivo de acesso, se consideram os dados de acidentes que acontecem ao longo de toda a extensão da ciclovia sem questionar as características dos mesmos. Vale destacar que o resultado alcançado, por ser fundamentado num único exemplo deste tipo de solução e sem dados desagregados por tipo de acidente, especificamente aqueles do tipo atropelamento de ciclistas, não poderá ser considerado como conclusivo.

TABELA 5. 13 - RESULTADOS PARA A SOLUÇÃO IMPLANTAÇÃO DE CICLOVIA

\begin{tabular}{|c|c|c|c|c|c|c|c|c|c|c|c|c|c|c|c|c|c|}
\hline \multicolumn{11}{|c|}{ RESUMO DE RESULTADOS POR TIPO DE SOLUÇÃO APLICADA } & \multicolumn{7}{|c|}{ RESULTADO MÉTODO "ANTES-DEPOIS" INGÊNUO } \\
\hline & LOCAL & TRATAMENTO & \begin{tabular}{|c|}
$\begin{array}{c}\text { Tempo } \\
\text { antes } \\
\text { (ano) }\end{array}$ \\
\end{tabular} & \begin{tabular}{|l|} 
Tempoo \\
depois \\
(ano)
\end{tabular} & $\begin{array}{l}\text { VDM } \\
\text { antes }\end{array}$ & $\begin{array}{c}\text { VDM } \\
\text { depois }\end{array}$ & $\begin{array}{c}\mathrm{rd}= \\
\mathrm{Td} / \mathrm{Ta}\end{array}$ & \begin{tabular}{|l|}
$\mathrm{rrt}=$ \\
$\mathrm{vd} / \mathrm{va}$
\end{tabular} & k & L & $\pi$ & $\lambda$ & $\delta=\pi-\lambda$ & $\theta^{\prime}$ & \begin{tabular}{|c|} 
Redução \\
$1-\theta^{\prime}$
\end{tabular} & $\sigma(\delta)$ & $\sigma(\theta)$ \\
\hline 9 & $\begin{array}{c}\text { Rodovia SP127 km } \\
0 \text { ao } 3+000 \text { - } \text { - Rio } \\
\text { Claro } \\
\text { Ciclistas e } \\
\text { Pedestres na Pista }\end{array}$ & $\begin{array}{l}\text { Construção de Ciclovia } \\
\text { finalizada em 01/12/06 }\end{array}$ & 3,92 & 4,08 & 6.754 & 9.427 & 1,04 & 1,40 & 232 & 235 & 337 & 235 & 102 & 0,69 & $30,5 \%$ & 24 & 0,059 \\
\hline & & & & & & & & & 232 & 235 & 337 & 235 & 102 & 0,69 & $30,5 \%$ & 24 & 0,059 \\
\hline
\end{tabular}

Fonte: Base de Dados gerada pelo autor (2011)

- O resultado obtido para este caso é de uma redução de $30,5 \% \pm 5,90 \%$ no número de acidentes totais.

\subsubsection{RESULTADOS PARA A SOLUÇÃO DO TIPO 7 - IMPLANTAÇÃO DE PASSAGEM SUPERIOR E TELA PROTETORA PARA IMPEDIR O CRUZAMENTO DE PEDESTRES EM NÍVEL}

Vale para este caso o que foi dito no item anterior. O seja, o valor obtido, de $12 \%$, com um desvio padrão de $9 \%$, na redução do número de acidentes totais, é uma primeira referência para este tipo de tratamento.

Porém, vale salientar que este resultado vai contra a regra prática aplicável ao método, que indica que "o desvio-padrão da estimativa deva estar entre 2 a 3 vezes menor do que o efeito que se espera detectar". O seja, para detectar uma alteração em $10 \%$ de mudança no número esperado de acidentes-alvo, $\sigma\left\{\hat{\theta}_{\}}\right.$deve ser menor que $5 \%$ e, de preferência, abaixo de $3 \%$, o que não se verifica neste caso. 
Segue na Tabela 5.14 o cálculo dos parâmetros principais do método "antes - depois" ingênuo.

TABELA 5. 14 - RESULTADOS PARA A SOLUÇÃO IMPLANTAÇÃO DE PASSAGEM SUPERIOR E TELA PROTETORA PARA IMPEDIR CRUZE DE PEDESTRES

\begin{tabular}{|c|c|c|c|c|c|c|c|c|c|c|c|c|c|c|c|c|c|}
\hline \multicolumn{11}{|c|}{ RESUMO DE RESULTADOS POR TIPO DE SOLUÇÃO APLICADA } & \multicolumn{7}{|c|}{ RESULTADO MÉTODO "ANTES-DEPOIS" INGÊNUO } \\
\hline & LOCAL & TRATAMENTO & \begin{tabular}{|c|} 
Tempo \\
antes \\
(ano) \\
\end{tabular} & \begin{tabular}{|l|} 
Tempo \\
depois \\
(ano)
\end{tabular} & $\begin{array}{c}\text { VDM } \\
\text { antes }\end{array}$ & $\begin{array}{c}\text { VDM } \\
\text { depois }\end{array}$ & $\begin{array}{c}\mathrm{rd}= \\
\mathrm{Td} / \mathrm{Ta}\end{array}$ & $\begin{array}{c}\mathrm{rft}= \\
\mathrm{vd} / \mathrm{Va}\end{array}$ & к & $\mathrm{L}$ & $\pi$ & $\lambda$ & $\delta=\pi-\lambda$ & $\theta^{\prime}$ & $\begin{array}{c}\text { Redução } \\
1-\theta^{\prime}\end{array}$ & $\sigma(\delta)$ & $\sigma(\theta)$ \\
\hline \multirow[t]{2}{*}{11} & $\begin{array}{c}\text { Rodovia SP075 km } \\
29+000 \text { ao } 32+000 \\
\text { Itu } \\
\text { Travessia de } \\
\text { Pedestres }\end{array}$ & $\begin{array}{l}\text { Tela de proteção no canteiro } \\
\text { central e construção de } \\
\text { escadas nos } \\
\text { viadutos do } \mathrm{km} 29 \mathrm{ekm} 32 \\
\text { finalizada em } 01 / 09 / 08\end{array}$ & 5,67 & 2,33 & 24.062 & 31.249 & 0,41 & 1,30 & 375 & 177 & 201 & 177 & 24 & 0,88 & $12,0 \%$ & 19 & 0,090 \\
\hline & & & & & & & & & 375 & 177 & 201 & 177 & 24 & 0,88 & $12,0 \%$ & 19 & 0,090 \\
\hline
\end{tabular}

Fonte: Base de Dados gerada pelo autor (2011).

\subsection{RESULTADOS DO MÉTODO GRUPOS DE COMPARAÇÃO}

Nas Tabelas 5.1 a 5.5 incluídas no resumo geral por rodovia, no início deste capítulo, foram apresentados os resultados obtidos da aplicação deste método para cada caso individualmente. Este fato possibilitou realizar uma comparação com o Método "antes depois" ingênuo, incluso com os diversos critérios adotados para estimar $\hat{\pi}$.

Neste item pretende-se apresentar os resultados de cada tipo de tratamento estudado de forma agrupada visando obter o resultado médio do mesmo, tal qual foi realizado com o Método "antes - depois" ingênuo no item 5.2 deste capítulo.

Como a informação dos números de acidentes foi processada com valores anuais foi preciso adotar uma premissa de trabalho para aqueles casos estudados, onde a entrada em operação da solução adotada acontecia nos meses intermédios do ano. Para tal caso, adotou o critério de considerar como valores do período "antes" todos aqueles acidentes que aconteceram no ano em que o tratamento foi concluído e posto em operação. Embora esta simplificação possa conduzir a pequenos desvios do verdadeiro valor, o que seria obtido com uso dos valores mensais (não disponíveis), consideraram-se os resultados aceitáveis. Futuros estudos contando com uma base de dados mais extensa poderão medir o desvio e realizar este ajuste.

Merece comentar que para cada tratamento analisado foi escolhido aquele grupo de comparação que verificava as condições exigidas pela metodologia. Esta seleção, realizada numericamente com a ajuda de uma planilha de cálculo é apresentada na Tabela 5.15. Esta seleção também foi verificada graficamente, conforme se mostra como exemplo, na Figura 110 
5.4. Salienta-se que esta análise gráfica não é suficiente para a escolha do melhor grupo de comparação, motivo pelo qual a escolha do GC se realizou sempre com os valores numéricos.

Como comentado anteriormente, não foi possível aplicar este método a todos os tratamentos estudados por falta de dados adequados. Porém, conseguiram-se obter resultados para duas soluções, que são apresentados no item a seguir. No caso do tratamento redução de velocidade foram processados os dados somente de dois dos quatro locais estudados. Um deles não dispõe de dados suficientes para seu cálculo e o outro, embora com dados, não encontrou um grupo de comparação adequado. Para o tratamento referente à implantação de passarela foi possível juntar os resultados de três locais.

Para diferenciar da denominação usada para o método "antes - depois" ingênuo, se acrescenta ao título dos tratamentos analisados pelo método dos grupos de comparação as letras G-C.

Finalmente se comenta que o G-C foi escolhido a partir dos dados contabilizando todos os acidentes, não sendo molificado para os outros casos analisados (DM, FE, MO, $\mathrm{FE}+\mathrm{MO})$. 


\section{Verificação gráfica da consistência dos Grupos de Comparação e o tratamento em analise}

\begin{tabular}{|c|c|c|c|c|c|c|c|c|c|}
\hline \multirow{3}{*}{$\begin{array}{c}\text { Acidentes } \\
\text { Totais } \\
\text { Pista S + N }\end{array}$} & \multicolumn{2}{|c|}{$\begin{array}{c}\text { COM } \\
\text { TRATAMENTO }\end{array}$} & \multicolumn{7}{|c|}{ SEM TRATAMENTO - LOCAIS DE REFERENCIA } \\
\hline & \multicolumn{2}{|c|}{$\begin{array}{l}\text { Rodovia SP310 } \\
\text { Km } 159 \text { ao } 161 \\
\text { Travessia Urbana } \\
\text { de Cordeirópolis }\end{array}$} & $\begin{array}{c}\text { Rodovia SP310 } \\
\text { Km } 228 \text { ao } \\
229 \text { (a) } \\
\text { Travessia } \\
\text { Urbana de São }\end{array}$ & $\mid \begin{array}{c}\text { Rodovia SP310 } \\
\text { Km } 230 \text { ao } \\
236 \text { (b) } \\
\text { Travessia } \\
\text { Urbana de São }\end{array}$ & $\begin{array}{c}\text { Rodovia SP310 } \\
\text { Km } 237 \text { ao } \\
241 \text { (c) } \\
\text { Travessia } \\
\text { Urbana de São }\end{array}$ & $\begin{array}{c}\text { Rodovia SP310 } \\
\text { Km } 167 \text { ao } \\
169 \text { (d) } \\
\text { Travessia } \\
\text { Urbana de } \\
\text { Santa }\end{array}$ & $\begin{array}{c}\text { Rodovia SP310 } \\
\text { Km } 172 \text { ao } \\
176 \text { (f) } \\
\text { Travessia } \\
\text { Urbana de Rio } \\
\text { Claro }\end{array}$ & $\begin{array}{c}\text { Rodovia SP075 } \\
\text { Km } 70 \text { ao } 77 \\
\text { (g) } \\
\text { Travessia } \\
\text { Urbana de } \\
\text { Campinas }\end{array}$ & $\begin{array}{c}\text { Rodovia SP127 } \\
\text { Km } 28 \text { ao } 32 \\
\text { (h) } \\
\text { Travessia } \\
\text { Urbana de } \\
\text { Piracicaba }\end{array}$ \\
\hline & GT Antes & $\begin{array}{c}\text { GT } \\
\text { Depois }\end{array}$ & GC a & GC b & GC c & GC d & GC $f$ & GC g & GC h \\
\hline 2002 & 24 & & 16 & 48 & 35 & 28 & 0 & 0 & 0 \\
\hline 2003 & 30 & & 28 & 43 & 31 & 36 & 113 & 202 & 37 \\
\hline 2004 & 36 & & 28 & 49 & 36 & 18 & 117 & 205 & 42 \\
\hline 2005 & 34 & & 34 & 56 & 33 & 24 & 137 & 212 & 37 \\
\hline 2006 & 38 & & 33 & 59 & 28 & 27 & 146 & 274 & 31 \\
\hline 2007 & 42 & & 37 & 63 & 38 & 31 & 93 & 297 & 49 \\
\hline 2008 & 45 & & 36 & 73 & 36 & 38 & 96 & 222 & 41 \\
\hline 2009 & & 24 & 35 & 57 & 36 & 31 & 68 & 256 & 32 \\
\hline 2010 & & 40 & 20 & 58 & 35 & 28 & 104 & 251 & 23 \\
\hline
\end{tabular}

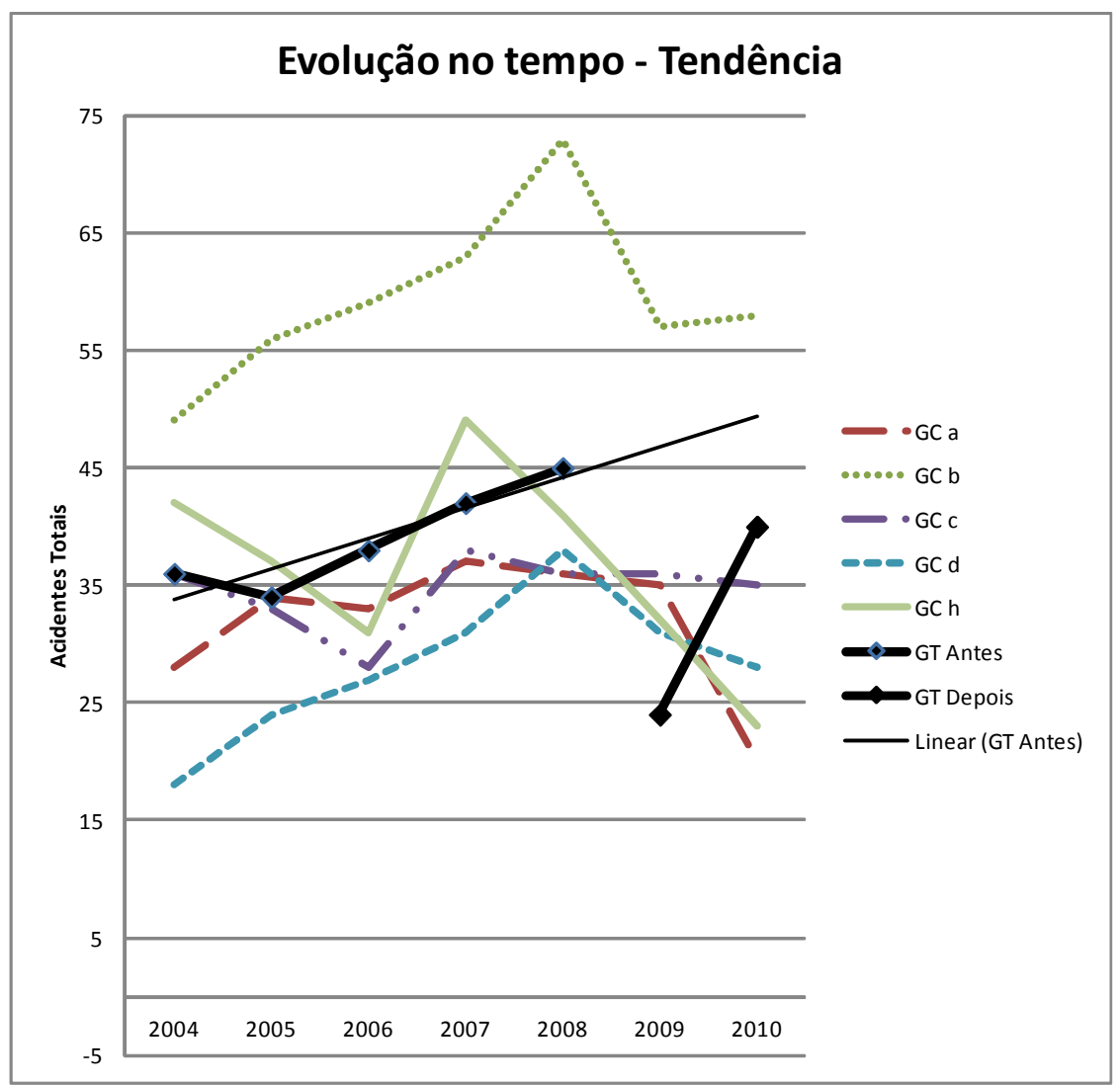

Não se graficam os dados dos grupos de comparação f e g (muitos maiores que os outros) para permitir visualizar mel hor a tendência do GC (b) escolhido

FIGURA 5. 4 - ANALISE GRÁFICA DOS GRUPOS DE COMPRAÇÃo

FONTE: BASE DE DADOS GERADA PELO AUTOR (2011) 
TABELA 5. 15 - PLANILHA DE CÁLCULO DO MÉTODO DE GRUPOS DE COMPARAÇÃO

\begin{tabular}{|c|c|c|c|c|c|c|c|c|c|c|c|c|c|c|c|c|}
\hline \multirow{2}{*}{$\begin{array}{c}\begin{array}{c}\text { Metodo de Grupos de } \\
\text { Comparação } \\
\text { TODOS }\end{array} \\
\text { ANO / PARÂMETRO }\end{array}$} & \multirow{2}{*}{\begin{tabular}{|c|}
$\begin{array}{c}\text { Rodovia SP310 } \\
\text { Km } 159 \text { ao } 161 \\
\text { Travessia Urbana } \\
\text { de Cordeiropolis }\end{array}$ \\
$\begin{array}{c}\text { G Tratamento } \\
\mathrm{K}, \mathrm{L}\end{array}$ \\
\end{tabular}} & \multirow{2}{*}{$\begin{array}{c}\text { Escolhido } \\
\text { como GC } \\
\text { GC_b } \\
M, N\end{array}$} & \multicolumn{2}{|c|}{$\begin{array}{c}\text { Rodovia SP310 } \\
\text { Km } 228 \text { ao } 229 \text { (a) } \\
\text { Travessia Urbana de São } \\
\text { Carlos }\end{array}$} & \multicolumn{2}{|c|}{\begin{tabular}{|c|} 
Rodovia SP310 \\
Km 230 ao 236 (b) \\
Travessia Urbana de São \\
Carlos
\end{tabular}} & \multicolumn{2}{|c|}{$\begin{array}{c}\text { Rodovia SP310 } \\
\text { Km } 237 \text { ao } 241 \text { (c) } \\
\text { Travessia Urbana de São } \\
\text { Carlos }\end{array}$} & \multicolumn{2}{|c|}{\begin{tabular}{|c|} 
Rodovia SP310 \\
Km 167 ao 169 (d) \\
Travessia Urbana de Santa \\
Gertrudes
\end{tabular}} & \multicolumn{2}{|c|}{$\begin{array}{l}\text { Rodovia SP075 } \\
\text { Km 49 ao 55,9 (f) } \\
\text { Travessia Urbana de } \\
\text { Indaiatuba }\end{array}$} & \multicolumn{2}{|c|}{$\begin{array}{c}\text { Rodovia SP075 } \\
\text { Km } 70 \text { ao } 77(\mathrm{~g}) \\
\text { Travessia Urbana de } \\
\text { Campinas }\end{array}$} & \multicolumn{2}{|c|}{$\begin{array}{c}\text { Rodovia SP127 } \\
\text { Km } 28 \text { ao } 32 \text { (h) } \\
\text { Travessia Urbana de } \\
\text { Piracicaba }\end{array}$} \\
\hline & & & $\begin{array}{l}\text { GC_a } \\
M, N\end{array}$ & o & $\begin{array}{l}\mathrm{GC} \mathrm{b}_{-} \\
\mathrm{M}, \mathrm{N}\end{array}$ & o & $\begin{array}{l}G C_{-} \mathrm{c} \\
M, N\end{array}$ & o & $\begin{array}{l}G C_{-} d \\
M, N\end{array}$ & o & $\begin{array}{l}G C_{-} f \\
M, N\end{array}$ & o & $\begin{array}{l}G C_{-g} \\
M, N\end{array}$ & o & $\begin{array}{l}G C_{-} h \\
M, N\end{array}$ & o \\
\hline \multicolumn{17}{|l|}{2002} \\
\hline 2003 & 30 & 43 & 28 & & 43 & & 31 & & 36 & & 113 & & 202 & & 37 & \\
\hline 2004 & 36 & 49 & 28 & 0,78358 & 49 & 0,90350 & 36 & 0,91293 & 18 & 0,39474 & 117 & 0,83235 & 205 & 0,81891 & 42 & 0,89680 \\
\hline 2005 & 34 & 56 & 34 & 1,20710 & 56 & 1,15266 & 33 & 0,91808 & 24 & 1,30120 & 137 & 1,19448 & 212 & 1,05868 & 37 & 0,88564 \\
\hline 2006 & 38 & 59 & 33 & 0,82258 & 59 & 0,90279 & 28 & 0,71849 & 27 & 0,94251 & 146 & 0,92251 & 274 & 1,12160 & 31 & 0,71168 \\
\hline 2007 & 42 & 63 & 37 & 0,96235 & 63 & 0,92827 & 38 & 1,15891 & 31 & 0,97922 & 93 & 0,55918 & 297 & 0,95450 & 49 & 1,35418 \\
\hline 2008 & 45 & 73 & 36 & 0,86548 & 73 & 1,04179 & 36 & 0,84328 & 38 & 1,08498 & 96 & 0,93269 & 222 & 0,68024 & 41 & 0,74902 \\
\hline 2009 & 24 & 57 & 35 & & 57 & & 36 & & 31 & & 68 & & 256 & & 32 & \\
\hline 2010 & 40 & 58 & 20 & & 58 & & 35 & & 28 & & 104 & & 251 & & 23 & \\
\hline soma anos antes & 225 & 343 & 196 & & 343 & & 202 & & 174 & & 702 & & 1.412 & & 237 & \\
\hline soma anos depois & 64 & 115 & 55 & & 115 & & 71 & & 59 & & 172 & & 507 & & 55 & \\
\hline média o & & & & 0,92822 & & 0,98580 & & 0,91034 & & 0,94053 & & 0,88824 & & 0,92678 & & 0,91946 \\
\hline $\operatorname{Var}(0)$ & & & & 0,02874 & & 0,01199 & & 0,02579 & & 0,11259 & & 0,05208 & & 0,03213 & & 0,06572 \\
\hline $\operatorname{Var}(w)$ & & & $-0,01461$ & & $-0,01969$ & & $-0,01332$ & & 0,06982 & & 0,02478 & & 0,00938 & & 0,02324 & \\
\hline $\operatorname{Var}(w)$ adotada & & & 0,00000 & & 0,00000 & & 0,00000 & & 0,06982 & & 0,02478 & & 0,00938 & & 0,02324 & \\
\hline $\operatorname{Var}(r c) / r c 2=1 / N+1 / M+\operatorname{VAR}(w)$ & & 0,01161 & 0,02328 & & 0,01161 & & 0,01904 & & 0,09252 & & 0,03202 & & 0,01207 & & 0,04565 & \\
\hline $\mathrm{rt}=\mathrm{rc}$ (ratio de compar.) & & 0,33430 & 0,27919 & & 0,33430 & & 0,34975 & & 0,33714 & & 0,24467 & & 0,35881 & & 0,23109 & \\
\hline $\mathrm{rtf}=\mathrm{VDM}$ depois / VDM antes & 1,29360 & 1,15397 & & & 1,15397 & & & & & & & & & & & \\
\hline$r c$, modif & 0,28981 & & & & & & & & & & & & & & & \\
\hline$\pi=r t f \times r c$, modif $\times K$ & 84 & & & & & & & & & & & & & & & \\
\hline$\lambda=L$ & 64 & & & & & & & & & & & & & & & \\
\hline$\delta=\pi-\lambda$ & 20 & & & & & & & & & & & & & & & \\
\hline$\theta=\lambda / \pi$ & 0,76 & & & & & & & & & & & & & & & \\
\hline$\theta^{\prime}$ & 0,77 & & & & & & & & & & & & & & & \\
\hline Redução $=\left(1-\theta^{\prime}\right)$ & $23 \%$ & & & & & & & & & & & & & & & \\
\hline $\operatorname{Var}(\pi)$ & 114 & & & & & & & & & & & & & & & \\
\hline $\operatorname{Var}(\lambda)$ & 64 & & & & & & & & & & & & & & & \\
\hline $\operatorname{Var}(\delta)$ & 178 & & & & & & & & & & & & & & & \\
\hline$\sigma(\delta)$ & 12,18 & & & & & & & & & & & & & & & \\
\hline $\operatorname{Var}(\theta)$ & 0,018 & & & & & & & & & & & & & & & \\
\hline$\sigma(\theta)$ & 0,14 & & & & & & & & & & & & & & & \\
\hline
\end{tabular}

Fonte: Base de Dados gerada pelo autor (2011) 


\subsubsection{RESULTADOS PARA A SOLUÇÃO DO TIPO 1 - REDUÇÃO DE VELOCIDADE (G-C)}

Neste caso foi aplicada para o cálculo a tabela sugerida por Hauer (1997), ligeiramente modificada para aplicar os dados dos VDM disponíveis para os períodos antes e depois do local de tratamento e dos grupos de comparação. Desta forma foi possível calcular uma $r_{C m}$ "razão de comparação modificada". A Tabela 5.16 mostra os dados e resultados obtidos.

TABELA 5. 16 - RESULTADOS PARA REDUÇÃO DE VELOCIDADE - G-C

\begin{tabular}{|c|c|c|c|c|c|c|c|}
\hline \multicolumn{8}{|c|}{ RESULTADO MÉTODO "ANTES-DEPOIS" GRUPOS DE COMPARAÇÃO } \\
\hline \multicolumn{8}{|c|}{ Tratamento Tipo 1 - Redução de velocidade } \\
\hline \multicolumn{8}{|c|}{ DADOS } \\
\hline \multirow{2}{*}{ Site } & Tratamento & Tratamento & Comparação & Comparação & Comparação & Tratamento & Comparação \\
\hline & Antes & Depois & Antes & Depois & $\operatorname{VÂ} R\{w\}$ & \multicolumn{2}{|c|}{$\mathrm{rtf}=\mathrm{VDM}$ depois $/$ VDM antes } \\
\hline j & $K(j)$ & $L(j)$ & $M(j)$ & $N(j)$ & calculado & calculado & calculado \\
\hline 1 & 161 & 667 & \multicolumn{5}{|c|}{ Não se aplica por falta de dados } \\
\hline 5 & 96 & 15 & \multicolumn{5}{|c|}{ Não se encontrou GC adequado } \\
\hline 8 & 479 & 183 & 1.412 & 507 & 0,0184 & 1,6689 & 1,2380 \\
\hline 12 & 757 & 99 & 1.668 & 251 & 0,0123 & 1,2927 & 1,2722 \\
\hline \multicolumn{6}{|c|}{ SITES INDIVIDUAIS } & & \\
\hline & $\hat{\lambda}$ & $\hat{r}$ & $\hat{\pi}$ & $\operatorname{Var}\{\hat{\lambda j})\}$ & $\operatorname{Var}\{\hat{\pi}(j)\}$ & & \\
\hline 1 & \multicolumn{5}{|c|}{ Não se aplica por falta de dados } & & \\
\hline 5 & \multicolumn{5}{|c|}{ Não se encontrou GC adequado } & & \\
\hline 8 & 183 & 0,2899 & 231,72 & 183 & $1.244,26$ & & \\
\hline 12 & 99 & 0,1182 & 115,70 & 99 & 243,02 & & \\
\hline \multicolumn{6}{|c|}{ SITES AGRUPADOS } & & \\
\hline \multirow{2}{*}{ Etapa 1} & $\hat{\lambda}$ & 282 & & & & & \\
\hline & $\hat{\pi}$ & 347 & & & & & \\
\hline \multirow{2}{*}{ Etapa 2} & $\operatorname{VÂR}\{\hat{\lambda}\}$ & 282 & & & & & \\
\hline & $\operatorname{VÂR}\{\hat{\pi}\}$ & 1.487 & & & & & \\
\hline \multirow{2}{*}{ Etapa 3} & $\hat{\delta}$ & 65 & & & & & \\
\hline & $\hat{\theta}$ & 0,802 & $1-\hat{\theta}$ & $19,8 \%$ & & & \\
\hline \multirow{2}{*}{ Etapa 4} & $\hat{\sigma}\{\hat{\bar{\delta}}\}$ & 42,06 & & & & & \\
\hline & $\hat{\sigma}\{\hat{\theta}\}$ & 0,100 & & & & & \\
\hline
\end{tabular}

Fonte: Base de Dados gerada pelo autor (2011)

- A análise da solução redução de velocidade pelo método de grupos de comparação também retorna um resultado positivo, neste caso menor ao calculado com o método "antes - depois" ingênuo: redução do número de acidentes totais de $19,8 \%$, com um desvio-padrão de $\pm 10 \%$ versus o valor de $31,9 \%$ anterior. 
- Este fato permite concluir favoravelmente pela conveniência da aplicação desta solução para travessias urbanas de rodovias que apresentem elevados índices de acidentalidade.

\subsubsection{RESULTADOS PARA A SOLUÇÃO DO TIPO 5 - IMPLANTAÇÃO DE PASSARELA (G-C)}

Para esta análise se desconsideram os dados do caso 6, definido como um caso especial não representativo pelos argumentos expostos no item 5.2.5. A seguir, na Tabela 5.17, se apresenta os resultados da aplicação do método de grupos de comparação.

TABELA 5. 17 - RESULTADOS PARA IMPLANTAÇÃO DE PASSARELA - G-C

\begin{tabular}{|c|c|c|c|c|c|c|c|}
\hline \multicolumn{8}{|c|}{ Tratamento Tipo 5 - Implantação de Passarelas } \\
\hline \multicolumn{8}{|c|}{ DADOS } \\
\hline \multirow{2}{*}{ Site } & Tratamento & Tratamento & Compa ra ção & Comparação & $\operatorname{VÂ} R\{w\}$ & Tratamento & Compa ra ção \\
\hline & Antes & Depois & Antes & Depois & & \multicolumn{2}{|c|}{$\mathrm{rtf}=\mathrm{VDM}$ depois $/$ VDM antes } \\
\hline j & $K(j)$ & L(j) & $M(j)$ & $N(j)$ & calculado & calculado & calculado \\
\hline 7 & 92 & 64 & 123 & 128 & 0,1420 & 1,1969 & 1,1308 \\
\hline 10 & 44 & 21 & 123 & 128 & 0,0562 & 1,4312 & 1,1308 \\
\hline 13 & 583 & 273 & 160 & 91 & 0,0218 & 1,2581 & 1,1425 \\
\hline \multicolumn{6}{|c|}{ SITES INDIVIDUAIS } & & \\
\hline & $\hat{\lambda}$ & $\hat{r}$ & $\hat{\pi}$ & $\operatorname{Var}\{\hat{\lambda(j)}\}$ & $\operatorname{Var}\{\hat{\pi}(\mathrm{j})\}$ & & \\
\hline 7 & 64 & 0,9137 & 100,61 & 64 & $1.709,28$ & & \\
\hline 10 & 21 & 0,9137 & 57,54 & 21 & 314,18 & & \\
\hline 13 & 273 & 0,4951 & 363,15 & 273 & $5.377,86$ & & \\
\hline \multicolumn{6}{|c|}{ SITES AGRUPADOS } & & \\
\hline \multirow{2}{*}{ Etapa 1} & $\hat{\lambda}$ & 358 & & & & & \\
\hline & $\hat{\pi}$ & 521 & & & & & \\
\hline \multirow{2}{*}{ Etapa 2} & $\operatorname{VÂR}\{\hat{\lambda}\}$ & 358 & & & & & \\
\hline & VÂR $\{\hat{\pi}\}$ & 7.401 & & & & & \\
\hline \multirow{2}{*}{ Etapa 3} & $\hat{\bar{\delta}}$ & 163 & & & & & \\
\hline & $\hat{\bar{\theta}}$ & 0,669 & $1-\hat{\theta}$ & $33,1 \%$ & & & \\
\hline \multirow{2}{*}{ Etapa 4} & $\hat{\sigma}\{\hat{\bar{\delta}}\}$ & 88,09 & & & & & \\
\hline & $\hat{\sigma}\{\hat{\bar{\theta}}\}$ & 0,114 & & & & & \\
\hline
\end{tabular}

Fonte: Base de Dados gerada pelo autor (2011)

- Igual ao caso anterior, este tratamento também apresenta resultados positivos e com valores menores aos resultantes pelo método "antes - depois" ingênuo. O valor da redução do número de acidentes totais foi de $33,1 \%$ neste caso, menor do valor de $40 \%$ obtido com o método ingênuo. 


\subsection{RESULTADOS - RESUMO FINAL}

Apresentam-se neste item o resumo dos resultados obtidos para os tratamentos analisados. A Tabela 5.18 traz os resultados dos métodos "antes - depois" ingênuo e dos grupos de comparação para os dados de todos os acidentes registrados (TO) junto com os correspondentes dos acidentes mais graves, com Feridos e Mortos (FE+MO).

TABELA 5. 18 - RESUMO DE RESULTADOS POR TRATAMENTO PARA ACIDENTES TOTAIS

\begin{tabular}{|c|c|c|c|c|c|}
\hline \multicolumn{6}{|c|}{$\begin{array}{c}\text { RESUMO DE RESULTADOS } \\
\text { MÉTODO "ANTES - DEPOIS" INGÊNUO }\end{array}$} \\
\hline \multicolumn{3}{|c|}{ TRATAMENTO } & \multicolumn{3}{|c|}{ Redução $=(1-\theta) \pm \sigma(\theta)$} \\
\hline Tipo & Descrição & № Casos & TO & DM & $\mathrm{FE}+\mathrm{MO}$ \\
\hline 1 & Redução de velocidade e outras medidas & 4 & $31,9 \% \pm 2,8 \%$ & $38,4 \% \pm 3,2 \%$ & $19,6 \% \pm 5,5 \%$ \\
\hline 2 & Implantação de Defesa NJ Elevada & 2 & $-19,4 \% \pm 7,4 \%$ & $-4,6 \% \pm 8,5 \%$ & $-42,9 \% \pm 13,8 \%$ \\
\hline 3 & Implantação de Dispositivo em desnível & 1 & $26,1 \% \pm 11,1 \%$ & $27,1 \% \pm 13,2 \%$ & $21,2 \% \pm 19,6 \%$ \\
\hline 4 & $\begin{array}{l}\text { Cruzamento de pedestre em nível em área } \\
\text { especialmente demarcada }\end{array}$ & 2 & $29,0 \% \pm 8,4 \%$ & $43,1 \% \pm 9,2 \%$ & $8,6 \% \pm 15,8 \%$ \\
\hline 5 & Implantação de passarela para pedestres & 3 & $40,5 \% \pm 5,6 \%$ & $40,8 \% \pm 7,1 \%$ & $40,3 \% \pm 8,9 \%$ \\
\hline 6 & Implantação de ciclovia & 1 & $30,4 \% \pm 5,9 \%$ & $39,7 \% \pm 7,1 \%$ & $19,3 \% \pm 9,9 \%$ \\
\hline 7 & $\begin{array}{l}\text { Passagem superior e Tela protetora para } \\
\text { impedir cruze de pedestres }\end{array}$ & 1 & $12,0 \% \pm 9,0 \%$ & $-2,1 \% \pm 13,3 \%$ & $31,6 \% \pm 11,5 \%$ \\
\hline
\end{tabular}

\begin{tabular}{|c|l|c|c|c|c|}
\hline \multicolumn{7}{|c|}{$\begin{array}{r}\text { RESUMO DE RESULTADOS PARA ACIDENTES TOTAIS } \\
\text { MÉTODO GRUPOS DE COMPARAÇÃO }\end{array}$} \\
\hline Tipo & Descrição & No Casos & TO & DM & FE+MO \\
\hline 1 & Redução de velocidade e outras medidas & 2 & $19,8 \% \pm 10,0 \%$ & $13,1 \% \pm 18,5 \%$ & $32,3 \% \pm 11,1 \%$ \\
\hline 5 & Implantação de passarela para pedestres & 3 & $33,1 \% \pm 11,4 \%$ & $37,3 \% \pm 16,3 \%$ & $34,8 \% \pm 21,4 \%$ \\
\hline
\end{tabular}

Fonte: Base de Dados gerada pelo autor (2011) 


\section{CONSIDERAÇÕES FINAIS}

Inicialmente, serão feitos considerações sobre o método utilizado, que possam vir a ajudar futuros pesquisadores que pretendam recorrer ao mesmo para seus trabalhos. O método de avaliação da eficácia de um tratamento ou ação para reduzir acidentes baseado na análise das situações antes e depois é de aplicação simples, o que o torna prático e muito atrativo. Para a obtenção de resultados confiáveis é de extrema importância trabalhar com uma base de dados extensa, de boa procedência e convenientemente processada.

Através do estudo "antes - depois" ingênuo, pode estimar-se o quanto a segurança mudou entre os períodos "antes" e "depois". No entanto, não se pode dizer que parte dessa mudança se deve ao tratamento aplicado e que parte é devida a todos os outros fatores que também mudaram durante esse tempo. Uma alternativa que resolve esta questão é desenvolver um estudo observacional "antes - depois" com grupos de comparação.

No estudo ingênuo as decisões recaem sobre o número de entidades a considerar para o grupo de tratamento e a duração dos períodos “antes" e "depois". Para o estudo com grupos de comparação se adiciona mais uma decisão: escolher qual dos candidatos disponíveis para grupos de comparação deve ser usado, já que esta decisão determina às conclusões a serem alcançadas.

Neste trabalho se teve a oportunidade de aplicar ambos os métodos para alguns dos casos estudados, verificando-se resultados aproximados e consistentes. Para cada caso analisado se obteve indicadores da eficácia da solução implantada. Neste trabalho foi escolhido indicar o grau de eficácia do tratamento a porcentagem de redução no número de acidentes total que tal tratamento propicia com sua aplicação. Entretanto, se entende incorreto supor a priori que tratamentos similares aplicados em locais semelhantes aos estudados apresentarão os mesmos resultados aos aqui encontrados. Assim sendo, salienta-se que os valores de redução indicados neste trabalho deverão ser considerados somente como referenciais. 
Verifica-se que o desvio-padrão das estimativas obtidas pelo método ingênuo é menor do que aqueles obtidos pelo método grupos de comparação. À primeira vista isso pode aparecer estranho, uma vez que este último pretende ser um melhoramento em relação ao método ingênuo. Pode comentar-se que o melhoramento existe, pois separa o efeito da ação em análise do efeito dos vários outros fatores que também mudaram entre os períodos "antes" e "depois". Este melhoramento é obtido à custa da precisão estatística que é medida pelo desvio-padrão. Isto acontece porque a precisão estatística com que se calcula o parâmetro $\pi$ no método de grupos de comparação deve, agora, depender não somente do var $\{k\}$, mas também da var $\left\{\hat{r}_{\mathrm{T}}\right\}$, apresentando uma fonte adicional de variância. Destaca-se, ainda, que neste trabalho optou-se pela aplicação do método de grupos de comparação considerando diretamente e explicitamente a mudança num fator causal medido e compreendido como o VDM, pois se contava com dados confiáveis de sua variação tanto nos trechos dos grupos de comparação quanto nos segmentos de travessias urbanas das rodovias analisados. Ao fazer isso se modificou o papel do grupo de comparação que passou a ser usado para considerar somente os fatores remanescentes, aqueles que não foram considerados explicitamente. Assim sendo, ao predizer $\pi=\mathrm{rtf} \times \mathrm{rcmod} \kappa$, o rtf considera diretamente o efeito do fluxo de tráfego e o

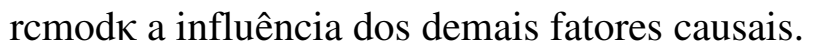

Dentre os vários grupos de comparação disponíveis (com uma média $\omega$ perto de 1 ) escolheu-se aquele grupo para o qual $1 / \mathrm{N}+1 / \mathrm{M}+\mathrm{VÂR}\{\omega\}$ é o menor, dado que conduz ao resultado final mais preciso.

É necessário destacar que quando o efeito de alguns tratamentos na segurança é grande, contagens de acidentes relativamente pequenas podem ser suficientes para chegar a conclusões satisfatórias. Inversamente, quando o efeito sobre a segurança é modesto, então, para chegar a conclusões razoavelmente precisas, as contagens de acidentes precisam ser muito grandes.

Finalmente, após a conclusão do trabalho e com os resultados atingidos, é possível enunciar respostas objetivas aos questionamentos que deram origem ao mesmo, em especial a aquela referente à eficácia da redução de velocidade em travessias urbanas de rodovias visando à diminuição de acidentes e suas consequências. Não ficam duvidas que esta solução, que se intuía a priori como positiva, é eficaz para a obtenção de reduções expressivas nos índices dos acidentes. Vale salientar, que não foi possível verificar a variação da esta eficácia, medida com alguns dos parâmetros usados pelos métodos aqui apresentados (método "antes depois" ingênuo ou método com grupos de comparação), em função da variação da redução 
da velocidade adotada. Certamente poderá ser tema de um futuro aprofundamento do assunto, o que se deixa como recomendação para novos pesquisadores. O que pode concluir-se é que a solução é eficaz e os valores médios atingidos: $20 \%$ (método de grupos de comparação) a $32 \%$ (método ingênuo) são consistentes com os mencionados pela bibliografia consultada.

Foi possível também verificar resultados positivos em outras soluções analisadas. Algumas delas verificando o que se intuía de antemão, como o caso da implantação de passarelas ou de investimentos de grande vulto como novos dispositivos de acesso a cidades. Em outros casos, contrariando o esperado, dado que uma medida de menor custo como a adoção de cruzamento de pedestres em nível, em locais especialmente tratados com: sinalização ostensiva, redução de velocidade e alambrado para canalizar a passagem por um único setor, que a priori gerou desconfiança quanto a ser uma solução adequada, também apresentou bons resultados com redução no número de acidentes totais da ordem de $29 \%$.

Existe um terceiro grupo de tratamentos que puderam ser analisados e cujos resultados foram positivos, como foram a implantação de uma ciclovia e a adoção de medidas para restringir o cruzamento em nível dos pedestres - reaproveitando a existência de uma passagem superior no local - em conjunto com a construção de uma escada confortável para que os interessados possam chegar até a parada do ônibus existente com conforto e segurança. Porém, sendo analisado apenas um caso de cada um entende-se que os valores obtidos são somente referências para futuros estudos.

Por último, um breve comentário sobre a ação que apresentou resultado negativo: a implantação de defesa New Jersey elevada. Entende-se incorreto concluir sobre a inconveniência da aplicação desta ação baseado no resultado obtido nesta pesquisa. Para tanto, sugere-se um estudo mais detalhado dos acidentes contabilizados considerando-os de forma segregada, verificando se existe diminuição dos atropelamentos em relação ao aumento de outros, comuns em áreas urbanas adjacentes à rodovia, o que não foi realizado neste estudo por fugir do escopo do mesmo. 


\section{REFERÊNCIAS BIBLIOGRÁFICAS}

ABRAMET - Associação Brasileira de Medicina de Tráfego. Acidentes de trânsito no Brasil: Um atlas de sua distribuição. São Paulo, 2007. Disponível em http://www.abramet.org.br. Acesso em 31 de janeiro de 2011.

ABNT. Associação Brasileira de Normas Técnicas. Norma NBR 10.697. Pesquisa de acidentes de trânsito, 1989. - Terminologia 10 p.

AMÍLCAR SAMPEDRO TAMAYO - Procedimento para Avaliação da Segurança De Tráfego em Vias Urbanas, 2006 - Dissertação de Mestrado.

ARAUJO CUPOLILLO - Estudo das medidas moderadoras do tráfego para controle da velocidade e dos conflitos em travessias urbanas - UFRJ, 2006.

BENJAMIN, J. e CORNELL, A. - Probability, Statistic and Decision for Civil Engineers, 1963.

BASTOS, J. T. - Geografia da Mortalidade no Trânsito no Brasil, Dissertação de Mestrado, Universidade de São Paulo, Escola de Engenharia de São Carlos, 2011.

BRASIL. Ministério dos transportes. Departamento Nacional de Estradas de Rodagem; Instituto de Pesquisas Rodoviárias. Manual de Ordenamento do Uso do Solo nas Faixas Lindeiras. Brasília, 1996.

BRASIL. Ministério dos Transportes. Departamento Nacional de Trânsito. Código de Trânsito Brasileiro. Lei 9.503 de 23 de setembro de 1997. 
DER/SP - Balanço Anual dos Transportes - Estudo de velocidade, 2006.

DNIT - Custos de Acidentes de Trânsito nas Rodovias Federais, 2004. Disponível em http://ipr.dnit.gov.br/manuais/custos_acidentes_sumario_executivo.pdf. Acesso em 5 de fevereiro de 2011.

ELVIK, R; HOYE, A.; VAA, T.; SORENSEN, M. - The Handbook of Road Safety Measures, 2004.

DNER - Guia de Redução de Acidentes com Base em Medidas de Engenharia de Baixo Custo, 1998.

FERRAZ, A. C. P.; RAIA JUNIOR, A. A.; BEZERRA, B. S. - Segurança no trânsito. São Carlos: NEST, 2008.

FRAMARIM CARLO - Procedimento para monitorar medidas voltadas à redução dos acidentes no sistema viário - UFRS, 2003.

FREIRE, Liz Helena Costa Varella. Análise de tratamentos adotados em travessias urbanas - rodovias arteriais que atravessam pequenas e médias cidades no RS. 2003. 148f. Dissertação (Mestrado Profissionalizante em Engenharia) - Escola de Engenharia, Universidade Federal do Rio Grande do Sul, Porto Alegre, 2003.

GLOBAL STATUS REPORT ON ROAD SAFETY, 2009. Disponível em http://www.cisev.org.ar/portuges/pdf/Global\%20Status\%20Report\%20on\%20Road\%20Safet y.pdf. Acesso em 3 de fevereiro de 2011.

HAUER, H. - Observation Before - After studies in road safety - Estimating the effect of highway and traffic engineering measures on road safety. Departament of Civil Engineering University of Toronto, 1997.

INST - Programa de Desenvolvimento de Segurança Rodoviária - Centrovias Sistemas Rodoviários S/A, 1999. 
IPEA - Impactos Sociais e Econômicos dos Acidentes de Trânsito nas Aglomerações Urbanas - Brasília, 2003.

IPEA/DENATRAN - "Impactos sociais e econômicos dos acidentes de trânsito nas rodovias brasileiras", 2006.

MINISTÉRIO DOS TRANSPORTES - Procedimentos para o tratamento de locais críticos de acidentes de trânsito. - Brasília, 2002.

RENAEST/DETRAN/ IBGE/ SERPRO - Sistema RENAVAM e RENAL/ DPRF/ DER/ Municípios - Anuário Estatístico do DENATRAN / RENAEST, 2006. Disponível em http://www.vias-

seguras.com/os_acidentes/estatisticas/estatisticas_nacionais/anuarios_estatisticos_do_denatran. Acesso em 5 de fevereiro de 2011.

ROSEBU - Road Safety And Environmental Benefit - Cost And Cost - Effectiveness Analysis For Use In Decision-Making, 2005. Disponível em http://ec.europa.eu/transport/roadsafety_library/publications/rosebud_flyer.pdf. Acesso em 5 de fevereiro de 2011.

YAMADA, M. G. - Impactos dos radares fixos na velocidade e na acidentalidade em trecho da rodovia Washington Luís. Dissertação de mestrado - EESCUSP. São Carlos, 2005. 


\section{APÊNDICES}

\subsection{CARTAS COM PEDIDOS DE DADOS}

\subsubsection{CARTA COM PEDIDO DE DADOS A ARTESP}

São Carlos, 17 de novembro de 2010.

$\grave{A}$

ARTESP

AT: Sr Diretor Marco Antonio Assalve

Ass.: Tese de Mestrado

Ref: Pedido de Dados Técnicos

Prezado Senhor:

Conforme comentei com o Sr. Carlos Campos, responsável da área de segurança dessa Agencia, venho desenvolvendo o tema "Eficácia da restrição de velocidade e outras ações na prevenção de acidentes em travessias urbanas" como tese de mestrado no Programa de Pósgraduação em Engenharia de Transportes - Área: Planejamento e operações de Sistema de Transportes, na Escola de Engenharia de São Carlos da Universidade de São Paulo, sob orientação do Professor Antonio Clóvis Pinto Ferraz.

Para a realização deste trabalho acadêmico, preciso de analisar soluções técnicas implantadas em coincidência de travessias urbanas, visando à redução de acidentes. Dado que muitas das concessionárias rodoviárias que administram importantes rodovias da malha estadual tem implementado um numero significativo de soluções como parte de seus programas de redução de acidentes (PRA), venho por este intermédio a solicitar informações das mesmas. 
Visando obter a maior quantidade de casos, e informação abundante de cada um, sem que isto venha a representar uma nova carga de trabalho às concessionárias, solicito tenha a bem requisitar a cada uma o material que já tenha disponível para o(s) caso(s) mais significativo(s) da sua malha.

A informação deveria conter necessariamente:

1. Identificação do local da travessia urbana: rodovia, $\mathrm{km}$, cidade, entidade específica (exemplo: acesso, passarela, cruzamento, entroncamento, semáforo, etc.);

2. Dados dos acidentes de tráfego, do maior período de tempo disponível, que transformaram o local (ou segmento) em ponto negro, antes da implantação da solução técnica para redução ou mitigação dos acidentes;

3. Tipo de solução ou elemento implantado (exemplo: passarela, radar, restrição de velocidade, restrição de movimentos; lombada, sinalização ostensiva, coletora, combinação das anteriores, etc.), com data do inicio de operação efetiva de cada uma;

4. Dados dos acidentes de tráfego, do maior período de tempo disponível, após o tratamento do local com a solução técnica escolhida;

e, se disponível:

5. Volume de tráfego do local e sua classificação, caso disponível;

6. Registro fotográfico do trecho ou local crítico e seus problemas;

Ainda, e aos efeitos de aplicação de metodologia de comparação com locais de referencia, identificação de outra(s) travessia(s) urbana(s) com similares características operacionais que não recebeu tratamento, sempre que existentes. Nestes casos, se pede informar os mesmos elementos dos itens 1, 2, 4, e 5 acima, sempre que disponíveis,

Como exemplo cita-se o caso da travessia urbana de Rio Claro, na SP-310, Rodovia Washington Luiz, sob administração da Centrovias, que recebeu tratamento específico para redução de acidentes, e a travessia da cidade contigua, Santa Gertrudes, como local de referencia.

A partir do material recebido, se realizará uma seleção de casos e, se necessário, se solicitarão os elementos faltantes para completar a informação mínima necessária para aplicar a metodologia escolhida.

Destaco que o material em questão será utilizado exclusivamente com fines acadêmicos, e que uma copia do trabalho resultante será entregue a essa Agencia, para uso técnico. 
Propõe-se que junto com o envio das informações se informe a pessoa de contato da concessionária que poderá ser consultada para avançar na analise do assunto, evitando ter que incomodar a essa Agencia durante o período de estudos.

Fico a disposição para esclarecimentos ou complementações necessários, assim como para combinar o envio das informações, que poderão ser realizadas por e-mail a jcamin@terra.com.br ou no endereço abaixo.

Desde já agradeço a atenção e a colaboração.

Atenciosamente,

\subsubsection{CARTA COM PEDIDO DE DADOS AO DER/SP}

$\grave{A}$

\section{Departamento de Estradas de Rodagens - DER SP}

Coordenadoria de Operações e Estadísticas - COE

AT: Sr Edson Ferreira Costa Junior

Ass.: Tese de Mestrado

\section{Ref.: Pedido de Dados Técnicos}

Prezado Senhor:

Conforme lhe comentei pessoalmente, venho desenvolvendo o tema "Eficácia da restrição de velocidade e outras ações na prevenção de acidentes em travessias urbanas" como tese de mestrado no Programa de Pós-graduação em Engenharia de Transportes - Área: Planejamento e operações de Sistema de Transportes, na Escola de Engenharia de São Carlos da Universidade de São Paulo, com orientação do Professor Antonio Clóvis Pinto Ferraz.

Para a realização deste trabalho acadêmico, preciso de analisar soluções técnicas implantadas em coincidência com travessias urbanas, visando à redução de acidentes. Dado que o COE - Coordenadoria de Operações e Estatísticas vem levantando de forma sistemática dados de velocidade em distintos locais da rede estadual, dentre os quais várias áreas urbanas onde se procedeu a restringir ou modificar a velocidade de circulação permitida, visando à diminuição dos índices de acidentes, entendo que estes dados podem vir a ser de grande ajuda 
na tese em desenvolvimento, motivo pelo qual os solicito pela presente, observando, se possível e disponível, de incluir a seguinte informação:

1. Identificação do local da travessia urbana: rodovia, $\mathrm{km}$, cidade, entidade específica (exemplo: acesso, passarela, cruzamento, entroncamento, semáforo, etc.);

2. Dados dos acidentes de tráfego, do maior período de tempo disponível, que transformaram o local (ou segmento) em ponto negro, antes da restrição de velocidade para redução ou mitigação dos acidentes;

3. Data do inicio de operação efetiva de nova velocidade implantada;

4. Dados dos acidentes de tráfego, do maior período de tempo disponível, após o tratamento do local com a solução técnica escolhida;

e, se disponível:

5. Volume de tráfego do local e sua classificação;

6. Registro fotográfico do trecho ou local crítico;

Ainda, e aos efeitos de aplicação de metodologia de comparação com locais de referencia, identificação de outra(s) travessia(s) urbana(s) com similares características operacionais que não recebeu tratamento, sempre que existentes. Nestes casos, se pede informar os mesmos elementos dos itens 1, 2, 4, e 5 acima, sempre que disponíveis,

A partir do material recebido, se realizará uma seleção de casos e, se necessário, se solicitarão os elementos faltantes para completar a informação mínima necessária para aplicar a metodologia escolhida.

Destaco que o material em questão será utilizado exclusivamente com fines acadêmicos, e que uma copia do trabalho resultante será entregue a essa Agencia, para uso técnico.

Propõe-se que junto com o envio das informações se informe a pessoa de contato que poderá ser consultada para avançar na analise do assunto.

Fico a disposição para esclarecimentos ou complementações necessários, assim como para combinar o envio das informações, que poderão ser realizadas por e-mail a jcamin@terra.com.br ou no endereço abaixo.

Desde já agradeço a atenção e a colaboração.

Atenciosamente, 
8.2. PLANILHAS COM RESULTADOS DE ACIDENTES COM DANOS MATERIAIS 
TABELA 8. 1 - RESULTADOS PARA REDUÇÃO DE VELOCIDADE (DM)

\begin{tabular}{|c|c|c|c|c|c|c|c|c|c|c|c|c|c|c|c|c|c|}
\hline \multicolumn{11}{|c|}{ RESUMO POR TIPO DE SOLUÇÃO APLICADA } & \multicolumn{7}{|c|}{ RESULTADO MÉTODO "ANTES-DEPOIS" INGÊNUO } \\
\hline & LOCAL & TRATAMENTO & $\begin{array}{l}\text { Tempo } \\
\text { antes } \\
\text { (ano) }\end{array}$ & $\begin{array}{l}\text { Tempo } \\
\text { depois } \\
\text { (ano) } \\
\end{array}$ & $\begin{array}{l}\text { VDM } \\
\text { antes }\end{array}$ & $\begin{array}{l}\text { VDM } \\
\text { depois }\end{array}$ & $\begin{array}{c}r d= \\
T d / T a\end{array}$ & $\begin{array}{c}r f t= \\
V d / V a\end{array}$ & $\mathrm{~K}$ & $\mathbf{L}$ & $\pi$ & $\boldsymbol{\lambda}$ & $\delta=\pi-\lambda$ & $\theta^{\prime}$ & $\begin{array}{c}\text { Redução } \\
1 \text { - } \theta^{\prime}\end{array}$ & $\sigma(\delta)$ & $\sigma(\theta)$ \\
\hline 1 & $\begin{array}{c}\text { Rodovia SP310 } \\
\text { Km 172 ao } 177 \\
\text { Travessia } \\
\text { Urbana de Rio } \\
\text { Claro }\end{array}$ & \begin{tabular}{|c} 
REDUÇÃO DE VELOCIDADE DE \\
$110 \mathrm{~A} 90 \mathrm{KM} / \mathrm{H}$ \\
Realizado em Jan00
\end{tabular} & 2,00 & 8,83 & 15.274 & 21.461 & 4,42 & 1,41 & 113 & 417 & 701 & 417 & 284 & 0,59 & $41,1 \%$ & 33 & 0,036 \\
\hline 5 & $\begin{array}{c}\text { Rodovia SP300 } \\
\text { km 68+500 ao } \\
69+500 \text { - Jundiaí } \\
\text { Travessia de } \\
\text { Pedestres }\end{array}$ & $\begin{array}{l}\text { Implantação de reforço de } \\
\text { sinalização horizontal e } \\
\text { vertical de travessia de } \\
\text { pedestres, redutor de } \\
\text { velocidade, tela de proteção } \\
\text { no cantei ro central, } \\
\text { iluminação e radar } \\
\text { finalizada em 01/05/09 } \\
\text { REDUÇÃO DE VELOCIDADE DE } \\
110 \text { A } 80 \text { KM/H }\end{array}$ & 6,33 & 1,67 & 26.717 & 20.069 & 0,26 & 0,75 & 60 & 7 & 12 & 7 & 5 & 0,58 & $41,9 \%$ & 4 & 0,255 \\
\hline 8 & $\begin{array}{c}\text { Rodovia SP } 225 \\
\text { Km } 177 \text { ao } 185 \\
\text { Travessia } \\
\text { Urbana de Jau }\end{array}$ & $\begin{array}{c}\text { Após estudo técnico, a } \\
\text { velocidade foi reduzida de } \\
110 \mathrm{~km} / \mathrm{h} \text { para } 90 \mathrm{~km} / \mathrm{h} \mathrm{em} \\
\text { jan } / 2009 .\end{array}$ & 7,00 & 2,00 & 16.786 & 28.014 & 0,29 & 1,67 & 308 & 111 & 147 & 111 & 36 & 0,75 & $24,7 \%$ & 16 & 0,094 \\
\hline 12 & $\begin{array}{c}\text { Rodovia SP075 } \\
\text { km } 66+000 \text { ao } \\
67+000- \\
\text { Campinas } \\
\text { Travessia de } \\
\text { Pedestres }\end{array}$ & \begin{tabular}{|} 
Implantação de sinalização \\
horizontal e vertical de \\
travessia de pedestres e \\
tela de proteção no canteiro \\
central finalizada em \\
$01 / 12 / 09$ \\
REDUÇÃO DE VELOCIDADE DE \\
110 A $80 \mathrm{KM} / \mathrm{H}$ \\
\end{tabular} & 6,92 & 1,08 & 36.514 & 47.201 & 0,16 & 1,29 & 450 & 52 & 91 & 52 & 39 & 0,57 & $43,2 \%$ & 12 & 0,098 \\
\hline \multicolumn{9}{|c|}{4,00} & 931 & 586 & 951 & 586 & 364 & 0,62 & $38,4 \%$ & 39 & 0,032 \\
\hline
\end{tabular}

Fonte: Base de Dados gerada pelo autor (2011) 
TABELA 8. 2 - RESULTADOS PARA IMPLANTAÇÃO DE DEFESA NEW JERSEY ELEVADA (DM)

\begin{tabular}{|c|c|c|c|c|c|c|c|c|c|c|c|c|c|c|c|c|c|}
\hline \multicolumn{11}{|c|}{ RESUMO POR TIPO DE SOLUÇÃO APLICADA } & \multicolumn{7}{|c|}{ RESULTADO MÉTODO "ANTES-DEPOIS" INGÊNUO } \\
\hline & LOCAL & TRATAMENTO & $\begin{array}{l}\text { Tempo } \\
\text { antes } \\
\text { (ano) }\end{array}$ & $\begin{array}{l}\text { Tempo } \\
\text { depois } \\
\text { (ano) }\end{array}$ & $\begin{array}{l}\text { VDM } \\
\text { antes }\end{array}$ & $\begin{array}{l}\text { VDM } \\
\text { depois }\end{array}$ & $\begin{array}{c}r d= \\
T d / T a\end{array}$ & $\begin{array}{c}\mathrm{rft}= \\
\mathrm{Vd} / \mathrm{Va}\end{array}$ & K & $\mathrm{L}$ & $\pi$ & $\lambda$ & $\delta=\pi-\lambda$ & $\theta^{\prime}$ & $\begin{array}{c}\text { Redução } \\
1 \text { - } \theta^{\prime}\end{array}$ & $\sigma(\delta)$ & $\sigma(\theta)$ \\
\hline 2 & \begin{tabular}{|c|} 
Rodovia SP310 \\
Km 174 ao 176 \\
Travessia Urbana de \\
Rio Claro
\end{tabular} & $\begin{array}{c}\text { Construção de NJ alta e novo } \\
\text { sistema de drenagem na pista } \\
\text { Sul } \\
\text { Realizado em Nov08 }\end{array}$ & 6,83 & 2,17 & 22.548 & 27.575 & 0,32 & 1,22 & 187 & 85 & 72 & 85 & (13) & 1,17 & $-17,6 \%$ & 13 & 0,184 \\
\hline 4 & \begin{tabular}{|c|} 
Rodovia SP310 \\
Km 231 ao 235 \\
Travessia Urbana de \\
São Carlos
\end{tabular} & $\begin{array}{l}\text { Construção de NJ alta } \\
\text { Concluído em jun2004 } \\
\text { (adotado) }\end{array}$ & 2,50 & 6,50 & 23.788 & 27.309 & 2,60 & 1,15 & 75 & 226 & 224 & 226 & (2) & 21,21 & $-1,0 \%$ & 894 & 0,017 \\
\hline & & & & & & & & & 262 & 311 & 296 & 311 & (15) & 1,05 & $-4,6 \%$ & 25 & 0,085 \\
\hline
\end{tabular}

Fonte: Base de Dados gerada pelo autor (2011) 
TABELA 8. 3 - RESULTADOS PARA CONSTRUÇÃO DE NOVO DISPOSITIVO DE ACESSO (DM)

\begin{tabular}{|c|c|c|c|c|c|c|c|c|c|c|c|c|c|c|c|c|c|}
\hline \multicolumn{11}{|c|}{ RESUMO POR TIPO DE SOLUÇÃO APLICADA } & \multicolumn{7}{|c|}{ RESULTADO MÉTODO "ANTES-DEPOIS" INGÊNUO } \\
\hline & LOCAL & TRATAMENTO & $\begin{array}{l}\text { Tempo } \\
\text { antes } \\
\text { (ano) }\end{array}$ & $\begin{array}{l}\text { Tempo } \\
\text { depois } \\
\text { (ano) }\end{array}$ & $\begin{array}{l}\text { VDM } \\
\text { antes }\end{array}$ & $\begin{array}{l}\text { VDM } \\
\text { depois }\end{array}$ & $\begin{array}{c}r d= \\
\mathrm{Td} / \mathrm{Ta}\end{array}$ & $\begin{array}{c}\mathrm{rft}= \\
\mathrm{Vd} / \mathrm{Va}\end{array}$ & $\mathrm{K}$ & $\mathbf{L}$ & $\pi$ & $\lambda$ & $\delta=\pi-\lambda$ & $\theta^{\prime}$ & $\begin{array}{c}\text { Redução } \\
1 \text { - } \theta^{\prime}\end{array}$ & $\sigma(\delta)$ & $\sigma(\theta)$ \\
\hline \multirow[t]{2}{*}{3} & \begin{tabular}{|c|} 
Rodovia SP310 \\
Km 159 ao 161 \\
Travessia Urbana \\
de Cordeirópolis
\end{tabular} & $\begin{array}{c}\text { Construção de mais } 1 \\
\text { dispositivo de acesso no } \\
\text { Km 161+200 } \\
\text { Concluído em Set08 }\end{array}$ & 6,75 & 2,25 & 21.309 & 27.386 & 0,33 & 1,29 & 159 & 50 & 68 & 50 & 18 & 0,72 & $27,1 \%$ & 11 & 0,133 \\
\hline & & & & & & & & & 159 & 50 & 68 & 50 & 18 & 0,72 & $27,1 \%$ & 11 & 0,133 \\
\hline
\end{tabular}

Fonte: Base de Dados gerada pelo autor (2011) 
TABELA 8. 4 - RESULTADOS PARA A SOLUÇÃo CRUZAMENTO DE PEDESTRE EM NÍVEL EM ÁREA ESPECIALMENTE DEMARCADA (DM)

\begin{tabular}{|c|c|c|c|c|c|c|c|c|c|c|c|c|c|c|c|c|c|}
\hline \multicolumn{11}{|c|}{ RESUMO POR TIPO DE SOLUÇÃO APLICADA } & \multicolumn{7}{|c|}{ RESULTADO MÉTODO "ANTES-DEPOIS" INGÊNUO } \\
\hline & LOCAL & TRATAMENTO & $\begin{array}{c}\text { Tempo } \\
\text { antes } \\
\text { (ano) }\end{array}$ & $\begin{array}{c}\text { Tempo } \\
\text { depois } \\
\text { (ano) }\end{array}$ & $\begin{array}{l}\text { VDM } \\
\text { antes }\end{array}$ & $\begin{array}{c}\text { VDM } \\
\text { depois }\end{array}$ & $\begin{array}{c}\mathrm{rd}= \\
\mathrm{Td} / \mathrm{Ta}\end{array}$ & $\begin{array}{c}\mathrm{rft}= \\
\mathrm{Vd} / \mathrm{Va}\end{array}$ & K & $\mathbf{L}$ & $\pi$ & $\lambda$ & $\delta=\pi-\lambda$ & $\theta^{\prime}$ & $\begin{array}{c}\text { Redução } \\
1 \text { - } \theta^{\prime}\end{array}$ & $\sigma(\delta)$ & $\sigma(\theta)$ \\
\hline 5 & $\begin{array}{c}\text { Rodovia SP300 km } \\
68+500 \text { ao } 69+500 \\
\text { Jundiaí } \\
\text { Travessia de } \\
\text { Pedestres }\end{array}$ & \begin{tabular}{|} 
Implantação de reforço de \\
sinalização horizontal e \\
vertical de travessia de \\
pedestres, redutor de \\
velocidade, tela de proteção \\
no canteiro central, \\
iluminação e radar finalizada \\
em 01/05/09 \\
REDUÇÃO DE VELOCIDADE DE \\
110 A $80 \mathrm{KM} / \mathrm{H}$
\end{tabular} & 6,33 & 1,67 & 26.717 & 20.069 & 0,26 & 0,75 & 60 & 7 & 12 & 7 & 5 & 0,58 & $41,9 \%$ & 4 & 0,255 \\
\hline 12 & $\begin{array}{c}\text { Rodovia SP075 km } \\
66+000 \text { ao } 67+000 \\
\text { Campinas } \\
\text { Travessia de } \\
\text { Pedestres }\end{array}$ & \begin{tabular}{|c|} 
Implantação de sinalização \\
horizontal e vertical de \\
travessia de pedestres e \\
tela de proteção no canteiro \\
central finalizada em \\
$01 / 12 / 09$ \\
REDUÇÃO DE VELOCIDADE DE \\
110 A $80 \mathrm{KM} / \mathrm{H}$ \\
\end{tabular} & 6,92 & 1,08 & 36.514 & 47.201 & 0,16 & 1,29 & 450 & 52 & 91 & 52 & 39 & 0,57 & $43,2 \%$ & 12 & 0,098 \\
\hline & & & & & & & & & 510 & 59 & 103 & 59 & 44 & 0,57 & $43,1 \%$ & 13 & 0,092 \\
\hline
\end{tabular}

Fonte: Base de Dados gerada pelo autor (2011) 
TABELA 8. 5 - RESULTADOS PARA IMPLANTAÇÃO DE PASSARELA, SEM CASO 6 (DM)

\begin{tabular}{|c|c|c|c|c|c|c|c|c|c|c|c|c|c|c|c|c|c|}
\hline \multicolumn{11}{|c|}{ RESUMO POR TIPO DE SOLUÇÃO APLICADA } & \multicolumn{7}{|c|}{ RESULTADO MÉTODO "ANTES-DEPOIS" INGÊNUO } \\
\hline & LOCAL & TRATAMENTO & $\begin{array}{c}\text { Tempo } \\
\text { antes } \\
\text { (ano) }\end{array}$ & $\begin{array}{c}\text { Tempo } \\
\text { depois } \\
\text { (ano) }\end{array}$ & $\begin{array}{l}\text { VDM } \\
\text { antes }\end{array}$ & $\begin{array}{l}\text { VDM } \\
\text { depois }\end{array}$ & $\begin{array}{l}\mathrm{rd}= \\
\mathrm{Td} / \mathrm{Ta}\end{array}$ & $\begin{array}{c}\mathrm{rft}= \\
\mathrm{Vd} / \mathrm{Va}\end{array}$ & K & L & $\pi$ & $\boldsymbol{\lambda}$ & $\delta=\pi-\lambda$ & $\theta^{\prime}$ & $\begin{array}{c}\text { Redução } \\
1-\theta^{\prime}\end{array}$ & $\sigma(\delta)$ & $\sigma(\theta)$ \\
\hline 7 & \begin{tabular}{|c|} 
Rodovia SP300 km \\
$\begin{array}{c}82+000 \text { - Cabreuva } \\
\text { Travessia de } \\
\text { Pedestres }\end{array}$ \\
\end{tabular} & $\begin{array}{l}\text { Construção de Passarela } \\
\text { Finalizada em 02/09/06 }\end{array}$ & 3,67 & 4,33 & 10.255 & 12.274 & 1,18 & 1,20 & 54 & 51 & 76 & 51 & 25 & 0,66 & $33,6 \%$ & 11 & 0,118 \\
\hline 10 & \begin{tabular}{|c} 
Rodovia SP127 km \\
$88+000$ - Cerquilho \\
Travessia de \\
Pedestres \\
\end{tabular} & $\begin{array}{l}\text { Construção de Passarela } \\
\text { Finalizada em 02/03/07 }\end{array}$ & 4,17 & 3,83 & 4.893 & 7.003 & 0,92 & 1,43 & 26 & 12 & 34 & 12 & 22 & 0,34 & $66,2 \%$ & 7 & 0,110 \\
\hline 13 & $\begin{array}{c}\text { Rodovia SP075 km } \\
64+000 \text { - Campinas } \\
\text { Travessia de } \\
\text { Pedestres } \\
\end{array}$ & $\begin{array}{l}\text { Construção de Passarela } \\
\text { Finalizada em 02/03/07 }\end{array}$ & 4,17 & 3,83 & 18.581 & 23.377 & 0,92 & 1,26 & 64 & 46 & 74 & 46 & 28 & 0,61 & $38,9 \%$ & 11 & 0,113 \\
\hline & & & & & & & & & 144 & 109 & 184 & 109 & 75 & 0,59 & $40,8 \%$ & 17 & 0,0710 \\
\hline
\end{tabular}

Fonte: Base de Dados gerada pelo autor (2011) 
TABELA 8. 6 - RESULTADOS PARA IMPLANTAÇÃO DE CICLOVIA (DM)

\begin{tabular}{|c|c|c|c|c|c|c|c|c|c|c|c|c|c|c|c|c|c|}
\hline \multicolumn{11}{|c|}{ RESUMO DE RESULTADOS POR TIPO DE SOLUÇÃO APLICADA } & \multicolumn{7}{|c|}{ RESULTADO MÉTODO "ANTES-DEPOIS" INGÊNUO } \\
\hline & LOCAL & TRATAMENTO & $\begin{array}{c}\text { Tempo } \\
\text { antes } \\
\text { (ano) }\end{array}$ & $\begin{array}{c}\text { Tempo } \\
\text { depois } \\
\text { (ano) }\end{array}$ & $\begin{array}{l}\text { VDM } \\
\text { antes }\end{array}$ & $\begin{array}{c}\text { VDM } \\
\text { depois }\end{array}$ & $\begin{array}{l}r d= \\
\mathrm{Td} / \mathrm{Ta}\end{array}$ & $\begin{array}{c}\mathrm{rft}= \\
\mathrm{Vd} / \mathrm{Va}\end{array}$ & $\mathrm{K}$ & L & $\pi$ & $\lambda$ & $\delta=\pi-\lambda$ & $\theta^{\prime}$ & $\begin{array}{c}\text { Redução } \\
1-\theta^{\prime}\end{array}$ & $\sigma(\delta)$ & $\sigma(\theta)$ \\
\hline 9 & $\begin{array}{c}\text { Rodovia SP127 km } \\
0 \text { ao } 3+000 \text { - Rio } \\
\text { Claro } \\
\text { Ciclistas e } \\
\text { Pedestres na Pista }\end{array}$ & $\begin{array}{l}\text { Construção de Ciclovia } \\
\text { finalizada em 01/12/06 }\end{array}$ & 3,92 & 4,08 & 6.754 & 9.427 & 1,04 & 1,40 & 132 & 116 & 191 & 116 & 75 & 0,60 & $39,7 \%$ & 18 & 0,071 \\
\hline & & & & & & & & & 132 & 116 & 191 & 116 & 75 & 0,60 & $39,7 \%$ & 18 & 0,071 \\
\hline
\end{tabular}

Fonte: Base de Dados gerada pelo autor (2011) 
TABELA 8. 7 - RESULTADOS PARA A SOLUÇÃO IMPLANTAÇÃO DE PASSAGEM SUPERIOR E TELA PROTETORA PARA IMPEDIR CRUZE DE PEDESTRES (DM)

\begin{tabular}{|c|c|c|c|c|c|c|c|c|c|c|c|c|c|c|c|c|c|}
\hline \multicolumn{11}{|c|}{ RESUMO DE RESULTADOS POR TIPO DE SOLUÇÃO APLICADA } & \multicolumn{7}{|c|}{ RESULTADO MÉTODO "ANTES-DEPOIS" INGÊNUO } \\
\hline & LOCAL & TRATAMENTO & $\begin{array}{c}\text { Tempo } \\
\text { antes } \\
\text { (ano) }\end{array}$ & $\begin{array}{c}\text { Tempo } \\
\text { depois } \\
\text { (ano) }\end{array}$ & $\begin{array}{l}\text { VDM } \\
\text { antes }\end{array}$ & $\begin{array}{l}\text { VDM } \\
\text { depois }\end{array}$ & $\begin{array}{c}r d= \\
T d / T a\end{array}$ & $\begin{array}{c}r f t= \\
V d / V a\end{array}$ & $\mathrm{~K}$ & L & $\pi$ & $\lambda$ & $\delta=\pi-\lambda$ & $\theta^{\prime}$ & $\begin{array}{c}\text { Redução } \\
1-\theta^{\prime}\end{array}$ & $\sigma(\delta)$ & $\sigma(\theta)$ \\
\hline 11 & $\begin{array}{c}\text { Rodovia SP075 km } \\
29+000 \text { ao } 32+000 \\
\text { Itu } \\
\text { Travessia de } \\
\text { Pedestres }\end{array}$ & $\begin{array}{l}\text { Tela de proteção no canteiro } \\
\text { central e construção de } \\
\text { escadas nos } \\
\text { viadutos do km } 29 \text { e km } 32 \\
\text { finalizada em } 01 / 09 / 08\end{array}$ & 5,67 & 2,33 & 24.062 & 31.249 & 0,41 & 1,30 & 216 & 118 & 115 & 118 & (3) & 1,02 & $-2,1 \%$ & 15 & 0,132 \\
\hline & & & & & & & & & 216 & 118 & 115 & 118 & (3) & 1,02 & $-2,1 \%$ & 15 & 0,132 \\
\hline
\end{tabular}

Fonte: Base de Dados gerada pelo autor (2011) 
TABELA 8. 8 - RESULTADOS PELO MÉTODO DE G-C (DM)

\begin{tabular}{|c|c|c|c|c|c|c|c|}
\hline \multicolumn{8}{|c|}{ RESULTADO MÉTODO "ANTES-DEPOIS" GRUPOS DE COMPARAÇÃO } \\
\hline \multicolumn{8}{|c|}{ Tratamento Tipo 1 - Redução de velocidade } \\
\hline \multicolumn{8}{|c|}{ DADOS } \\
\hline \multirow{2}{*}{ Site } & Tratamento & Tratamento & Comparação & Comparação & Compara ção & Tratamento & Compa ra ção \\
\hline & Antes & Depois & Antes & Depois & $V \hat{A} R\{w\}$ & \multicolumn{2}{|c|}{$\mathrm{rtf}=\mathrm{VDM}$ depois $/$ VDM antes } \\
\hline j & $K(j)$ & $L(j)$ & $M(j)$ & $N(j)$ & calculado & calculado & calculado \\
\hline 1 & 113 & 417 & \multicolumn{5}{|c|}{ Não se aplica por falta de dados } \\
\hline 5 & 60 & 7 & \multicolumn{5}{|c|}{ Não se encontrou GC adequado } \\
\hline 8 & 265 & 111 & 836 & 255 & 0,0661 & 1,6689 & 1,2380 \\
\hline 12 & 455 & 47 & 955 & 136 & 0,0700 & 1,2927 & 1,2722 \\
\hline \multicolumn{6}{|c|}{ SITES INDIVIDUAIS } & & \\
\hline & $\hat{\lambda}$ & $\hat{r}$ & $\hat{\pi}$ & $\operatorname{Var}\{\hat{\lambda \mathrm{j})}\}$ & $\operatorname{Var}\{\hat{\pi}(\mathrm{j})\}$ & & \\
\hline 1 & \multicolumn{5}{|c|}{ Não se aplica por falta de dados } & & \\
\hline 5 & \multicolumn{5}{|c|}{ Não se encontrou GC adequado } & & \\
\hline 8 & 111 & 0,2461 & 108,86 & 111 & 888,94 & & \\
\hline 12 & 47 & 0,1118 & 65,79 & 47 & 348,72 & & \\
\hline \multicolumn{6}{|c|}{ SITES AGRUPADOS } & & \\
\hline \multirow{2}{*}{ Etapa 1} & $\hat{\lambda}$ & 158 & & & & & \\
\hline & $\hat{\pi}$ & 175 & & & & & \\
\hline \multirow{2}{*}{ Etapa 2} & $\operatorname{VÂR}\{\hat{\lambda}\}$ & 158 & & & & & \\
\hline & VÂR $\{\hat{\pi}\}$ & 1.238 & & & & & \\
\hline \multirow{2}{*}{ Etapa 3} & $\hat{\bar{\delta}}$ & 17 & & & & & \\
\hline & $\hat{\bar{\theta}}$ & 0,869 & $1-\hat{\theta}$ & $13,1 \%$ & & & \\
\hline \multirow{2}{*}{ Etapa 4} & $\hat{\sigma}\{\hat{\delta}\}$ & 37,36 & & & & & \\
\hline & $\hat{\sigma}\{\hat{\bar{\theta}}\}$ & 0,185 & & & & & \\
\hline \multicolumn{8}{|c|}{ Tratamento Tipo 5 - Implantação de Passarelas } \\
\hline \multicolumn{8}{|c|}{ DADOS } \\
\hline \multirow{2}{*}{ Site } & Tratamento & Tratamento & Comparação & Comparação & $\operatorname{VÂ} R\{w\}$ & Tratamento & Compara ção \\
\hline & Antes & Depois & Antes & Depois & & \multicolumn{2}{|c|}{ rtf = VDM depois / VDM antes } \\
\hline j & $K(j)$ & $L(j)$ & $M(j)$ & $N(j)$ & calculado & calculado & calculado \\
\hline 7 & 60 & 45 & 75 & 70 & 0,0270 & 1,1969 & 1,1308 \\
\hline 10 & 25 & 13 & 75 & 70 & - & 1,4312 & 1,1308 \\
\hline 13 & 356 & 146 & 93 & 52 & 0,0941 & 1,2581 & 1,1425 \\
\hline \multicolumn{6}{|c|}{ SITES INDIVIDUAIS } & & \\
\hline & $\hat{\lambda}$ & $\hat{r}$ & $\hat{\pi}$ & $\operatorname{Var}\{\hat{\lambda}(\mathrm{j})\}$ & $\operatorname{Var}\{\hat{\pi}(\mathrm{j})\}$ & & \\
\hline 7 & 45 & 0,8158 & 58,58 & 45 & 244,49 & & \\
\hline 10 & 13 & 0,8158 & 29,19 & 13 & 57,61 & & \\
\hline 13 & 146 & 0,4848 & 217,16 & 146 & $5.986,14$ & & \\
\hline \multicolumn{6}{|c|}{ SITES AGRUPADOS } & & \\
\hline \multirow{2}{*}{ Etapa 1} & $\hat{\lambda}$ & 204 & & & & & \\
\hline & $\hat{\pi}$ & 305 & & & & & \\
\hline Etapa 2 & $\operatorname{VÂR}\{\hat{\lambda}\}$ & 204 & & & & & \\
\hline thest & $\operatorname{VÂR}\{\hat{\pi}\}$ & 6.288 & & & & & \\
\hline Etapa 3 & $\hat{\delta}$ & 101 & & & & & \\
\hline & $\hat{\bar{\theta}}$ & 0,627 & $1-\hat{\theta}$ & $37,3 \%$ & & & \\
\hline Etapa 4 & $\hat{\sigma}\{\hat{\delta}\}$ & 80,57 & & & & & \\
\hline cents & $\hat{\sigma}\{\hat{\hat{\theta}}\}$ & 0,163 & & & & & \\
\hline
\end{tabular}

Fonte: Base de Dados gerada pelo autor (2011) 
8.3. PLANILHAS COM RESULTADOS DE ACIDENTES COM FERIDOS E MORTOS 
TABELA 8. 9 - RESULTADOS PARA REDUÇÃO DE VELOCIDADE (FE+MO)

\begin{tabular}{|c|c|c|c|c|c|c|c|c|c|c|c|c|c|c|c|c|c|}
\hline \multicolumn{11}{|c|}{ RESUMO POR TIPO DE SOLUÇÃO APLICADA } & \multicolumn{7}{|c|}{ RESULTADO MÉTODO "ANTES-DEPOIS" INGÊNUO } \\
\hline & LOCAL & TRATAMENTO & $\begin{array}{l}\text { Tempo } \\
\text { antes } \\
\text { (ano) }\end{array}$ & $\begin{array}{l}\text { Tempo } \\
\text { depois } \\
\text { (ano) } \\
\end{array}$ & $\begin{array}{l}\text { VDM } \\
\text { antes }\end{array}$ & $\begin{array}{l}\text { VDM } \\
\text { depois }\end{array}$ & $\begin{array}{c}r d= \\
T d / T a\end{array}$ & $\begin{array}{c}r f t= \\
V d / V a\end{array}$ & $\mathrm{~K}$ & $\mathbf{L}$ & $\pi$ & $\boldsymbol{\lambda}$ & $\delta=\pi-\lambda$ & $\theta^{\prime}$ & $\begin{array}{c}\text { Redução } \\
1 \text { - } \theta^{\prime}\end{array}$ & $\sigma(\delta)$ & $\sigma(\theta)$ \\
\hline 1 & $\begin{array}{c}\text { Rodovia SP310 } \\
\text { Km 172 ao } 177 \\
\text { Travessia } \\
\text { Urbana de Rio } \\
\text { Claro }\end{array}$ & \begin{tabular}{|c} 
REDUÇÃO DE VELOCIDADE DE \\
$110 \mathrm{~A} 90 \mathrm{KM} / \mathrm{H}$ \\
Realizado em Jan00
\end{tabular} & 2,00 & 8,83 & 15.274 & 21.461 & 4,42 & 1,41 & 48 & 251 & 298 & 251 & 47 & 0,82 & $17,5 \%$ & 23 & 0,070 \\
\hline 5 & $\begin{array}{c}\text { Rodovia SP300 } \\
\text { km } 68+500 \text { ao } \\
69+500 \text { - Jundiaí } \\
\text { Travessia de } \\
\text { Pedestres }\end{array}$ & $\begin{array}{l}\text { Implantação de reforço de } \\
\text { sinalização horizontal e } \\
\text { vertical de travessia de } \\
\text { pedestres, redutor de } \\
\text { velocidade, tela de proteção } \\
\text { no cantei ro central, } \\
\text { iluminação e radar } \\
\text { finalizada em 01/05/09 } \\
\text { REDUÇÃO DE VELOCIDADE DE } \\
110 \text { A } 80 \text { KM/H }\end{array}$ & 6,33 & 1,67 & 26.717 & 20.069 & 0,26 & 0,75 & 36 & 8 & 7 & 8 & (0) & 1,04 & $-3,9 \%$ & 4 & 0,474 \\
\hline 8 & $\begin{array}{c}\text { Rodovia SP } 225 \\
\text { Km } 177 \text { ao } 185 \\
\text { Travessia } \\
\text { Urbana de Jau }\end{array}$ & $\begin{array}{c}\text { Após estudo técnico, a } \\
\text { velocidade foi reduzida de } \\
110 \mathrm{~km} / \mathrm{h} \text { para } 90 \mathrm{~km} / \mathrm{h} \mathrm{em} \\
\text { jan } / 2009 .\end{array}$ & 7,00 & 2,00 & 16.786 & 28.014 & 0,29 & 1,67 & 230 & 69 & 110 & 69 & 41 & 0,63 & $37,4 \%$ & 13 & 0,095 \\
\hline 12 & $\begin{array}{c}\text { Rodovia SP075 } \\
\text { km } 66+000 \text { ao } \\
67+000- \\
\text { Campinas } \\
\text { Travessia de } \\
\text { Pedestres }\end{array}$ & \begin{tabular}{|} 
Implantação de sinalização \\
horizontal e vertical de \\
travessia de pedestres e \\
tela de proteção no canteiro \\
central finalizada em \\
$01 / 12 / 09$ \\
REDUÇÃO DE VELOCIDADE DE \\
110 A $80 \mathrm{KM} / \mathrm{H}$ \\
\end{tabular} & 6,92 & 1,08 & 36.514 & 47.201 & 0,16 & 1,29 & 299 & 55 & 61 & 55 & 5 & 0,91 & $9,3 \%$ & 11 & 0,166 \\
\hline \multicolumn{9}{|c|}{4,00} & 613 & 382 & 475 & 382 & 93 & 0,80 & $19,6 \%$ & 29 & 0,055 \\
\hline
\end{tabular}

Fonte: Base de Dados gerada pelo autor (2011) 
TABELA 8. 10 - RESULTADOS PARA IMPLANTAÇÃO DE DEFESA NEW JERSEY ELEVADA (FE+MO)

\begin{tabular}{|c|c|c|c|c|c|c|c|c|c|c|c|c|c|c|c|c|c|}
\hline \multicolumn{11}{|c|}{ RESUMO POR TIPO DE SOLUÇÃO APLICADA } & \multicolumn{7}{|c|}{ RESULTADO MÉTODO "ANTES-DEPOIS" INGÊNUO } \\
\hline & LOCAL & TRATAMENTO & $\begin{array}{l}\text { Tempo } \\
\text { antes } \\
\text { (ano) }\end{array}$ & $\begin{array}{l}\text { Tempo } \\
\text { depois } \\
\text { (ano) }\end{array}$ & $\begin{array}{l}\text { VDM } \\
\text { antes }\end{array}$ & $\begin{array}{l}\text { VDM } \\
\text { depois }\end{array}$ & $\begin{array}{c}r d= \\
T d / T a\end{array}$ & $\begin{array}{c}\mathrm{rft}= \\
\mathrm{Vd} / \mathrm{Va}\end{array}$ & K & $\mathrm{L}$ & $\pi$ & $\lambda$ & $\delta=\pi-\lambda$ & $\theta^{\prime}$ & $\begin{array}{c}\text { Redução } \\
1 \text { - } \theta^{\prime}\end{array}$ & $\sigma(\delta)$ & $\sigma(\theta)$ \\
\hline 2 & \begin{tabular}{|c|} 
Rodovia SP310 \\
Km 174 ao 176 \\
Travessia Urbana de \\
Rio Claro
\end{tabular} & $\begin{array}{c}\text { Construção de NJ alta e novo } \\
\text { sistema de drenagem na pista } \\
\text { Sul } \\
\text { Realizado em Nov08 }\end{array}$ & 6,83 & 2,17 & 22.548 & 27.575 & 0,32 & 1,22 & 152 & 94 & 59 & 94 & (36) & 1,59 & $-60,4 \%$ & 12 & 0,260 \\
\hline 4 & \begin{tabular}{|c|} 
Rodovia SP310 \\
Km 231 ao 235 \\
Travessia Urbana de \\
São Carlos
\end{tabular} & $\begin{array}{l}\text { Construção de NJ alta } \\
\text { Concluído em jun2004 } \\
\text { (adotado) }\end{array}$ & 2,50 & 6,50 & 23.788 & 27.309 & 2,60 & 1,15 & 41 & 165 & 121 & 165 & (44) & 16,89 & $-36,1 \%$ & 525 & 0,052 \\
\hline & & & & & & & & & 192 & 259 & 180 & 259 & (79) & 1,43 & $-42,9 \%$ & 21 & 0,138 \\
\hline
\end{tabular}

Fonte: Base de Dados gerada pelo autor (2011) 
TABELA 8. 11 - Resultados para construção de novo dispositivo de acesso (FE+MO)

\begin{tabular}{|c|c|c|c|c|c|c|c|c|c|c|c|c|c|c|c|c|c|}
\hline \multicolumn{11}{|c|}{ RESUMO POR TIPO DE SOLUÇÃO APLICADA } & \multicolumn{7}{|c|}{ RESULTADO MÉTODO "ANTES-DEPOIS" INGÊNUO } \\
\hline & LOCAL & TRATAMENTO & $\begin{array}{c}\text { Tempo } \\
\text { antes } \\
\text { (ano) }\end{array}$ & $\begin{array}{l}\text { Tempo } \\
\text { depois } \\
\text { (ano) }\end{array}$ & $\begin{array}{l}\text { VDM } \\
\text { antes }\end{array}$ & $\begin{array}{l}\text { VDM } \\
\text { depois }\end{array}$ & $\begin{array}{c}\mathrm{rd}= \\
\mathrm{Td} / \mathrm{Ta}\end{array}$ & $\begin{array}{c}r f t= \\
V d / V a\end{array}$ & K & $\mathrm{L}$ & $\pi$ & $\lambda$ & $\delta=\pi-\lambda$ & $\theta^{\prime}$ & $\begin{array}{c}\text { Redução } \\
1 \text { - } \theta^{\prime}\end{array}$ & $\sigma(\delta)$ & $\sigma(\theta)$ \\
\hline \multirow[t]{2}{*}{3} & $\begin{array}{c}\text { Rodovia SP310 } \\
\text { Km } 159 \text { ao } 161 \\
\text { Travessia Urbana } \\
\text { de Cordeirópolis }\end{array}$ & $\begin{array}{c}\text { Construção de mais } 1 \\
\text { dispositivo de acesso no } \\
\text { Km } 161+200 \\
\text { Concluído em Set08 }\end{array}$ & 6,75 & 2,25 & 21.309 & 27.386 & 0,33 & 1,29 & 79 & 27 & 34 & 27 & 7 & 0,78 & $21,2 \%$ & 8 & 0,196 \\
\hline & & & & & & & & & 79 & 27 & 34 & 27 & 7 & 0,78 & $21,2 \%$ & 8 & 0,196 \\
\hline
\end{tabular}

Fonte: Base de Dados gerada pelo autor (2011) 
TABELA 8. 12 - Resultados para a solução cruzamento de pedestre em nível em área especialmente demarcada (FE+MO)

\begin{tabular}{|c|c|c|c|c|c|c|c|c|c|c|c|c|c|c|c|c|c|}
\hline \multicolumn{11}{|c|}{ RESUMO POR TIPO DE SOLUÇÃO APLICADA } & \multicolumn{7}{|c|}{ RESULTADO MÉTODO "ANTES-DEPOIS" INGÊNUO } \\
\hline & LOCAL & TRATAMENTO & $\begin{array}{c}\text { Tempo } \\
\text { antes } \\
\text { (ano) }\end{array}$ & $\begin{array}{c}\text { Tempo } \\
\text { depois } \\
\text { (ano) }\end{array}$ & $\begin{array}{l}\text { VDM } \\
\text { antes }\end{array}$ & $\begin{array}{l}\text { VDM } \\
\text { depois }\end{array}$ & $\begin{array}{c}\mathrm{rd}= \\
\mathrm{Td} / \mathrm{Ta}\end{array}$ & $\begin{array}{c}\mathrm{rft}= \\
\mathrm{Vd} / \mathrm{Va}\end{array}$ & K & $\mathbf{L}$ & $\pi$ & $\lambda$ & $\delta=\pi-\lambda$ & $\theta^{\prime}$ & $\begin{array}{c}\text { Redução } \\
1 \text { - } \theta^{\prime}\end{array}$ & $\sigma(\delta)$ & $\sigma(\theta)$ \\
\hline 5 & $\begin{array}{c}\text { Rodovia SP300 km } \\
68+500 \text { ao } 69+500 \\
\text { Jundiaí } \\
\text { Travessia de } \\
\text { Pedestres }\end{array}$ & \begin{tabular}{|} 
Implantação de reforço de \\
sinalização horizontal e \\
vertical de travessia de \\
pedestres, redutor de \\
velocidade, tela de proteção \\
no canteiro central, \\
iluminação e radar finalizada \\
em 01/05/09 \\
REDUÇÃO DE VELOCIDADE DE \\
110 A $80 \mathrm{KM} / \mathrm{H}$
\end{tabular} & 6,33 & 1,67 & 26.717 & 20.069 & 0,26 & 0,75 & 36 & 8 & 7 & 8 & (0) & 1,04 & $-3,9 \%$ & 4 & 0,474 \\
\hline 12 & $\begin{array}{c}\text { Rodovia SP075 km } \\
66+000 \text { ao } 67+000 \\
\text { Campinas } \\
\text { Travessia de } \\
\text { Pedestres }\end{array}$ & \begin{tabular}{|c|} 
Implantação de sinalização \\
horizontal e vertical de \\
travessia de pedestres e \\
tela de proteção no canteiro \\
central finalizada em \\
$01 / 12 / 09$ \\
REDUÇÃO DE VELOCIDADE DE \\
$110 \mathrm{~A} 80 \mathrm{KM} / \mathrm{H}$ \\
\end{tabular} & 6,92 & 1,08 & 36.514 & 47.201 & 0,16 & 1,29 & 299 & 55 & 61 & 55 & 5 & 0,91 & $9,3 \%$ & 11 & 0,166 \\
\hline & & & & & & & & & 335 & 63 & 68 & 63 & 5 & 0,91 & $8,6 \%$ & 11 & 0,158 \\
\hline
\end{tabular}

Fonte: Base de Dados gerada pelo autor (2011) 
TABELA 8. 13 - Resultados para implantação de passarela, sem caso 6 (FE+MO)

\begin{tabular}{|c|c|c|c|c|c|c|c|c|c|c|c|c|c|c|c|c|c|}
\hline \multicolumn{11}{|c|}{ RESUMO POR TIPO DE SOLUÇÃO APLICADA } & \multicolumn{7}{|c|}{ RESULTADO MÉTODO "ANTES-DEPOIS" INGÊNUO } \\
\hline & LOCAL & TRATAMENTO & $\begin{array}{c}\text { Tempo } \\
\text { antes } \\
\text { (ano) }\end{array}$ & $\begin{array}{c}\text { Tempo } \\
\text { depois } \\
\text { (ano) }\end{array}$ & $\begin{array}{l}\text { VDM } \\
\text { antes }\end{array}$ & $\begin{array}{l}\text { VDM } \\
\text { depois }\end{array}$ & $\begin{array}{l}\mathrm{rd}= \\
\mathrm{Td} / \mathrm{Ta}\end{array}$ & $\begin{array}{c}\mathrm{rft}= \\
\mathrm{Vd} / \mathrm{Va}\end{array}$ & K & L & $\pi$ & $\boldsymbol{\lambda}$ & $\delta=\pi-\lambda$ & $\theta^{\prime}$ & $\begin{array}{c}\text { Redução } \\
1-\theta^{\prime}\end{array}$ & $\sigma(\delta)$ & $\sigma(\theta)$ \\
\hline 7 & \begin{tabular}{|c|} 
Rodovia SP300 km \\
$\begin{array}{c}82+000 \text { - Cabreuva } \\
\text { Travessia de } \\
\text { Pedestres }\end{array}$ \\
\end{tabular} & $\begin{array}{l}\text { Construção de Passarela } \\
\text { Finalizada em 02/09/06 }\end{array}$ & 3,67 & 4,33 & 10.255 & 12.274 & 1,18 & 1,20 & 30 & 21 & 43 & 21 & 22 & 0,47 & $53,4 \%$ & 8 & 0,122 \\
\hline 10 & \begin{tabular}{|c} 
Rodovia SP127 km \\
$88+000$ - Cerquilho \\
Travessia de \\
Pedestres \\
\end{tabular} & $\begin{array}{l}\text { Construção de Passarela } \\
\text { Finalizada em 02/03/07 }\end{array}$ & 4,17 & 3,83 & 4.893 & 7.003 & 0,92 & 1,43 & 19 & 8 & 25 & 8 & 18 & 0,29 & $71,4 \%$ & 6 & 0,114 \\
\hline 13 & $\begin{array}{c}\text { Rodovia SP075 km } \\
64+000 \text { - Campinas } \\
\text { Travessia de } \\
\text { Pedestres } \\
\end{array}$ & $\begin{array}{l}\text { Construção de Passarela } \\
\text { Finalizada em 02/03/07 }\end{array}$ & 4,17 & 3,83 & 18.581 & 23.377 & 0,92 & 1,26 & 44 & 43 & 51 & 43 & 8 & 0,83 & $16,8 \%$ & 10 & 0,169 \\
\hline & & & & & & & & & 94 & 72 & 119 & 72 & 48 & 0,60 & $40,3 \%$ & 14 & 0,0886 \\
\hline
\end{tabular}

Fonte: Base de Dados gerada pelo autor (2011) 
TABELA 8. 14 - Resultados para implantação de ciclovia (FE+MO)

\begin{tabular}{|c|c|c|c|c|c|c|c|c|c|c|c|c|c|c|c|c|c|}
\hline \multicolumn{11}{|c|}{ RESUMO DE RESULTADOS POR TIPO DE SOLUÇÃO APLICADA } & \multicolumn{7}{|c|}{ RESULTADO MÉTODO "ANTES-DEPOIS" INGÊNUO } \\
\hline & LOCAL & TRATAMENTO & $\begin{array}{c}\text { Tempo } \\
\text { antes } \\
\text { (ano) }\end{array}$ & $\begin{array}{c}\text { Tempo } \\
\text { depois } \\
\text { (ano) }\end{array}$ & $\begin{array}{l}\text { VDM } \\
\text { antes }\end{array}$ & $\begin{array}{c}\text { VDM } \\
\text { depois }\end{array}$ & $\begin{array}{l}r d= \\
\mathrm{Td} / \mathrm{Ta}\end{array}$ & $\begin{array}{c}\mathrm{rft}= \\
\mathrm{Vd} / \mathrm{Va}\end{array}$ & $\mathrm{K}$ & L & $\pi$ & $\lambda$ & $\delta=\pi-\lambda$ & $\theta^{\prime}$ & $\begin{array}{c}\text { Redução } \\
1 \text { - } \theta^{\prime}\end{array}$ & $\sigma(\delta)$ & $\sigma(\theta)$ \\
\hline 9 & $\begin{array}{c}\text { Rodovia SP127 km } \\
0 \text { ao } 3+000 \text { - Rio } \\
\text { Claro } \\
\text { Ciclistas e } \\
\text { Pedestres na Pista }\end{array}$ & $\begin{array}{l}\text { Construção de Ciclovia } \\
\text { finalizada em 01/12/06 }\end{array}$ & 3,92 & 4,08 & 6.754 & 9.427 & 1,04 & 1,40 & 100 & 119 & 146 & 119 & 27 & 0,81 & $19,3 \%$ & 16 & 0,099 \\
\hline & & & & & & & & & 100 & 119 & 146 & 119 & 27 & 0,81 & $19,3 \%$ & 16 & 0,099 \\
\hline
\end{tabular}

Fonte: Base de Dados gerada pelo autor (2011) 
TABELA 8. 15 - Resultados para a solução implantação de passagem superior e tela protetora para impedir cruze de pedestres (FE+MO)

\begin{tabular}{|c|c|c|c|c|c|c|c|c|c|c|c|c|c|c|c|c|c|}
\hline \multicolumn{11}{|c|}{ RESUMO DE RESULTADOS POR TIPO DE SOLUÇÃO APLICADA } & \multicolumn{7}{|c|}{ RESULTADO MÉTODO "ANTES-DEPOIS" INGÊNUO } \\
\hline & LOCAL & TRATAMENTO & $\begin{array}{c}\text { Tempo } \\
\text { antes } \\
\text { (ano) }\end{array}$ & $\begin{array}{c}\text { Tempo } \\
\text { depois } \\
\text { (ano) }\end{array}$ & $\begin{array}{l}\text { VDM } \\
\text { antes }\end{array}$ & $\begin{array}{c}\text { VDM } \\
\text { depois }\end{array}$ & $\begin{array}{c}\mathrm{rd}= \\
\mathrm{Td} / \mathrm{Ta}\end{array}$ & $\begin{array}{c}\mathrm{rft}= \\
\mathrm{Vd} / \mathrm{Va}\end{array}$ & K & $\mathbf{L}$ & $\pi$ & $\lambda$ & $\delta=\pi-\lambda$ & $\theta^{\prime}$ & $\begin{array}{c}\text { Redução } \\
1 \text { - } \theta^{\prime}\end{array}$ & $\sigma(\delta)$ & $\sigma(\theta)$ \\
\hline \multirow[t]{2}{*}{11} & $\begin{array}{c}\text { Rodovia SP075 km } \\
29+000 \text { ao } 32+000 \\
\text { Itu } \\
\text { Travessia de } \\
\text { Pedestres }\end{array}$ & $\begin{array}{l}\text { Tela de proteção no canteiro } \\
\text { central e construção de } \\
\text { escadas nos } \\
\text { viadutos do km } 29 \text { e km } 32 \\
\text { finalizada em } 01 / 09 / 08\end{array}$ & 5,67 & 2,33 & 24.062 & 31.249 & 0,41 & 1,30 & 159 & 59 & 85 & 59 & 27 & 0,68 & $31,6 \%$ & 12 & 0,115 \\
\hline & & & & & & & & & 159 & 59 & 85 & 59 & 27 & 0,68 & $31,6 \%$ & 12 & 0,115 \\
\hline
\end{tabular}

Fonte: Base de Dados gerada pelo autor (2011) 
TABELA 8. 16 - Resultados pelo método de G-C (FE+MO)

\begin{tabular}{|c|c|c|c|c|c|c|c|}
\hline \multicolumn{8}{|c|}{ RESULTADO MÉTODO "ANTES-DEPOIS" GRUPOS DE COMPARAÇÃO } \\
\hline \multicolumn{8}{|c|}{ Tratamento Tipo 1 - Redução de velocidade } \\
\hline \multicolumn{8}{|c|}{ DADOS } \\
\hline \multirow{2}{*}{ Site } & Tratamento & Tratamento & Comparação & Comparação & Comparação & Tratamento & Compa ração \\
\hline & Antes & Depois & Antes & Depois & VÂR $\{w\}$ & \multicolumn{2}{|c|}{$\mathrm{rtf}=\mathrm{VDM}$ depois / VDM antes } \\
\hline j & $K(j)$ & L(j) & $M(j)$ & $N(j)$ & calculado & calculado & calculado \\
\hline 1 & 48 & 251 & \multicolumn{5}{|c|}{ Não se aplica por falta de dados } \\
\hline 5 & 36 & 8 & \multicolumn{5}{|c|}{ Não se encontrou GC adequado } \\
\hline 8 & 214 & 69 & 576 & 252 & 0,0172 & 1,6689 & 1,2380 \\
\hline 12 & 302 & 52 & 713 & 115 & 0,0501 & 1,2927 & 1,2722 \\
\hline \multicolumn{6}{|c|}{ SITES INDIVIDUAIS } & & \\
\hline & $\hat{\lambda}$ & $\hat{r}$ & $\hat{\pi}$ & $\operatorname{Var}\{\hat{\lambda \mathrm{j})\}}$ & $\operatorname{Var}\{\hat{\pi}(\mathrm{j})\}$ & & \\
\hline 1 & \multicolumn{5}{|c|}{ Não se aplica por falta de dados } & & \\
\hline 5 & \multicolumn{5}{|c|}{ Não se encontrou GC adequado } & & \\
\hline 8 & 69 & 0,3529 & 126,03 & 69 & 438,46 & & \\
\hline 12 & 52 & 0,1266 & 49,44 & 52 & 155,24 & & \\
\hline \multicolumn{8}{|c|}{ SITES AGRUPADOS } \\
\hline \multirow{2}{*}{ Etapa 1} & $\hat{\lambda}$ & 121 & & & & & \\
\hline & $\hat{\pi}$ & 175 & & & & & \\
\hline \multirow{2}{*}{ Etapa 2} & $\operatorname{VÂ} R\{\hat{\lambda}\}$ & 121 & & & & & \\
\hline & VÂR $\{\hat{\pi}\}$ & 594 & & & & & \\
\hline \multirow{2}{*}{ Etapa 3} & $\hat{\bar{\delta}}$ & 54 & & & & & \\
\hline & $\hat{\bar{\theta}}$ & 0,677 & $1-\hat{\theta}$ & $32,3 \%$ & & & \\
\hline \multirow{2}{*}{ Etapa 4} & $\hat{\sigma}\{\hat{\delta}\}$ & 26,73 & & & & & \\
\hline & $\hat{\sigma}\{\hat{\bar{\theta}}\}$ & 0,111 & & & & & \\
\hline \multicolumn{8}{|c|}{ Tratamento Tipo 5 - Implantação de Passarelas } \\
\hline \multicolumn{8}{|c|}{ DADOS } \\
\hline \multirow{2}{*}{ Site } & Tratamento & Tratamento & Comparação & Comparação & VÂR $\{w\}$ & Tratamento & Comparação \\
\hline & Antes & Depois & Antes & Depois & & \multicolumn{2}{|c|}{$\mathrm{rtf}=\mathrm{VDM}$ depois $/$ VDM antes } \\
\hline j & $K(j)$ & L(j) & $M(j)$ & $N(j)$ & calculado & calculado & calculado \\
\hline 7 & 32 & 19 & 48 & 58 & 0,3840 & 1,1969 & 1,1308 \\
\hline 10 & 19 & 8 & 48 & 58 & 0,3352 & 1,4312 & 1,1308 \\
\hline 13 & 227 & 127 & 67 & 39 & 0,1497 & 1,2581 & 1,1425 \\
\hline \multicolumn{6}{|c|}{ SITES INDIVIDUAIS } & & \\
\hline & $\hat{\lambda}$ & $\hat{r}$ & $\hat{\pi}$ & $\operatorname{Var}\{\hat{\lambda(j)\}}$ & $\operatorname{Var}\{\hat{\pi}(\mathrm{j})\}$ & & \\
\hline 7 & 19 & 1,0493 & 40,19 & 19 & 732,10 & & \\
\hline 10 & 8 & 1,0493 & 28,53 & 8 & 346,71 & & \\
\hline 13 & 127 & 0,5029 & 143,63 & 127 & $4.015,24$ & & \\
\hline \multicolumn{6}{|c|}{ SITES AGRUPADOS } & & \\
\hline \multirow{2}{*}{ Etapa 1} & $\hat{\lambda}$ & 154 & & & & & \\
\hline & $\hat{\pi}$ & 212 & & & & & \\
\hline Etana 2 & $\operatorname{VÂR}\{\hat{\lambda}\}$ & 154 & & & & & \\
\hline Etapa 2 & VÂR $\begin{cases}\hat{\pi}\end{cases}$ & 5.094 & & & & & \\
\hline Etana 3 & $\hat{\bar{\delta}}$ & 58 & & & & & \\
\hline Eldpd 3 & $\hat{\bar{\theta}}$ & 0,652 & $1-\hat{\bar{\theta}}$ & $34,8 \%$ & & & \\
\hline Etana 4 & $\hat{\sigma}\{\hat{\bar{\delta}}\}$ & 72,44 & & & & & \\
\hline Etapa 4 & $\hat{\sigma}\{\hat{\bar{\theta}}\}$ & 0,213 & & & & & \\
\hline
\end{tabular}

Fonte: Base de Dados gerada pelo autor (2011) 
8.4. CD COM ARQUIVOS DAS PLANILHAS DE CÁLCULO E BASES DE DADOS UTILIZADOS. 